\title{
ESTUDIO GENÉTICO DE LA CATARATA PRESENIL
}

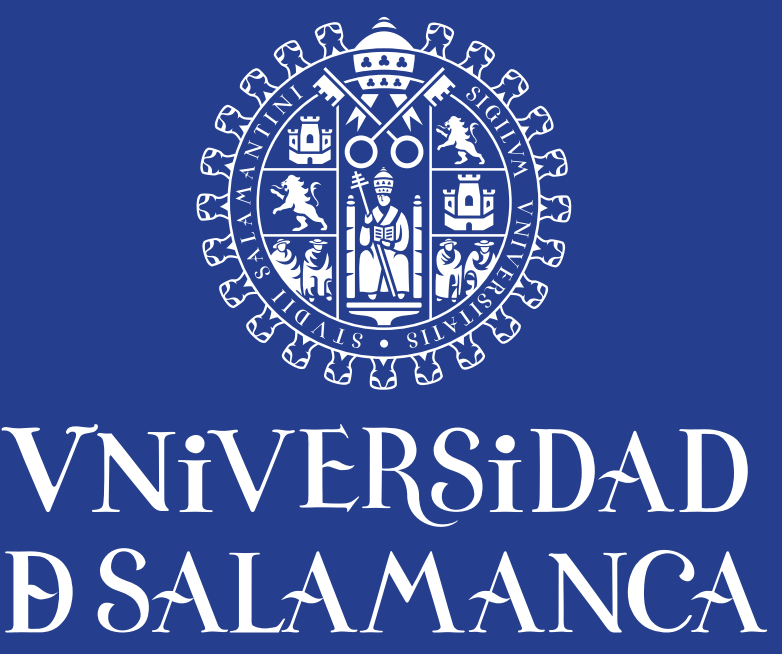

CAMPUS OF INTERNATIONAL EXCELLENCE

DEPARTAMENTO DE CIRUGIA

TESIS DOCTORAL

GLORIA LÓPEZ VALVERDE 



\section{ESTUDIO GENÉTICO DE LA CATARATA PRESENIL}

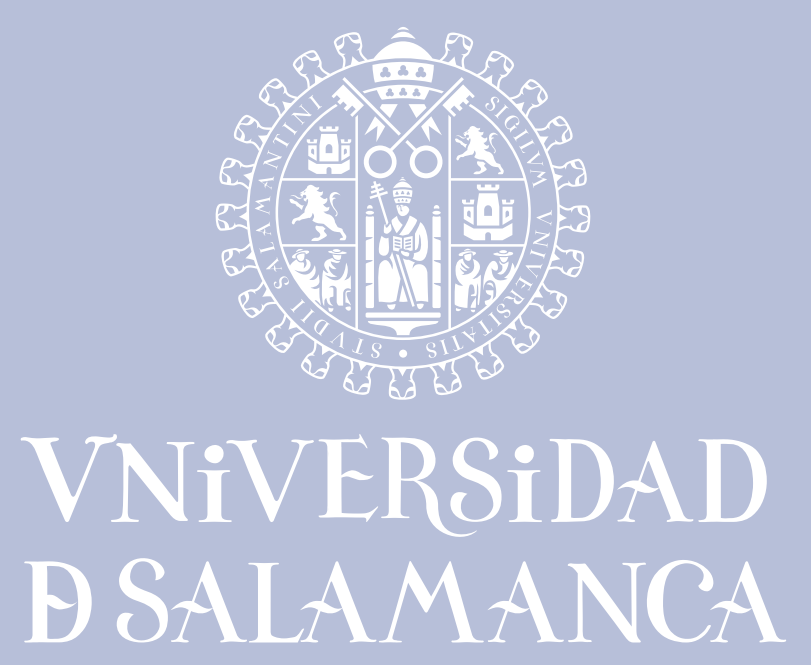

CAMPUS OF INTERNATIONAL EXCELLENCE DEPARTAMENTO DE CIRUGIA

TESIS DOCTORAL

GLORIA LÓPEZ VALVERDE

DIRECTORES:

PROF. DR. D. FERNANDO CRUZ GONZÁLEZ

PROF. DR. D. ROGELIO GONZÁLEZ SARMIENTO PROF. DR. D. EMILIANO HERNÁNDEZ GALILEA 

PROF. DR. D. FERNANDO CRUZ GONZÁLEZ. PROFESOR TITULAR DE MEDICINA DE LA UNIVERSIDAD DE SALAMANCA,

PROF. DR. D. ROGELIO GONZÁLEZ SARMIENTO. CATEDRÁTICO DE MEDICINA DE LA UNIVERSIDAD DE SALAMANCA,

PROF. DR. D. EMILIANO HERNÁNDEZ GALILEA. PROFESOR TITULAR DE MEDICINA DE LA UNIVERSIDAD DE SALAMANCA

\section{CERTIFICAN:}

Que el presente trabajo titulado "Estudio genético de la catarata presenil", realizado por D. Gloria López Valverde bajo su dirección en el Departamento de Cirugía, reúne, a su juicio, todos los requisitos exigidos para ser presentado ante el tribunal correspondiente y optar al grado de Doctor por la Universidad de Salamanca.

Y para que así conste, y a los efectos oportunos, firman la presente en Salamanca en Febrero de dos mil quince.

FERNANDO CRUZ GONZÁLEZ

DOCTOR EN MEDICINA

D. ROGELIO GONZÁLEZ SARMIENTO CATEDRÁTICO DE MEDICINA
D. EMILIANO HERNÁNDEZ GALILEA DOCTOR EN MEDICINA 

Agradecimientos:

A todas las personas implicadas en este trabajo.

A mi lala, espero que te sientas orgullosa.

A mi familia, por vuestro apoyo incondicional.

A Jose, por tu ayuda y confianza. 



\section{INDICE}

\section{ESTUDIO GENÉTICO DE LA CATARATA PRESENIL}

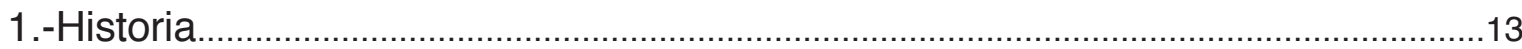

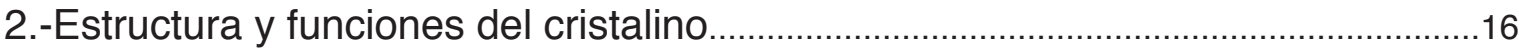

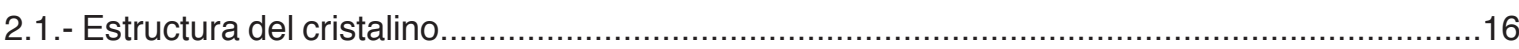

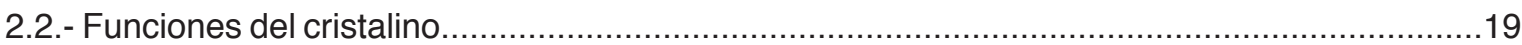

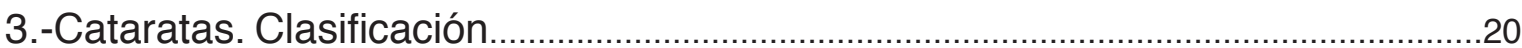

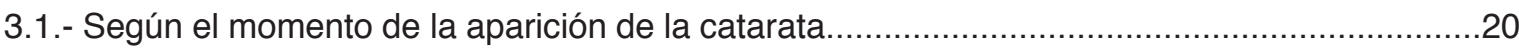

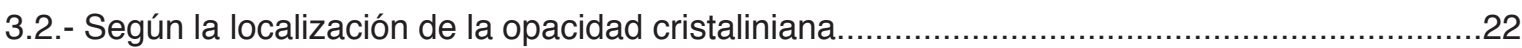

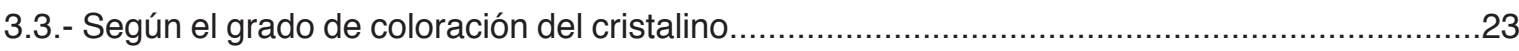

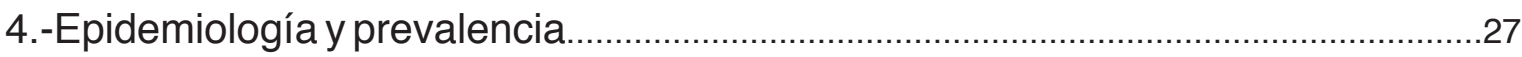

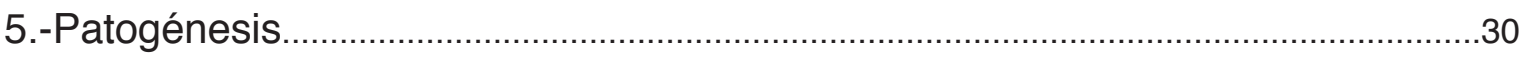

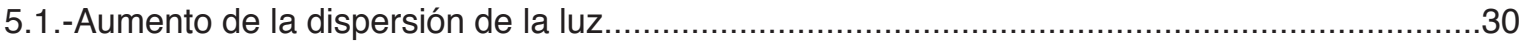

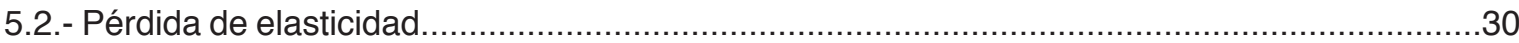

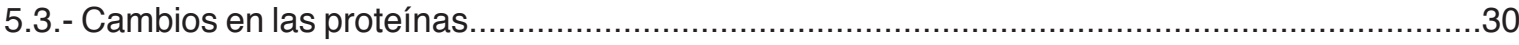

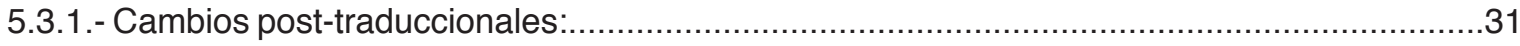

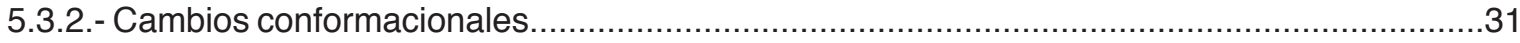

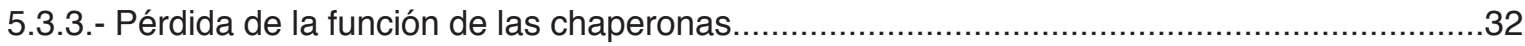

5.3.4.- Pérdida de la capacidad anti-oxidante y de neutralización de radicales libres......................32

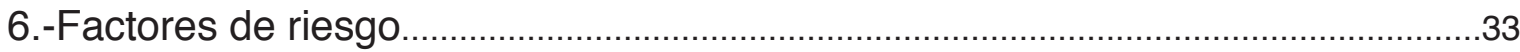

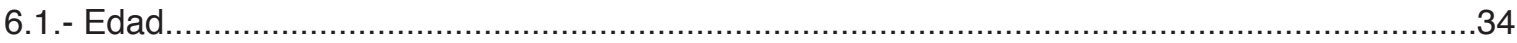

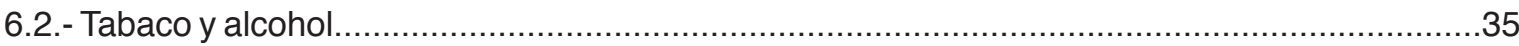

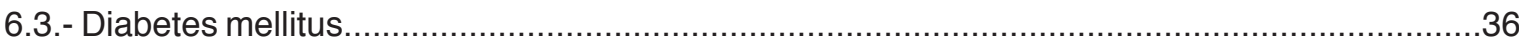

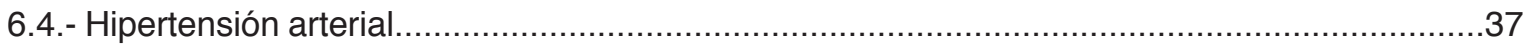

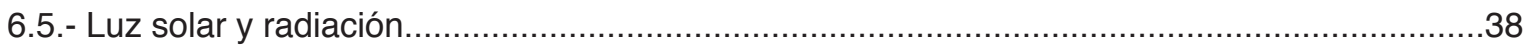

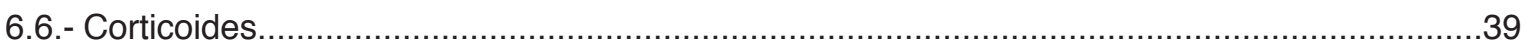

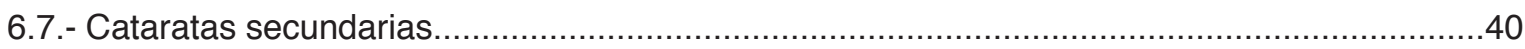

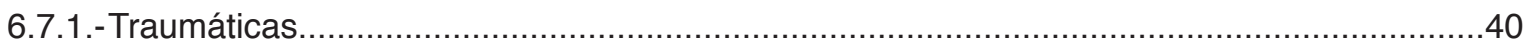

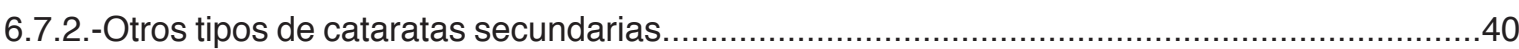




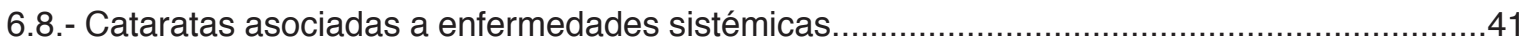

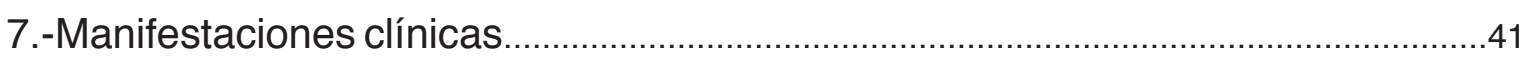

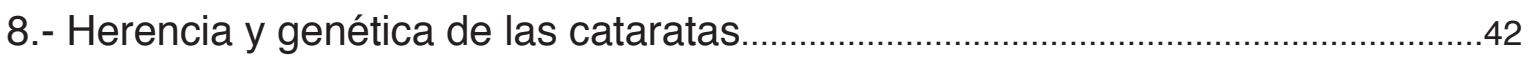

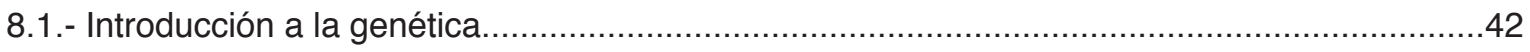

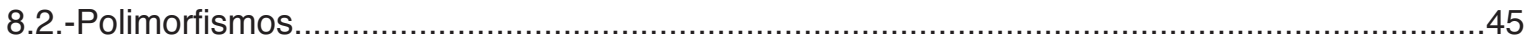

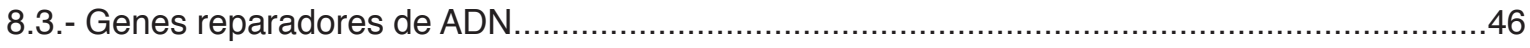

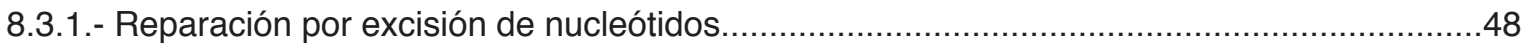

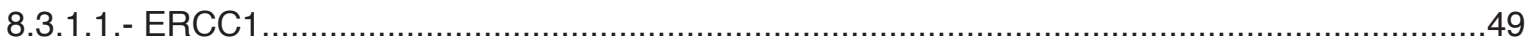

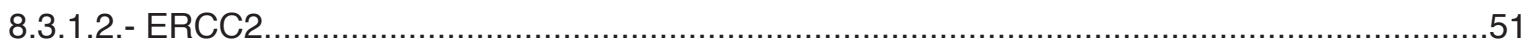

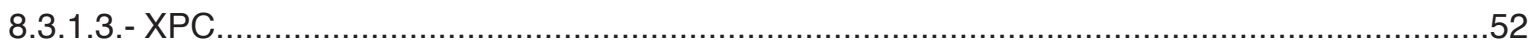

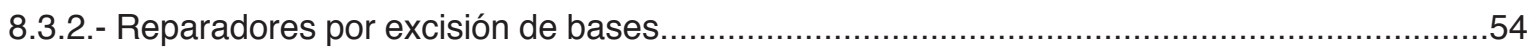

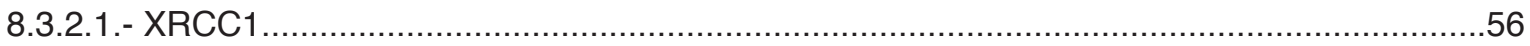

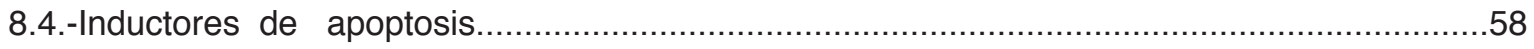

8.4.1.- P53

2.- HIPÓTESIS Y OBJETIVOS

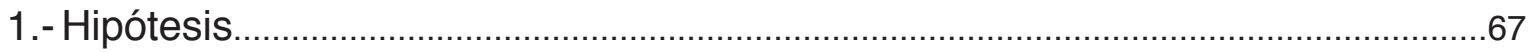

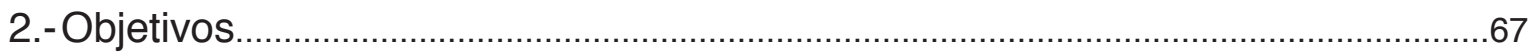

3.- PACIENTES Y MÉTODOS

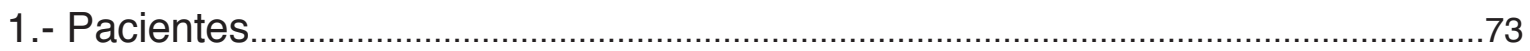

2.- Diseño del estudio........................................................................................................

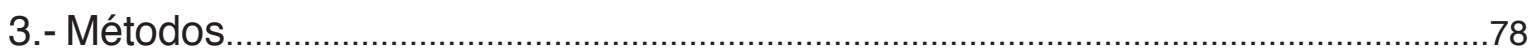

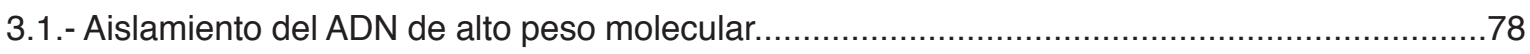

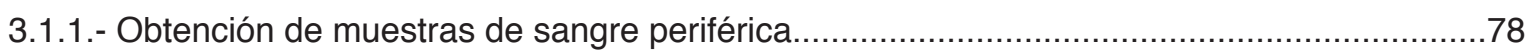

3.1.2.- Obtención de células mononucleadas de sangre periférica.........................................78

3.1.3.- Aislamiento del ADN total de alto peso molecular...............................................78

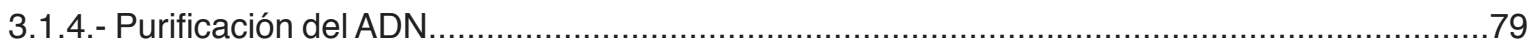

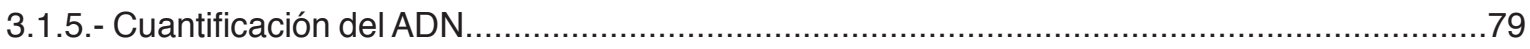

3.2.- Amplificación de fragmentos de ADN mediante reacción en

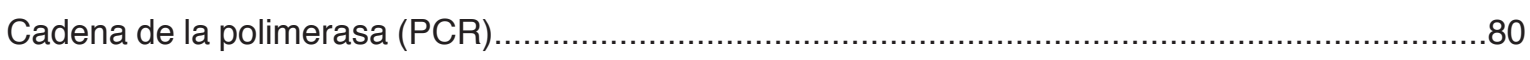

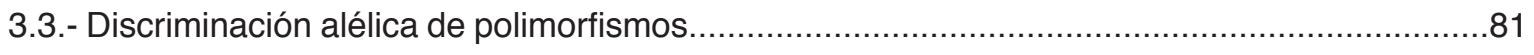

3.3.1.- Discriminación alélica mediante PCR con sondas taqman...........................................81

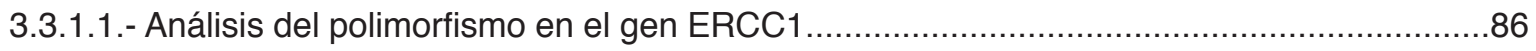




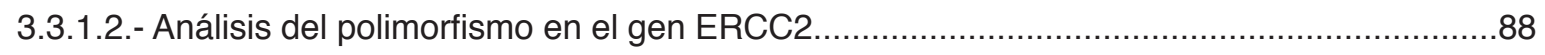

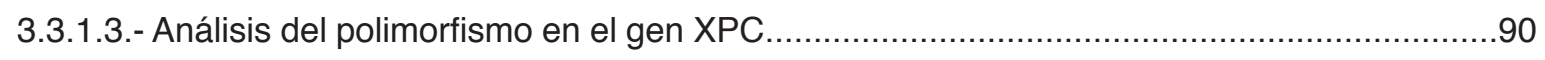

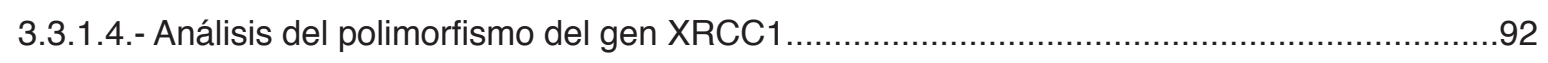

3.3.2.- Discriminación alélica mediante digestión con nucleasas de restricción..............................94

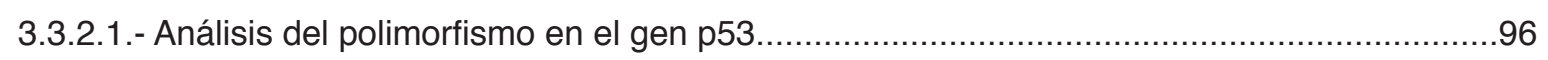

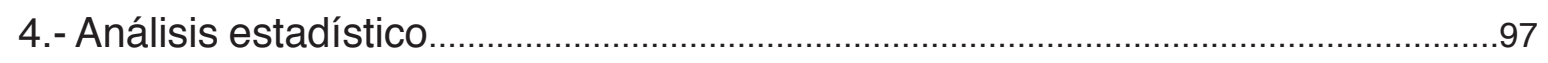

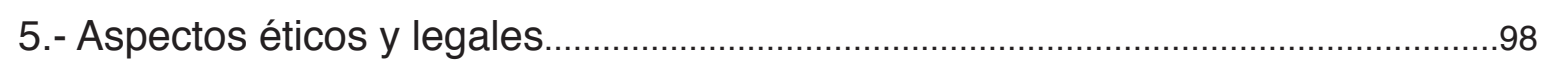

4.- RESULTADOS

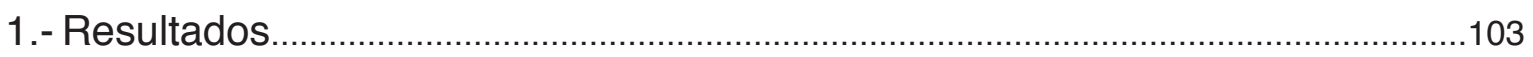

2.- Estudio genético de la susceptibilidad al desarrollo de cataratas preseniles...108

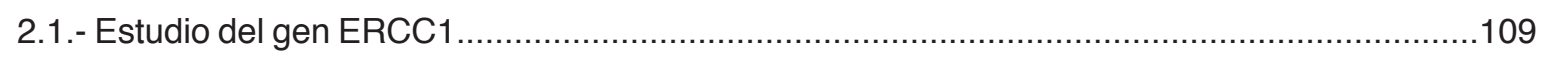

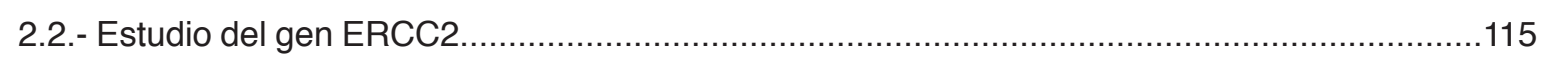

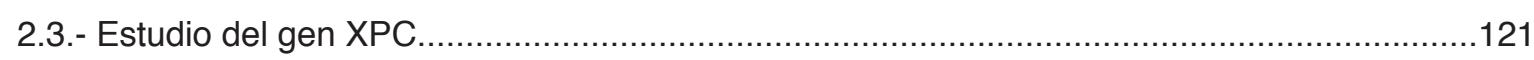

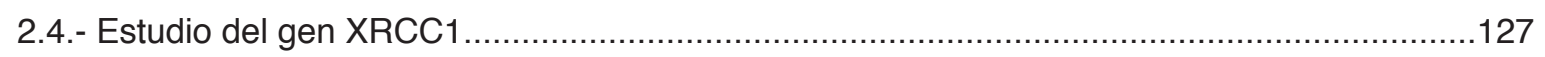

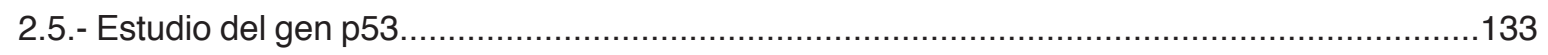

5.- DISCUSIÓN

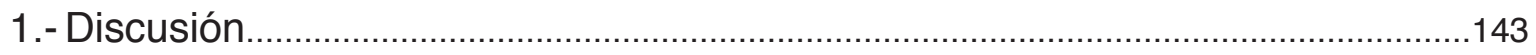

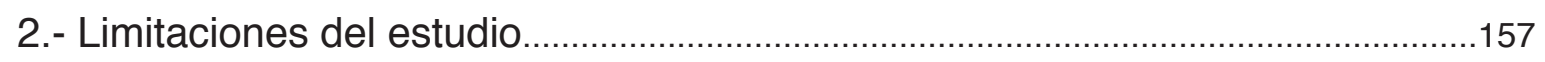

6.- CONCLUSIONES

7.- BIBLIOGRAFÍA

1.- Bibliografía. .165

ANEXO 

Introducción 



\section{1.-INTRODUCCIÓN}

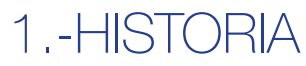

Se denomina catarata a una pérdida progresiva de transparencia en el cristalino y es la principal causa de ceguera tratable en el mundo ${ }^{(1-3)}$. Suele producirse como consecuencia del proceso fisiológico del envejecimiento ${ }^{(4)}$; sin embargo, un pequeño porcentaje de pacientes puede presentar cataratas en fases previas a la senectud.

Las primeras menciones a esta patología datan de más de 4000 años; se han encontrado textos en Egipto, Oriente Medio, Asia Central y Extremo Oriente que describen y hacen referencia a las cataratas como causa de pérdida visual. En la antigua Roma el texto De Medicinae, obra del enciclopedista Aulo Cornelio Celso ${ }^{(5)}$ publicada el año 29 antes de Cristo, hace alusión a su tratamiento.

La primera descripción escrita de su eliminación quirúrgica fue la del cirujano indio Susruta y data aproximadamente del año 600 antes de Cristo en sus "Tratados de anatomía y cirugía" ${ }^{(6)}$. Este autor hace referencia a la técnica del couching o reclinación por desconocimiento de la anatomía ocular. Esta técnica estuvo vigente desde varios siglos antes de Cristo hasta el siglo XIX. Consideraba que una membrana se formaba delante del cristalino por coagulación en el locuus vacuus (la cámara anterior) del humor visual (el humor vítreo) y se suponía que la cirugía removía esta membrana. Para ello se realizaba una esclerotomía sin anestesia, y con ayuda de una aguja se desinsertaba la zónula del cristalino ${ }^{(5)}$.

El conocimiento de la retina y otros elementos de la anatomía ocular gracias a Van Leeuwenhoek en el siglo XVII supusieron un gran avance para el desarrollo de la técnica de extracción de la catarata.

En el 1747 Jacques Daviel (Figura 1) realizó en Francia la primera cirugía extracapsular de cataratas programada sin anestesia, métodos de asepsia, ni suturas ${ }^{(7)}$. 


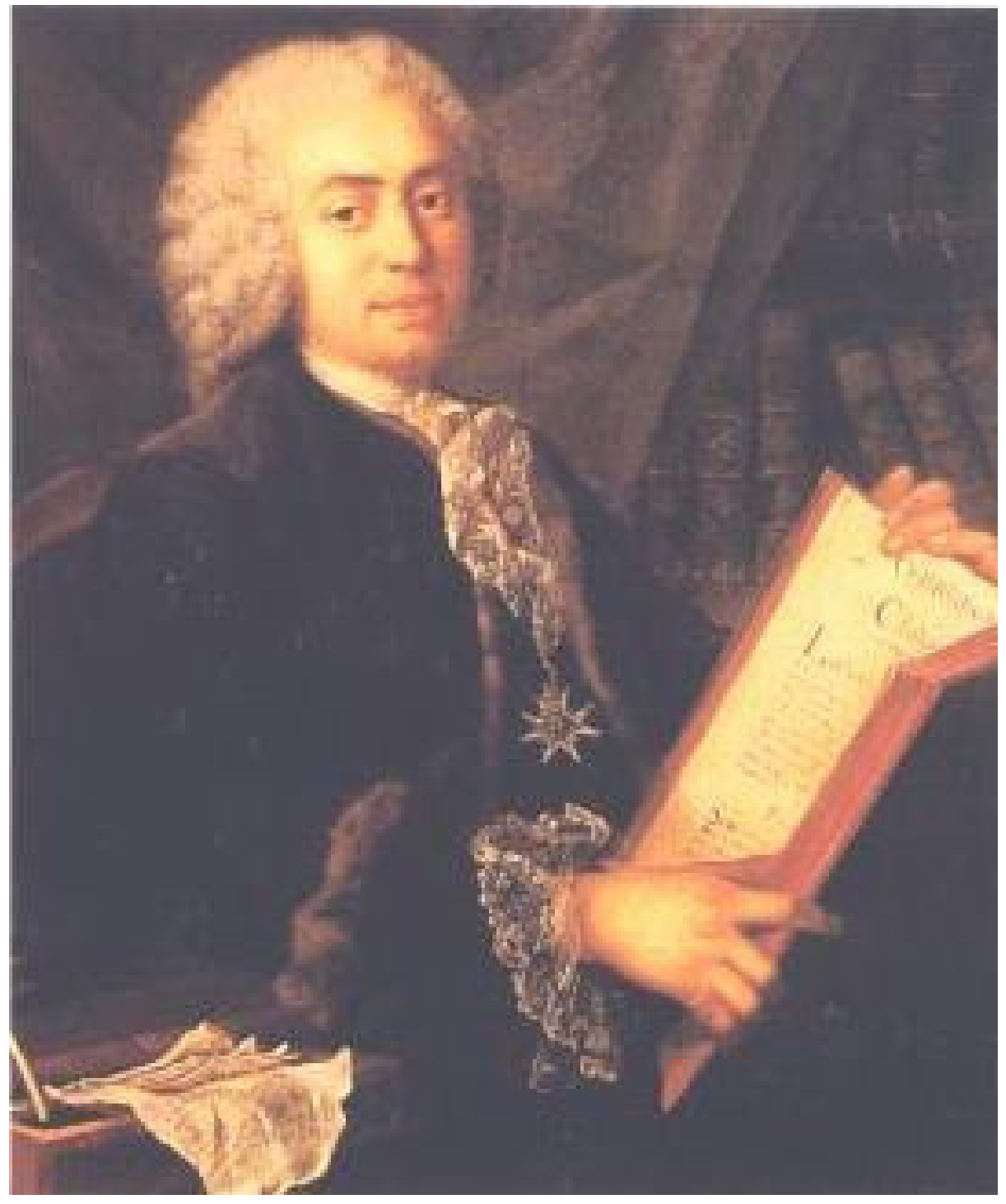

Figura 1: Jacques Daviel (1696-1762) 
La cirugía Intracapsular, que consistía en la extracción del cristalino in toto con su envoltura capsular incluida, se desarrolló durante el siglo XIX y la primera mitad del XX y supuso una alternativa a la cirugía extracapsular ${ }^{(8)}$.

Sin embargo, el intento de implantar lentes intraoculares motivó la vuelta a la técnica extracapsular ya que se advirtió la importancia de la integridad capsular para su colocación. Harold Ridley en $1949^{(9-10)}$ consiguió la implantación de la primera lente intraocular en la cápsula posterior del cristalino tras la realización de una cirugía extracapsular.

A finales del siglo XX, el desarrollo de la facoemulsificación y la utilización de los ultrasonidos impulsan uno de los mayores avances para la cirugía de la catarata. Descrita por primera vez en 1967 por Charles Kelman ${ }^{(11-12)}$, esta técnica consiste en la fragmentación mediante ultrasonidos del cristalino y su aspiración mediante un terminal de irrigación-aspiración. Su aparición, junto con el desarrollo de las medidas de asepsia y antisepsia, han reducido de forma muy importante la tasa de complicaciones ${ }^{(13)}$.

Con el desarrollo de las lentes intraoculares, tanto en materiales como en diseños, la cirugía de catarata alcanzó un nuevo objetivo, además de ser una cirugía rehabilitadora, permite corregir los defectos refractivos de los pacientes que se someten a esta intervención ${ }^{(14)}$. 


\section{2.-ESTRUCTURA Y FUNCIONES DEL CRISTALINO}

\section{1.- ESTRUCTURA DEL CRISTALINO}

El cristalino es una lente biconvexa avascular que no posee inervación, con poder de convergencia variable de aproximadamente +22 dioptrías, dependiendo de la tracción que ejerzan las fibras zonulares sobre su ecuador ${ }^{(15)}$.

En su estructura se distinguen (Figura 2):

a) La cápsula o cristaloides:

Fina membrana elástica y semipermeable que envuelve totalmente al cristalino y que está fundamentalmente compuesta por colágeno tipo IV ${ }^{(16)}$. La cápsula anterior es la membrana basal del epitelio anterior del cristalino; siendo la membrana basal más gruesa del organismo $^{(16)}$.

Mientras que la cápsula anterior presenta un engrosamiento progresivo con la edad, la posterior mantiene su grosor durante todo la vida ${ }^{(15,17)}$.

b) El epitelio subcapsular:

Está formado por una sola capa de células cúbicas germinativas que originan fibras que se van sumando a las subyacentes durante toda la vida. Estas células germinativas ocupan la cara anterior y el ecuador del cristalino, aunque se encuentran ausentes en la región posterior. Esto se debe a que durante el desarrollo embrionario, en la región posterior del cristalino se forman fibras primarias del cristalino a partir de este epitelio ${ }^{(18)}$. A nivel ecuatorial existen gran cantidad de uniones intercelulares (interdigitaciones, zónulas-ocludens y mácula-adherens) ${ }^{(17) .}$

Las células que forman el cristalino presentan distintas características histológicas en función de su localización ${ }^{(18,19)}$ : 
-Zona central: Células poligonales ó cúbicas con mínima actividad mitótica. Pueden sufrir procesos de metaplasia fibrosa tras un estímulo, como en la cirugía de la catarata.

-Zona intermedia o pregerminal: Células cilíndricas de menor tamaño, pero con mayor actividad mitótica.

-Zona ecuatorial o germinal: Células más alargadas situadas en el ecuador del cristalino.

c) El córtex:

Está formado por fibras hexagonales que se superponen de forma similar a las capas de una cebolla. Proceden de las células epiteliales hexagonales ectodérmicas; células que proliferan durante toda la vida ${ }^{(16)}$. En la zona cortical son nucleadas pero pierden sus organelas según pasan a formar parte del núcleo.

Conforme se acercan a las líneas de sutura van adquiriendo forma de Y. Existen dos líneas de sutura tras el desarrollo embrionario, una anterior y otra posterior. Corresponden a la zona de unión final de los diferentes componentes embrionarios del cristalino durante su desarrollo.

d) El núcleo:

Constituye la zona central del cristalino formada por la aposición de alrededor de 22.000 capas de fibras. Es más denso que la corteza porque las fibras están estrechamente unidas hacia el interior.

De las proteínas que lo integran las más frecuentes son las cristalinas tipo alfa, beta y gamma (20-22).

Las proteínas cristalinas son solubles en niños y jóvenes, pero se van transformando en insolubles en el adulto ya que las celulas cristalinianas pierden su núcleo, sus lípidos y el contenido líquido que contienen y se van solidificando por deshidratación, lo que le resta elasticidad y transparencia al cristalino. 
El cristalino forma nuevas fibras a lo largo de toda la vida. En los seres humanos las fibras viejas se comprimen centralmente para formar un núcleo cristaliniano inelástico cada vez mayor.

e) La zónula, o ligamento suspensorio:

Se extiende desde los procesos ciliares al ecuador del cristalino, manteniéndolo en posición y transmitiéndole las contracciones del músculo ciliar. Con la edad las fibras que lo componen disminuyen en número y resistencia.

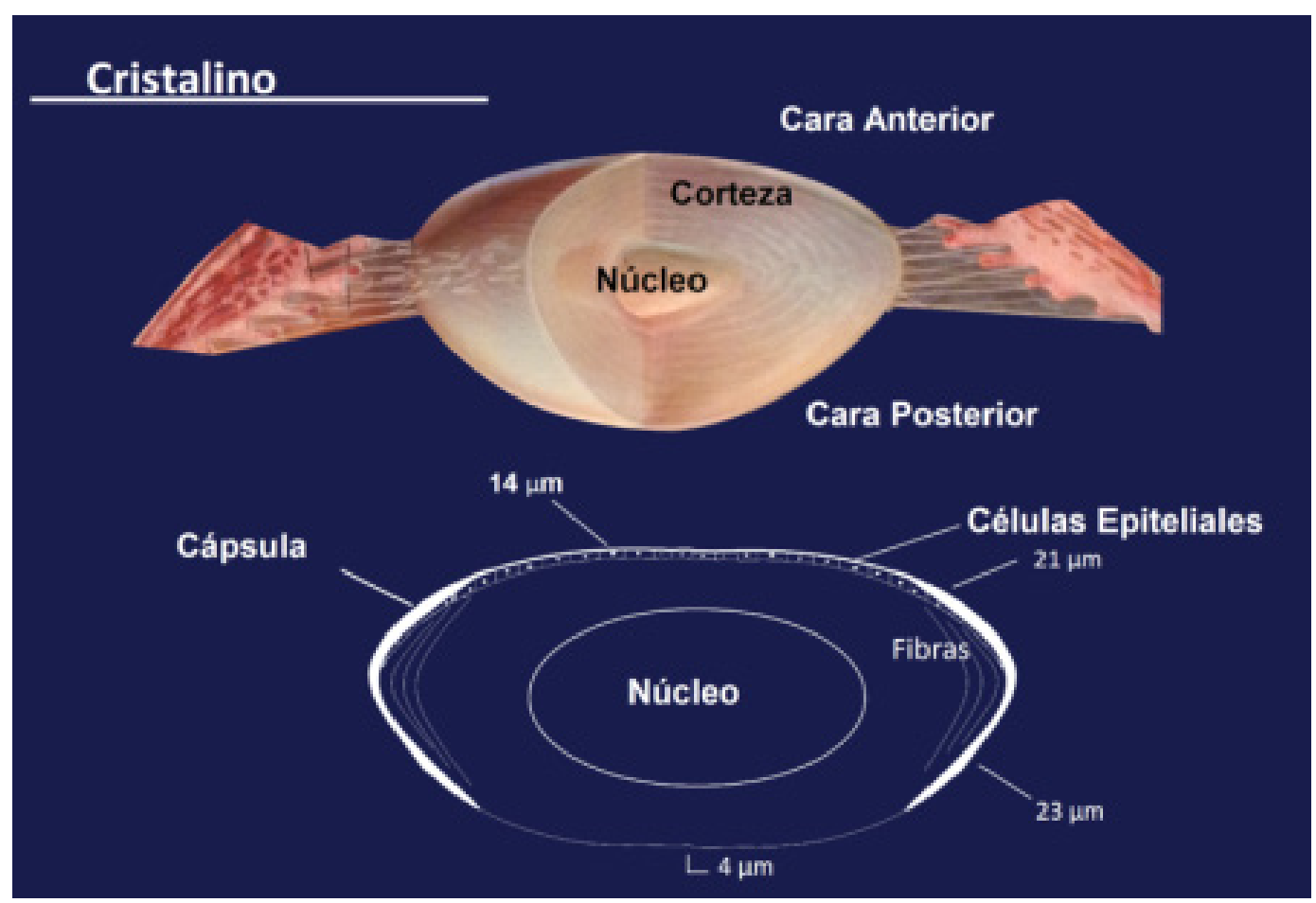

Figura 2: Estructura cristaliniana. 


\section{2.- FUNCIONES DEL CRISTALINO}

La principal función del cristalino es la acomodación, que es la capacidad para producir una potencia refractiva aditiva mediante el aumento de la curvatura del cristalino ${ }^{(23)}$.

La acomodación depende de la capacidad de contracción del músculo ciliar, pero también se ve afectada por la consistencia del córtex. Mientras que en la juventud es blando y flexible, con la edad disminuye su flexibilidad al ir ocupando el núcleo la mayor parte del cristalino ${ }^{(17) .}$

Cuando las fibras circulares del músculo ciliar se contraen, se relajan las fibras zonulares, y el cristalino tiende a hacerse más convexo aumentando su potencia refractiva.

Al realizar la acomodación se producen otros dos procesos de forma simultánea: la convergencia (para la fusión de las imágenes retinianas) y la miosis (que disminuye las aberraciones de los cambios de curvatura del cristalino) ${ }^{(24)}$.

En un ojo emétrope en reposo, los objetos situados a menos de 6 metros de distancia no se verán nítidos. Es mediante la acomodación que podemos focalizar en la retina los objetos situados entre el punto remoto (punto más lejano que se ve nítido) y el punto próximo (punto más cercano que se ve nítido).

La capacidad de acomodación se expresa en dioptrías y es máxima en la infancia, disminuyendo de forma fisiológica al disminuir la elasticidad cristaliniana.

A partir de los 40-45 años, aparece en el sujeto emétrope cierta dificultad a la visión próxima, es lo que se denomina presbicia o vista cansada y está causada por la disminución de la capacidad de acomodación (24). 


\section{3.-CATARATAS. CLASIFICACIÓN}

Se denomina catarata a la aparición de cualquier tipo de opacidad en el cristalino. Las clasificaciones de las cataratas son muy variadas y se superponen unas con otras ${ }^{(25)}$, todas tienen sus ventajas y desventajas ${ }^{(26,27)}$.

\section{1.- SEGÚN EL MOMENTO DE LA APARICIÓN DE LA CATARATA}

Clínicamente, según la edad de aparición las cataratas se clasifican en:

\section{A-Congénitas:}

Aparecen en el momento del nacimiento (28), aunque las bilaterales pueden permanecer latentes hasta las 10 primeras semanas de vida ${ }^{(29)}$. A su vez, las cataratas congénitas se pueden clasificar en ${ }^{(30)}$ :

-Zonulares:

Se trata del subtipo más frecuente. A su vez se pueden subdividir en nucleares, lamelares, suturales y capsulares.

-Polares:

Se trata de opacidades que se desarrollan en el polo anterior o posterior del cristalino. La polar anterior suele ser una opacidad bien delimitada con mejor pronóstico visual que la polar posterior; sin embargo, éstas suelen presentar mayor alteración visual y precisan cirugía.

-Totales:

Se trata de opacidades completas presentes al nacimiento o que progresan rápidamente los primeros meses de vida. Suelen encontrarse asociadas a malformaciones sistémicas u oculares. 
-Membranosas:

Tipo terminal que ha experimentado reabsorción y en el que la cápsula posterior y anterior están superpuestas.

B-Infantiles:

El desarrollo visual se produce hasta los 6-7 años de vida. Las cataratas desarrolladas hasta esta edad pueden suponer un riesgo de ambliopía para los pacientes ${ }^{(28)}$, considerándose la ambliopía una disminución de la agudeza visual sin lesión orgánica que lo justifique. Generalmente es unilateral y está producida por una falta de estimulación nerviosa durante el desarrollo visual.

C-Juveniles:

Las cataratas desarrolladas más tarde del periodo neonatal o infantil, posteriores a los 7 años, suelen ser de tipo secundario y se asocian a episodios repetidos de uveítis, empleo de corticoides o traumatismos.

D-Preseniles:

No hay consenso sobre la edad de aparición de estas cataratas. Hay autores que incluyen en esta clasificación a las cataratas que se presentan en menores de 45 años mientras que hay otros que las consideran en menores de 65 años.

Vîrgolici y colaboradores consideraron cataratas preseniles a las desarrolladas por pacientes entre 50 y 65 años en su estudio sobre el aumento del estado oxidativo del plasma y el desarrollo de cataratas tempranas ${ }^{(31)}$; sin embargo, Praveen y colaboradores determinaron la edad de aparición de cataratas entre 30 y 45 años; en este trabajo observaron que la atopia predisponía, de manera muy significativa, a su desarrollo ${ }^{(32)}$. El grupo liderado por Chiang encontró un aumento del riesgo de padecer cáncer en pacientes de $20 \mathrm{a}$ 55 años que fueron intervenidos de cataratas ${ }^{(33)}$. 
E-Seniles:

El tipo más frecuente de catarata, justificado ya que el envejecimiento es el factor de riesgo más importante asociado a su desarrollo. $(4,26,34)$

\section{2. - SEGÚN LA LOCALIZACIÓN DE LA OPACIDAD CRISTALINIANA}

Las cataratas se clasifican en:

\section{A-Corticales:}

El tipo más común de catarata en diabéticos, secundaria a la ingesta de corticoides, o en pacientes expuestos a radiación.

La parte más superficial del córtex, formada por células epiteliales nucleadas, es capaz de resistir mejor al daño oxidativo que las fibras más profundas sin organelas. En él pueden aparecer diferentes tipos de opacidades, que se aprecian mejor en una exploración por trasluminación, bajo midirasis. Las más frecuentes son las opacidades puntiformes que con el paso del tiempo evolucionan a opacidades radiales y posteriormente a opacidades circulares ${ }^{(35)}$.

\section{B-Nucleares:}

El tipo más frecuente en la catarata senil. La típica catarata nuclear se caracteriza por un aumento en la coloración de su núcleo; este cambio de color hacia tonos más oscuros se encuentra asociado a la edad y al aumento de la dureza nuclear.

El cambio en la coloración nuclear es producido por fluctuaciones locales en la densidad nuclear debido a la formación de agregados proteicos insolubles. En el centro del núcleo, debido a la ruptura de la membrana celular, el contenido fibrilar queda expuesto al espacio extracelular. Esto da lugar a la formación de unos agregados de mayor densidad por el depósito de material pseudo-proteico ${ }^{(36)}$, insoluble, que es el responsable del aumento de opacidad nuclear. 
C-Subcapsulares posteriores:

El subtipo más frecuente de opacidad subcapsular posterior es la asociada a la edad y secundarias a tratamientos de corticoides sistémicos. Son las más frecuentes en el caso de los sujetos jóvenes.

Se trata de una opacidad discoide subyacente a la cápsula posterior del cristalino. Por su situación central provoca una gran pérdida de agudeza visual no justificada por su densidad. Se han asociado a la migración de células metaplásicas desde el ecuador del cristalino hasta el polo posterior del mismo, lo que produce defectos en la producción de fibras por el epitelio cristaliniano ${ }^{(37)}$.

\section{3.- SEGÚN EL GRADO DE COLORACIÓN DEL CRISTALINO}

Los últimos estudios epidemiológicos emplean la Clasificación de Pirie ${ }^{(38)}$, la cual define cuatro grupos diferentes según el grado de coloración del cristalino in toto (Figura 3):

Tipo I: Predomina la catarata de tipo cortical encontrándose el resto del cristalino transparente.

Tipo II: El primer estadío de la catarata nuclear, muestra un leve aumento en la coloración del cristalino.

Tipos III y IV: El color nuclear se vuelve aún más oscuro.

Tipo V: Añadido en algunas ocasiones ${ }^{(34,39)}$, deja entrever lo subjetivo de esta clasificación ${ }^{(34)}$. 

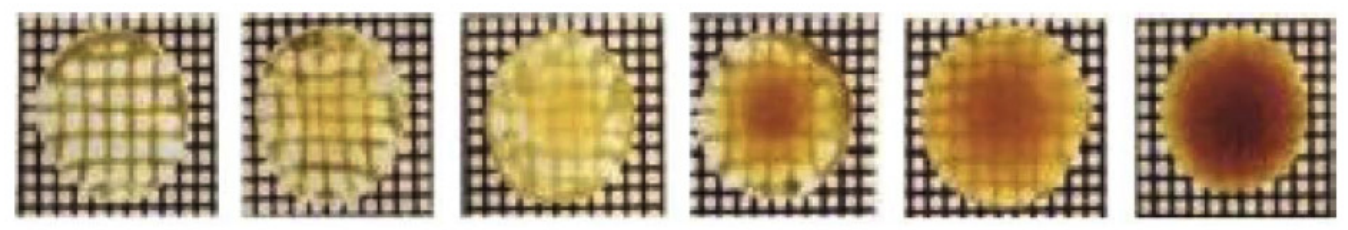

Figura 3: Sistema de clasificación de la catarata según Pirie ${ }^{(4,35)}$.

Uno de los sistemas de clasificación más completos y utilizados es el Lens Opacities Classification System (LOCS) que ha ido evolucionando en los últimos años hasta el LOCS III, que es el más actual ${ }^{(40,41)}$ (Figura 4).

-LOCS I (42): Dividía las cataratas en corticales, subcapsulares posteriores y nucleares; y estas últimas las subdividía en función del color y la opacidad posterior.

-LOCS II (43): Estratifica también la catarata cortical y la subcapsular posterior.

-LOCS III (40-41): Respecto a los anteriores ha aumentado los grados de cataratas, estableciendo grados intermedios. Expande las escalas que definen la opacidad nuclear, valora grados más precoces de catarata subcapsular. Desarrolla así una escala decimal que define muy bien el tipo y grado de catarata.

En ellos se emplean una serie de fotografías para graduar la opacidad y opalescencia nuclear, otra serie de imágenes tomadas por retroiluminación en la lámpara de hendidura para graduar las cataratas corticales y una tercera serie de imágenes también tomadas por retroiluminación para graduar las cataratas subcapsulares posteriores.

Así, en función de estas imágenes, podemos clasificar las cataratas según la gradación que presente a nivel: 
-Nuclear: Existen hasta 6 niveles de opacidad nuclear. Se escriben con las iniciales NO o NC y el número del 1 al 6 según su coloración, siendo uno las cataratas más incipientes y reservándose el 6 para las más brunescentes.

-Cortical: Se definen con la letra $\mathrm{C}$ y hasta 5 niveles de gradación.

-Opacidades posteriores: también existen 5 tipos que se denominan con la letra P seguida del número del 1 al 5 en función de la intensidad de la opacidad.

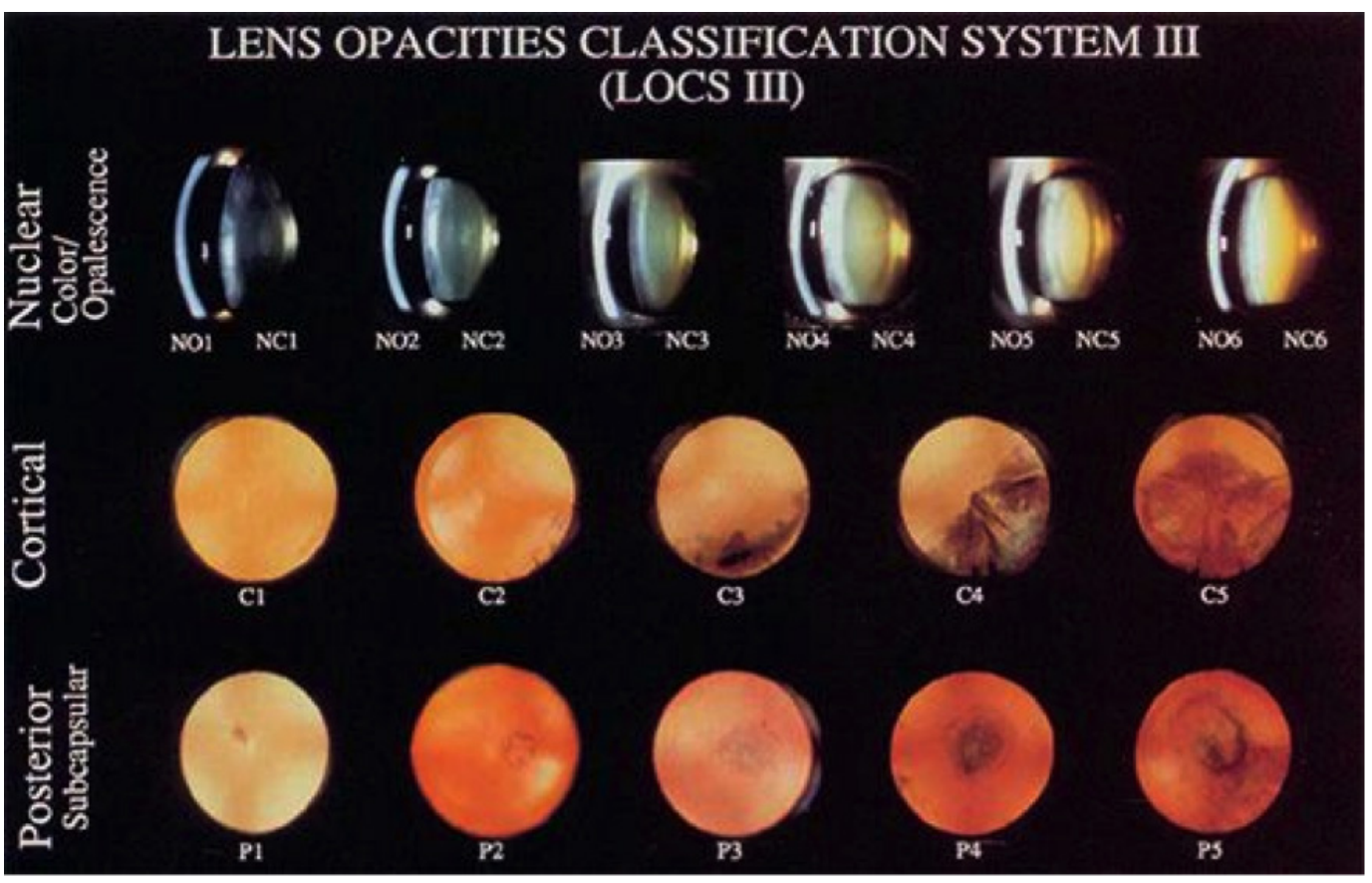

Figura 4: El sistema de clasificación de cataratas LOCS III ${ }^{(41)}$. 
Otras clasificaciones menos empleadas son ${ }^{(45)}$ :

-The Age-Related Eye Disease Study (AREDS) system ${ }^{(46)}$ : Emplea imágenes obtenidas por lámpara de hendidura y por retroiluminación y diferencian, por un lado la opacidad nuclear (con escala numérica del 0,9 al 7,1), y por otro la opacidad cortical y subcapsular posterior (medida sobre una gradilla con distintas marcas). (Figura 5)

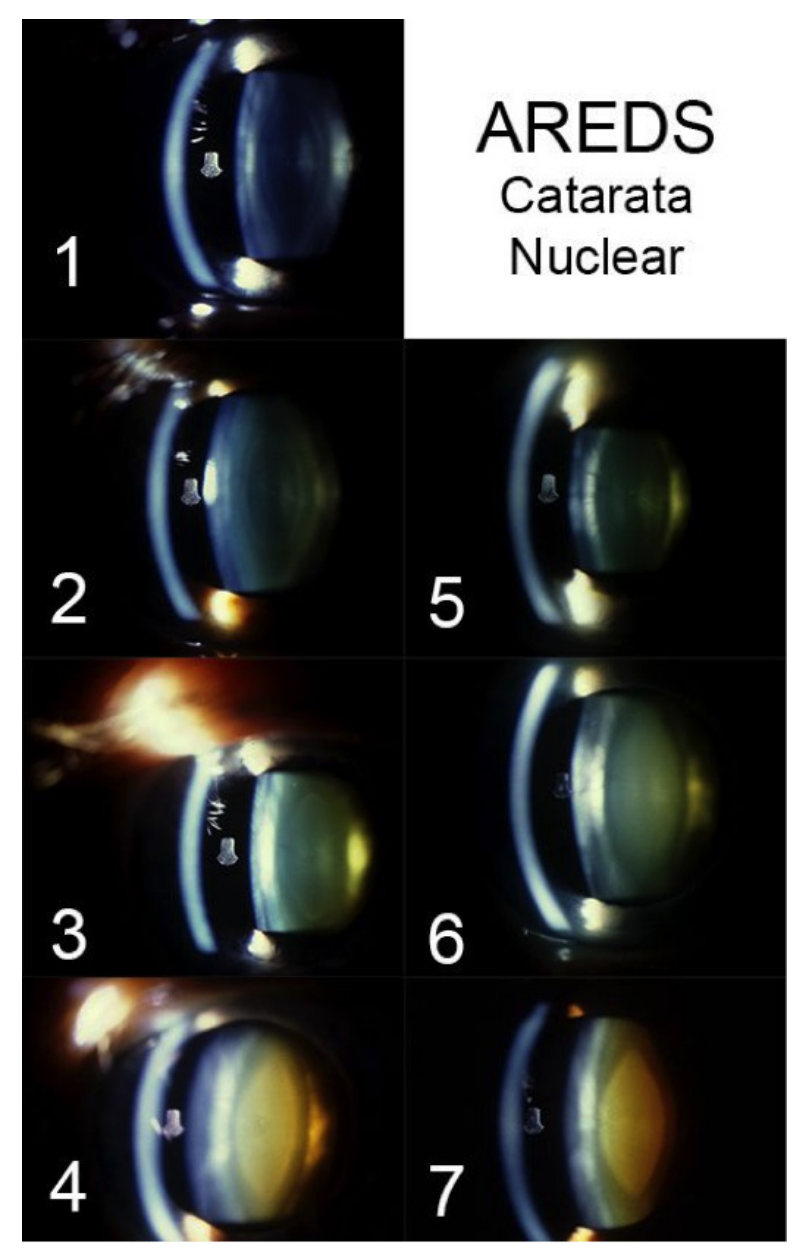

Figura 5: Escala de clasificación de las cataratas según el ARED-S. 
- The Oxford Clinical Cataract Classification and Grading System (47): Define las zonas del cristalino en función de la dispersión de la luz, dividiendo en zona nuclear y cortical. Ésta última es dividida en zonas concéntricas al núcleo, cada una de ellas con zona anterior y posterior.

- El Beaver Dam Eye Study ${ }^{(48)}$ : Valoraba la esclerosis nuclear en cinco niveles y la opacidad cortical en función del área afectada.

-The National Eye Institute Scheimpflug system ${ }^{(49)}$, divide las cataratas en cuanto a densidad nuclear comparativamente con LOCS II y estudió si diversas medicaciones disminuían esa opacidad nuclear.

\section{4.-EPIDEMIOLOGÍA Y PREVALENCIA}

No son frecuentes los estudios en la población española sobre la prevalencia de las cataratas (Tabla 1), y en especial sobre las cataratas preseniles, siendo más frecuentes los realizados en países en vías de desarrollo ${ }^{(50,51)}$.

Todos los estudios refieren que la catarata es la principal causa de ceguera reversible en el mundo ${ }^{(1-3)}$, llegando a causar hasta el $50 \%$ de los casos de ceguera en la población ${ }^{(52)}$, y predominando en países en vías de desarrollo de África, Asia y Sudamérica ${ }^{(52)}$. El que la población de estos países no pueda acceder a una adecuada atención médica supone que la ceguera asociada a cataratas se encuentre en valores tan altos ${ }^{(53)}$. Otra de las posibles causas que favorecen el aumento de su prevalencia es la constante exposición a los rayos ultravioleta (UVA) sin protección a la que, por su situación geográfica, se ve sometida la población de estos países; ya que la luz ultravioleta ha sido descrita como un factor de riesgo que precipita la aparición de cataratas ${ }^{(34,54-57)}$. 
El estudio Beaver Dam Eye Study analizó la prevalencia de los distintos tipos de cataratas en una población de entre 43 a 84 años demostrando que el tipo nuclear era el más frecuente, estando presente en el 17,3\% de la población con un nivel de opacidad 3 sobre 5, el $16,3 \%$ de los pacientes presentaban opacidades de tipo cortical y tan sólo un 6,0\% presentaban el tipo subcapsular posterior. Los subtipos cortical y nuclear eran los más frecuentes en las personas de mayor edad $(56,58-62)$.

En los países desarrollados, el aumento en la esperanza de vida ha aumentado significativamente la prevalencia de cataratas en las últimas décadas debido a que se trata de una patología altamente asociada al envejecimiento ${ }^{(63)}$.

Así mismo, se ha encontrado una mayor prevalencia en mujeres respecto a hombres, hecho que puede verse justificado por la mayor esperanza de vida de éstas, por factores hormonales o por las diferencias en el acceso y utilización de los servicios de sanidad (63-64). 
Tabla 1: Características de los estudios más relevantes sobre la prevalencia de cataratas y criterios de cálculo ${ }^{(60)}$.

\begin{tabular}{|c|c|c|c|c|c|c|c|}
\hline Estudio & Año & $\begin{array}{l}\text { Tamaño } \\
\text { Muestral }\end{array}$ & $\% \mathrm{R}^{*}$ & Edad & Medición & Criterio & $\begin{array}{l}\text { Prevalencia } \\
(\%)\end{array}$ \\
\hline $\begin{array}{l}\text { Europa: } \\
\text {-Rotterdam } \\
\text {-Casteldaccia } \\
\text { - North Londom }\end{array}$ & $\begin{array}{l}1990-93 \\
1994 \\
1995-95\end{array}$ & $\begin{array}{l}6.775 \\
1.068 \\
\\
1.547\end{array}$ & $\begin{array}{l}84,8 \\
67,3\end{array}$ & $\begin{array}{l}55+ \\
40+\end{array}$ & $\begin{array}{l}\text { AV } \\
\text { AV } \\
\text { Op+AV } \\
\text { Op+AV }\end{array}$ & $\begin{array}{l}\text { OMS }(A \bigvee \leq 0,3) \\
\text { OMS(AV } \leq 0,3) \\
\text { LOCS II: Cualquier } \\
\text { opacidad con una } \\
\text { AV corregida } \leq 0,7 \\
\text { en el peor ojo } \\
\text { LOCS II: Cualquier } \\
\text { opacidad con una } \\
\text { AV con su } \\
\text { graduación } \leq 0,5 \text { en } \\
\text { uno o ambos ojos }\end{array}$ & $\begin{array}{l}0,52 \\
0,65 \\
19,4\end{array}$ \\
\hline $\begin{array}{l}\text { ESTADOS } \\
\text { UNIDOS: } \\
\text {-Framingham } \\
\text {-Baltimore }\end{array}$ & $\begin{array}{l}1984 \\
1985-88\end{array}$ & $\begin{array}{l}2.477 \\
5.300\end{array}$ & 79 & $52+$ & Op+AV & $\begin{array}{l}\text { Cualquier opacidad } \\
\text { con una } \mathrm{AV} \\
\text { corregida } \leq 0,7 \text { en el } \\
\text { peor ojo } \\
\text { EEUU }(A V \leq 0,5)\end{array}$ & $\begin{array}{l}15,5 \\
0,91\end{array}$ \\
\hline $\begin{array}{l}\text {-SEE } \\
\text {-VER }\end{array}$ & $\begin{array}{l}1993 \\
2001\end{array}$ & $\begin{array}{l}2.519 \\
4.774\end{array}$ & $\begin{array}{l}66 \\
72,0\end{array}$ & $\begin{array}{l}65-84 \\
40+\end{array}$ & $\begin{array}{l}\text { Op } \\
\text { Op+AV }\end{array}$ & $\begin{array}{l}\text { Wisconsin: } \\
\text { opacidad nuclear }>4 \text {, } \\
\text { o cortical }>25 \% \text {, o } \\
\text { subcapsular } \\
\text { posterior }>5 \% \text { en el } \\
\text { ojo } \\
\text { derecho/izquierdo } \\
\text { Wisconsin: } \\
\text { Cualquier opacidad } \\
\text { con una AV } \\
\text { corregida } \leq 0,7 \text { en el } \\
\text { peor/mejor ojo } \\
\text { EEUU (AV } \leq 0,5) \\
\text { EEUU (AV } \leq 0,5)\end{array}$ & $\begin{array}{l}15,3 / 15,5 \\
5,0 / 14,2 \\
\\
1,08 \\
0,94\end{array}$ \\
\hline $\begin{array}{l}\text { AUSTRALIA: } \\
\text {-Blue Mountains }\end{array}$ & $\begin{array}{l}1992-94 \\
1992-96\end{array}$ & 3.564 & 82,4 & $49+$ & $\begin{array}{l}\text { Op } \\
\text { AV }\end{array}$ & $\begin{array}{l}\text { Wisconsin: } \\
\text { opacidad nuclear }>4 \text {, } \\
\text { o cortical }>25 \% \text {, o } \\
\text { subcapsular } \\
\text { posterior }>5 \% \text { en el } \\
\text { ojo derecho } \\
\text { OMS(AV } \leq 0,3 \text { ) } \\
\text { Wilmer: opacidad } \\
\text { nuclear }>2, \text { o } \\
\text { cortical }>4 / 16 \text { o } \\
\text { cualquier opacidad } \\
\text { subcapsular } \\
\text { posterior en uno o } \\
\text { ambos ojos }\end{array}$ & $\begin{array}{l}0,47 \\
18,0\end{array}$ \\
\hline
\end{tabular}

*: Porcentaje de respuesta; AV: agudeza visual; Op: Opacidad del cristalino; Op+AV: Criterio combinado opacidad del cristalino y agudeza visual; LOCS II: Lens Opacities Classification system; Wilmer: Wilmer cataract grading system; Wisconsin: Wisconsin cataract grading system 


\section{5.-PATOGÉNESIS}

No hay duda de que uno de los principales factores responsables de la formación de cataratas es el proceso de envejecimiento. Podemos diferenciar múltiples cambios asociados a la edad, siendo los más importantes:

\section{1.-AUMENTO DE LA DISPERSIÓN DE LA LUZ}

Con la edad, aún en ausencia de catarata, se produce un aumento de la dispersión de la luz tanto a nivel cortical como nuclear, más evidente después de los 40 años. (37)

Esto se debe a las variaciones en la densidad nuclear que se produce por la formación de agregados proteicos insolubles.

\section{2.- PÉRDIDA DE ELASTICIDAD}

El aumento de rigidez que se produce en el cristalino comienza desde el nacimiento ${ }^{(65)}$, siendo más llamativo con el paso de los años. Este aumento en la rigidez del cristalino es mayor en el núcleo que en el córtex ${ }^{(66)}$ y es determinante para el desarrollo de la presbicia ${ }^{(67)}$. Así, hasta los 40 años el núcleo es más flexible y deformable debido a que su rigidez es menor que la del córtex; sin embargo, posteriormente la situación se revierte, resultando cada vez más difícil la acomodación.

\section{3.- CAMBIOS EN LAS PROTEÍNAS}

Junto con el aumento de rigidez capsular y del tamaño del cristalino, los cambios en las proteínas son responsables de la pérdida de elasticidad y determinan la aparición de opacidades cristalinianas. Debido a este proceso se producen una serie de cambios en las proteínas del cristalino que justifican el desarrollo de opacidades.

Los cambios más significativos son: 


\subsection{1.- Cambios post-traduccionales:}

Las proteínas del cristalino (cristalinas) son proteínas estables que son sometidas desde edades muy tempranas a cambios no enzimáticos de estructura y función. Sufren procesos de tiolación, deamilación, glicación, carbamilación, cismetilación, fosforilación y acetilación, así como proteólisis, lo que lleva al truncamiento y liberación de fragmentos de cristalinas. ${ }^{(26,68)}$

Las modificaciones post-traducción que se producen con el envejecimiento de las cristalinas conllevan una pérdida de la transparencia cristaliniana. Las proteínas desnaturalizadas son más susceptibles a la oxidación, que a su vez se ve favorecida por el envejecimiento al disminuir las concentraciones de glutatión reducido.

A la vez que las cristalinas $\beta$ y y son oxidadas también lo hacen las cristalinas $a A$ y $a B$, produciéndose una pérdida de la actividad de las chaperonas, lo que da lugar a un acúmulo de fragmentos proteicos en las fibras cristalinianas, más evidente a nivel nuclear que cortical. Algunos autores han expuesto la teoría de que los fragmentos derivados de las cristalinas oxidadas pueden interferir en la actividad de las proteínas chaperonas a produciéndose la agregación de proteínas desnaturalizadas en fragmentos con actividad anti-chaperonas. ${ }^{69)}$

Aunque en el cristalino existe una vía que elimina y degrada las proteínas oxidadas, la ubiquitina-proteosoma, su actividad decae con la edad produciéndose así el acúmulo de fragmentos de cristalinas oxidadas e iniciándose la catarata nuclear. ${ }^{(37,70)}$

\subsection{2.- Cambios conformacionales:}

La oxidación de las proteínas induce a la formación de agregados de alto peso molecular que producen la insolubilidad proteica. Se va produciendo un endurecimiento progresivo sobre todo a nivel nuclear, siendo ésta una de las causas de la pérdida de la transparencia cristaliniana. Esto, junto al acúmulo de cromóforos fluorescentes produce un cambio en la coloración nuclear pasando desde el amarillo en fases iniciales al marrón en casos más avanzados. ${ }^{(37)}$ 


\subsection{3.- Pérdida de la función de las chaperonas:}

La pérdida de la actividad de las proteínas chaperonas a, máxima a los 50 años, contribuye a la agregación y pérdida de solubilidad proteica con la consecuente pérdida de transparencia.

En los jóvenes, las proteínas cristalinas a interactúan produciendo agregados proteicos solubles formados por cristalinas de tipo a, $\beta$ y y que conservan sus funciones. Con el paso de los años, debido a la ausencia de síntesis de nuevas proteínas, las tipo a comienzan a escasear, sobre todo a nivel nuclear, formándose agregados insolubles en los que predominan las proteínas de tipo $\beta$ y $ү$. ${ }^{(37)}$

\subsection{4.- Pérdida de la capacidad anti-oxidante y de neutralización de radicales libres:}

La cantidad de glutatión reducido disminuye de manera casi lineal con la edad (71), aumentando el glutatión oxidado. Además, a nivel nuclear se observa una disminución de la cisteína, no observable en el córtex, que explica la falta de protección frente al daño oxidativo en el núcleo.

Además de los cambios moleculares a nivel proteico, a nivel cortical se produce un aumento de la permeabilidad de la membrana celular con la consecuente acumulación de $\mathrm{Na}^{+}$y Ca${ }^{2+}$ intracelulares. Estos cambios, que se producen tanto en la formación de catarata cortical como en las cataratas de los pacientes diabéticos, producen un descenso en la actividad de la bomba $\mathrm{Na}^{+} / \mathrm{K}^{+}$ATP-asa lo que conlleva una hiperhidratación celular, pérdida proteica y un aumento del $\mathrm{Na}^{+}$y $\mathrm{Ca}^{2+}$ junto con un descenso del $\mathrm{K}^{+}$. (72)

Algunos autores ${ }^{(73)}$ han propuesto que el aumento del $\mathrm{Ca}^{2+}$ intracelular favorece la agregación proteica y la proteólisis, contribuyendo así a un aumento en la densidad del cristalino desde la quinta década de la vida. 


\section{6. -FACTORES DE RIESGO}

La catarata es una enfermedad multifactorial ${ }^{(37)}$. Identificar los factores de riesgo prevenibles puede resultar de utilidad para retrasar la aparición de esta patología ${ }^{(44)}$. (Tabla 2).

Tabla 2: Diferentes factores de riesgo asociados a catarata y algunos de los estudios que los analizan ${ }^{(26)}$.

\begin{tabular}{|c|c|c|c|}
\hline Factor & Odds Ratio $(95 \% \mathrm{Cl})$ & $\begin{array}{l}\text { Posible factor } \\
\text { etiológico }\end{array}$ & Estudio \\
\hline $\begin{array}{l}\text { Tratamiento anti- } \\
\text { hipertensivo }\end{array}$ & $6,2(2,1-18,4)$ & $\begin{array}{l}\text { Cianato* de la urea (o } \\
\text { glucosa) }\end{array}$ & Chen et al \\
\hline Furosemida & $2,0(1,2-3,3)$ & & Szmyd and Schwart \\
\hline Hipertensión & $1,5(1,06-2,1)$ & & Szmyd and Schwart \\
\hline Insuficiencia cardica & $3,4(1,6-7,4)$ & & Chen et al \\
\hline $\begin{array}{l}\text { Trabajo en bases } \\
\text { militares }\end{array}$ & $2,5(1,1-5,7)$ & $\begin{array}{l}\text { Radiación } \\
\text { microondas }\end{array}$ & $\begin{array}{l}\text { Harding and van } \\
\text { Heyningen }\end{array}$ \\
\hline Alcoholismo & $2,3(1,07-5,0)$ & Acetaldehído $^{*}$ & $\begin{array}{l}\text { Harding and van } \\
\text { Heyningen }\end{array}$ \\
\hline $\begin{array}{l}\text { Consumo importante } \\
\text { de tabaco } \\
\text {-Presente } \\
\text {-Pasado }\end{array}$ & $\begin{array}{l}2,09(1,4-5,9) \\
\text { Dosis dependiente } \\
2,6(1,4-5,0)\end{array}$ & $\begin{array}{l}\text { Tiocianato }{ }^{*} \text {, cianato }{ }^{*} \\
\text { y epóxidos }\end{array}$ & $\begin{array}{l}\text { Flaye et al } \\
\text { West et al } \\
\text { Flaye et al }\end{array}$ \\
\hline $\begin{array}{l}\text { Diabetes } \\
\begin{array}{l}\text {-Hombres } \\
\text {-Mujeres }\end{array}\end{array}$ & $\begin{array}{l}4,2(2,6-7,0) \\
1,8(1,2-2,6) \\
3,4(1,8-6,4) \\
6,0(2,6-14,2) \\
\end{array}$ & $\begin{array}{l}\text { Glucosa* y sus } \\
\text { metabolitos }\end{array}$ & $\begin{array}{l}\text { Harding et al } \\
\text { Szmyd and Schwart } \\
\text { Harding et al } \\
\text { Harding et al }\end{array}$ \\
\hline Miopía & $1,7(1,2-2,4)$ & & Harding et al \\
\hline Glaucoma & $2,9(1,5-5,7)$ & & Harding et al \\
\hline Cirugía de glaucoma & $14,3(3,3-62)$ & Trauma & Harding et al \\
\hline Neuropatía periférica & $1,5(1,1-1,9)$ & $\begin{array}{l}\text { Modificación } \\
\text { proteica }\end{array}$ & Harding et al \\
\hline Diarrea severa & $1,7(1,1-2,8)$ & Cianato* de la urea & Harding et al \\
\hline Óxido de etileno & $>6$ & Óxido de Etileno ${ }^{*}$ & Deschamp et al \\
\hline $\begin{array}{l}\text { Déficit de Glucosa-6- } \\
\text { fosfato } \\
\text { deshidrogenasa }\end{array}$ & --- & Glutation oxidado ${ }^{*}$ & $\begin{array}{l}\text { Yuregir et al } \\
\text { (Ophthalmic Res 1989; } \\
\text { 21:155-157) }\end{array}$ \\
\hline Consumo de leche & --- & Galactosa $^{*}$ & $\begin{array}{l}\text { Bhatnagar et al (Dig Dis } \\
\text { Sci 1989; 34: 1745- } \\
1750)\end{array}$ \\
\hline
\end{tabular}

CI: Intervalo de confianza; * Capaz de reaccionar con proteínas; +: Sólo opacidad nuclear 
El término envejecimiento implica la aparición de cambios a nivel celular que se acumulan con el tiempo y que conllevan una pérdida funcional. Se trata de un proceso no homogéneo en el individuo, de manera que los diferentes órganos y tejidos, como es el cristalino, pueden envejecer de forma asimétrica ${ }^{(37)}$.

La edad avanzada es el principal factor de riesgo asociado a la aparición de cataratas, de tal modo que se ha observado un aumento de su prevalencia con la edad ${ }^{(4,37)}$ debido a los cambios progresivos y secuenciales que sufren las proteínas cristalinianas con el envejecimiento. Además, la adición fibrilar al cristalino se produce durante toda la vida, aumentando por tanto la densidad cristaliniana con el paso de los años.

La transparencia del cristalino depende de su avascularidad, la falta de organelas, el escaso espacio entre sus fibras y la gran organización entre sus células y proteínas. ${ }^{(74)}$ A nivel cortical, la transparencia está relacionada con el gran orden espacial de la arquitectura fibrilar y los escasos espacios intercelulares que compensa la dispersión de la luz causada por las fluctuaciones de los índices de refracción entre las membranas y el citoplasma. Sin embargo, la poca dispersión de la luz en el núcleo no se debe al gran orden espacial de sus fibras, sino a que el índice de dispersión entre las membranas fibrilares y el citoplasma es mínimo. ${ }^{(37,75)}$

Desde el momento de su formación, las fibras son sometidas a un proceso de diferenciación terminal que implica una pérdida de organelas secuencialmente programada, y que culmina en un proceso de denucleación. Así, a cierta profundidad las fibras activas nucleadas pierden sus organelas y, con ellas, su capacidad de transcripción y de síntesis, por lo que se vuelven relativamente inactivas metabólicamente. ${ }^{(74,76-77)}$ 


\section{2.- TABACO Y ALCOHOL}

Se han realizado múltiples estudios tratando de demostrar una asociación entre el tabaco y las enfermedades oculares, habiéndose encontrado asociación con la degeneración macular asociada a la edad (DMAE), la formación de cataratas, la orbitopatía tiroidea y la retinopatía diabética. Otros estudios más recientes también han hallado asociación entre el tabaco y la inflamación ocular. ${ }^{(78-79)}$

Uno de estos estudios, realizado en Edimburgo ${ }^{(80)}$, no demostró que existiera asociación entre la aparición de cataratas y el tabaco, aunque podía deberse a que sólo tuvo en cuenta fumadores en el momento del estudio sin considerar a aquellos pacientes que habían fumado en el pasado y que posteriormente desarrollaron cataratas.

Otro trabajo realizado en Maryland ${ }^{(81)}$ tampoco demostró asociación significativa entre el tabaco y la aparición de cataratas; sin embargo, sí demostró una mayor progresión en el desarrollo de catarata nuclear en los pacientes fumadores actuales.

No obstante, otro estudio realizado sobre población caucásica en Estados Unidos sí ha encontrado asociación entre el tabaco y el desarrollo de cataratas de tipo nuclear y subcapsulares posteriores. ${ }^{(82)}$

El Andhra Pradesh fue un trabajo realizado sobre población de la India que demostró una mayor prevalencia de catarata en pacientes fumadores con respecto a los no fumadores; ${ }^{(83)}$ se evidenció además una relación dosis dependiente, de modo que los grandes fumadores presentaban mayor riesgo de desarrollar catarata que los fumadores ocasionales.

Una de las teorías por las que el tabaco parece estar implicado en la formación de cataratas es por la disminución de los anti-oxidantes endógenos favoreciendo el daño oxidativo. ${ }^{(84)}$ 
También se han realizado múltiples estudios tratando de encontrar una asociación entre el consumo de alcohol y la formación de cataratas, como el realizado en Maryland no demostró asociación entre el tabaco y la aparición de cataratas, pero sí que demostró asociación entre el consumo diario de alcohol (tanto moderado como severo) y la aparición de cataratas subcapsulares posteriores. Esta asociación no se encontró en bebedores ocasionales de alcohol. ${ }^{(85)}$

El Beaver Dam eye Study también han demostrado una asociación entre el consumo de alcohol y el desarrollo de cualquiera de los subtipos de cataratas. ${ }^{(86)}$

\section{3.- DIABETES MELLITUS}

A pesar de que la retinopatía diabética es la principal causa de ceguera legal en menores de 65 años en países desarrollados, en los países subdesarrollados es la catarata. Además, su incidencia y progreso en los pacientes diabéticos es mayor que en el resto de la población ${ }^{(87-88)}$ y se han encontrado tasas de complicaciones más elevadas en la cirugía de cataratas de los pacientes diabéticos. ${ }^{(89)}$

En los países en vías de desarrollo, el tratamiento de la diabetes es insuficiente y la cirugía de catarata resulta en muchas ocasiones inaccesible ${ }^{(90)}$; esto produce que las complicaciones visuales por falta de tratamiento de estas patologías sean más elevadas.

El enzima Aldolasa Reductasa cataliza la reducción de la glucosa a sorbitol a través de la vía de polyol. Se ha demostrado que el acúmulo de sorbitol produce cambios osmóticos que ocasionan la degeneración hidrópica de las fibras del cristalino y la consecuente aparición de cataratas ${ }^{(91-92)}$. En el caso de las células nerviosas de la retina, el acúmulo de sorbitol intracelular reduce la síntesis y la entrada del mioinositol, lo que conlleva la reducción de la velocidad de conducción nerviosa desarrollándose así la neuropatía diabética. Este hecho, junto con las alteraciones vasculares que se producen por la diabetes predispone al desarrollo de retinopatía diabética. 
Debemos añadir que otros estudios han demostrado que el estrés osmótico que supone el acúmulo de sorbitol (93) induce la apoptosis de las células epiteliales del cristalino ${ }^{(94)}$ favoreciendo el desarrollo de cataratas ${ }^{(95)}$. Este estrés osmótico desempeña un papel especialmente importante en el rápido desarrollo de cataratas en pacientes jóvenes con diabetes mellitus tipo $1^{(96-97)}$.

\section{4.- HIPERTENSIÓN ARTERIAL}

Se ha propuesto que la hipertensión arterial (HTA), tanto la sistólica ${ }^{(88)}$ como la diastólica ${ }^{(98)}$, o las líneas de tratamiento antihipertensivo ${ }^{(99)}$ pueden inducir a la formación de cataratas, aunque se desconoce el mecanismo y no existe un consenso sobre el tema.

El Barbados Eye Study ${ }^{(100)}$, realizado por Leske y colaboradores en pacientes de raza negra, encontró una relación entre la hipertensión y el desarrollo de opacidad cortical. El Beaver Dam Eye Study ${ }^{(60)}$ realizado en caucásicos americanos, aunque no relacionó la HTA con la catarata, sugería que dicha relación podría demostrarse en estudios más extensos. Estos autores publicaron un artículo que encontró una mayor incidencia de catarata en ojos con hallazgos patológicos asociados a la HTA en el fondo de ojo; sin embargo esta asociación no fue estadísticamente significativa ${ }^{(101)}$.

Otros estudios realizados en caucásicos americanos sí encontraron relación entre hipertensión y cataratas. El Allen Park Michigan Veterans Administration Medical Center ${ }^{(102)}$, encontró que la hipertensión arterial aumentaba el riesgo de opacificación capsular posterior; y el Physicians Health Study ${ }^{(103)}$ observó una relación entre la catarata y la presión arterial sistólica aunque no con la presión arterial diastólica ni con la hipertensión (104).

El Blue Mountains Eye Study ${ }^{(105)}$ realizado en la población australiana, comparó el calibre arterial con el venoso concluyendo que el estrechamiento vascular no es factor de riesgo para padecer catarata sino que se trata de un marcador de riesgo; siendo la edad el factor de riesgo real. 


\section{5.- LUZ SOLAR Y RADIACIÓN}

Los efectos de la radiación solar sobre la salud humana han sido ampliamente estudiados. Pueden resultar nocivos, sobre todo en tejidos como la piel, pero también presenta efectos positivos en patologías como la osteoporosis al mejorar la síntesis de Vitamina D.

Los componentes de la luz solar más dañinos para la salud son las radiaciones ultravioleta (UV) tipo A y B. Debido a la pérdida de la capa de ozono, se ha producido un aumento en el componente UV- B de radiación ultravioleta (UV-R) que alcanza la superficie terrestre de entre $280-315 \mathrm{~nm}$. ${ }^{(57)}$

Los tejidos y órganos que se ven afectados de forma más negativa son la piel, el globo ocular y el sistema inmunológico.

A nivel ocular los efectos de la radiación pueden ser de tipo agudo o aparecer a largo plazo; bien tras una corta exposición a radiación de gran intensidad o bien por exposición prolongada a intensidades de radiación menores. Estas radiaciones pueden condicionar el desarrollo de queratitis, pterigion o cataratas ${ }^{(55-57,106)}$, sobre todo de tipo cortical ${ }^{(107)}$.

Mientras que el daño de las UV-R sobre la piel está más relacionado con la exposición directa ${ }^{(108)}$, a nivel ocular la aparición de cataratas se debe a la luz reflejada. Así, la dispersión y reflexión de la luz por las nubes aumenta la cantidad de radiación difusa incidente en el ojo. ${ }^{(109-110)} \mathrm{Sin}$ embargo, los efectos de la UV-R sobre el ojo no están relacionados con la latitud o la intensidad solar total. ${ }^{(48)}$

En Estados Unidos se realizó un estudio que estimaba el riesgo de catarata en una zona que presentaba una disminución en la capa de ozono de entre un 5 y un $20 \%$ y se encontró un aumento de las cataratas corticales de un 1,3\% en las zonas con una disminución del $5 \%$ de la capa de ozono y un aumento del 6,9\% de las cataratas corticales en aquellas zonas en las que la capa de ozono se había visto disminuida un $20 \%$. ${ }^{(111)}$ 
Se ha descrito que múltiples fármacos aumentan la sensibilidad a la radiación de la luz solar, por lo que se ha propuesto que su uso está asociado a una mayor incidencia de catarata. ${ }^{(112)}$

Pero no sólo la exposición a la luz solar favorece la aparición de cataratas. Las cataratas inducidas por radiación fueron descritas en modelos animales un año después del descubrimiento de los rayos-X por Roentgen en 1895. ${ }^{(113-114)}$

Se cree que la opacificación del cristalino se inicia por daños en el epitelio cristaliniano situado en el ecuador, que sufre daños en el ADN nuclear, produciéndose una diferenciación anormal de las fibras de elongación y su migración hacia el área subcapsular posterior ${ }^{(115)}$.

El periodo de latencia desde de la exposición a la radiación y la aparición de opacidades cristalinianas varía. Las cataratas inducidas por radiación suelen desarrollarse con mayor frecuencia después de 6 meses a un año de la exposición, sin embargo pueden producirse cataratas por radiación ionizante incluso 35 años después de la exposición. (116)

\section{6.- CORTICOIDES}

Los efectos adversos a nivel ocular derivados del uso de corticoides han sido ampliamente estudiados, siendo la elevación de la presión intraocular (PIO) y la aparición de cataratas los más frecuentes.

Se ha descrito la aparición de cataratas subcapsulares posteriores en pacientes que han tomado corticoides por vía sistémica, tópica, subconjuntival, inhalatorios e incluso intravítreos.

En el caso de los sistémicos se ha comprobado que la utilización durante más de 1 mes de corticoides por vía oral se relaciona con la aparición de cataratas subcapsulares posteriores, asociación que también se ha observado con el uso de los inhalados ${ }^{(99,117)}$. 
La mayor parte de los asmáticos asocian una terapia inhalatoria junto a administraciones sistémicas en las agudizaciones, por lo que resulta difícil diferenciar el efecto de ambas posologías.

Esto nos hace pensar en un factor de susceptibilidad individual ${ }^{(118)}$ para desarrollar cataratas secundarias a corticoides ${ }^{(19)}$ independientemente de la edad, el tipo de corticoide, la dosis total o la duración del tratamiento.

\section{7.- CATARATAS SECUNDARIAS 6.7.1.- Traumáticas}

A diferencia de las cataratas primarias las cataratas traumáticas suelen ser unilaterales.

Este tipo de cataratas se pueden presentar como consecuencia de cualquier tipo de traumatismo ocular ${ }^{(120-123)}$, aunque se ha visto con mayor frecuencia en traumatismos de tipo penetrante o en laceraciones corneales que suelen involucrar al iris. ${ }^{(124-126)}$

La decisión de tratar quirúrgicamente una catarata traumática se debe individualizar dependiendo de la integridad del globo ocular. En los últimos años, debido a las mejoras tecnológicas y al desarrollo de las técnicas quirúrgicas, se consigue un diagnóstico más preciso y un mejor manejo de la patología ocular asociada al traumatismo, observándose mejores resultados anatómicos y funcionales que los obtenidos hace unos años.

\subsection{2.-Otros tipos de cataratas secundarias}

Además de las cataratas traumáticas son frecuentes las producidas por uveítis de repetición ${ }^{(127)}$. En este caso la catarata puede ser debida bien a episodios inflamatorios a nivel ocular, o bien secundaria al tratamiento con corticoides. Otras enfermedades oftalmológicas que se asocian con cataratas son la miopía magna o el glaucoma. 


\section{8.- CATARATAS ASOCIADAS A ENFERMEDADES SISTÉMICAS}

Además de la diabetes existen múltiples enfermedades sistémicas que pueden asociarse con el desarrollo de cataratas a edades más tempranas como síntoma acompañante.

Algunas de las más importantes son la distrofia miotónica de Steinert, el síndrome de

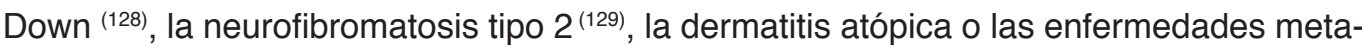
bólicas ${ }^{(130)}$ o de depósito. En su mayoría la opacidad que producen es de tipo subcapsular posterior y suele tratarse de cataratas bilaterales.

\section{7.-MANIFESTACIONES CLÍNICAS DE LAS CATARATAS}

Como hemos expuesto anteriormente, la catarata es la principal causa de ceguera tratable en el mundo. ${ }^{(1-3)}$.

Al producirse una pérdida de la transparencia de cristalino, la luz no es capaz de atravesar las estructuras oculares de igual forma que en un ojo sin ella, aumentando los fenómenos de dispersión y reflexión desde estadíos muy tempranos ${ }^{(37)}$.

Estos fenómenos, que son especialmente frecuentes en pacientes que han desarrollado cataratas de tipo cortical, resultan en síntomas como visión de halos o dificultad en la visión nocturna. También se ha descrito una alteración en la sensibilidad al contraste y disminución en la percepción de los colores. ${ }^{(131)}$

Al inicio de su desarrollo la catarata puede producir defectos refractivos, por lo general miopía de índice, que pueden solucionarse con la debida corrección óptica. 
Sin embargo, el principal motivo de consulta quirúrgica es la discapacidad visual que produce la catarata en estadíos más avanzados. En las cataratas de tipo cortico-nuclear esta discapacidad está relacionada con el aumento de densidad del cristalino; sin embargo, las cataratas de tipo subcapsular posterior suelen ocasionar una gran pérdida visual a pesar de no verse aumentada la densidad de cristalino. Esto es debido a su situación, en la mayoría de los casos a nivel central del eje visual. En el caso de las cataratas seniles, la discapacidad visual que ocasionan las cataratas suele llevar asociado el aumento de la morbilidad de estos pacientes, produciéndose aumentos en el número de accidentes o dificultad para la marcha, tanto así que el grado de discapacidad visual se ha utilizado para predecir accidentes como el aumento en el número de caídas. ${ }^{(132)}$

Además, durante el tiempo en el que los pacientes esperan la cirugía se ha observado un aumento de los episodios depresivos. ${ }^{(133)}$

\section{8. - HERENCIA Y GENÉTICA DE LAS CATARATAS 8.1.- INTRODUCCIÓN A LA GENÉTICA}

La función del ácido desoxirribonucleico o ADN es almacenar y transmitir la información genética. Además, dirige el proceso de síntesis de proteínas y su expresión puede traducirse en un determinado fenotipo.

Se denomina fenotipo a la manifestación externa de la carga genética (genotipo).

Al estudiar la estructura del ADN podemos observar que se trata de polímeros de nucleótidos, los cuales están formados por tres tipos de moléculas: pentosa (desoxirribosa en el $A D N$, ribosa en el ácido ribonucleico, ARN), bases nitrogenadas y ácido fosfórico. 
La unión aislada de la pentosa y la base nitrogenada se denomina nucleósido.(Figura 6)

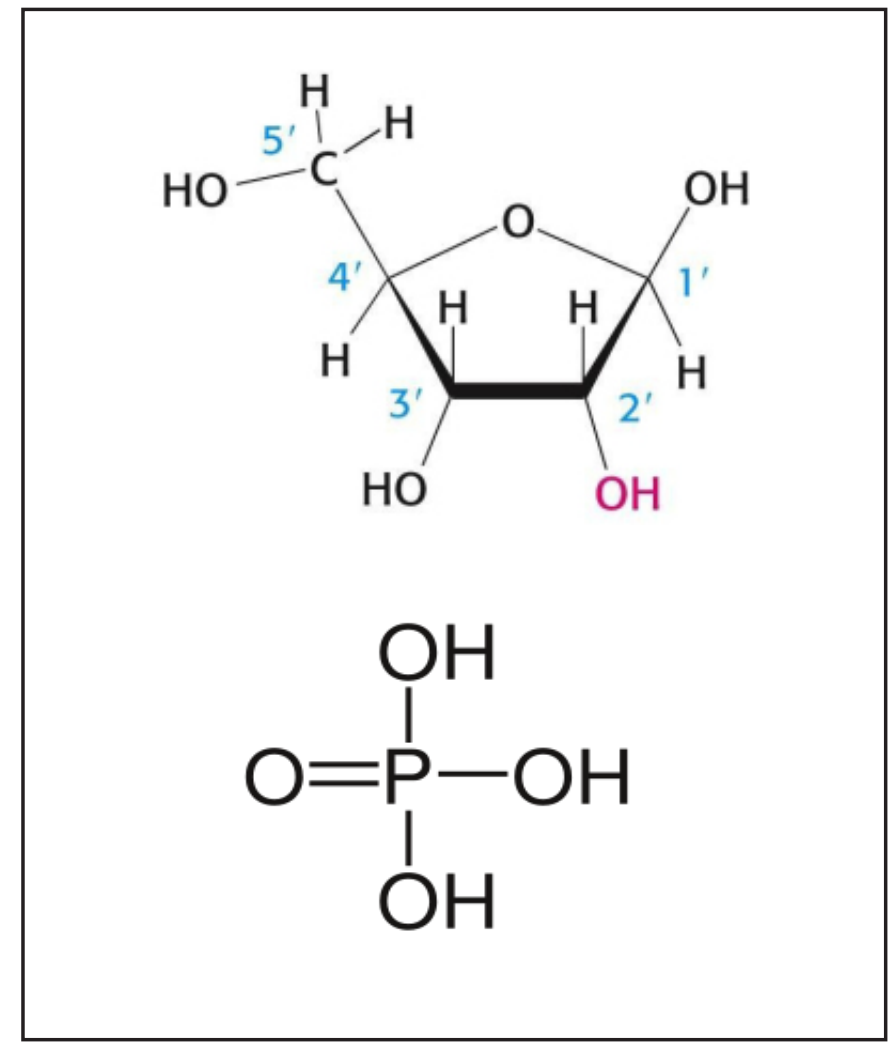

Figura 6: Estructura de la base de desoxirribosa y del ácido fosfórico 
Las bases nitrogenadas se pueden clasificar en (Figura 7):

-Púricas: Son la adenina y la guanina.

-Pirimidínicas: La citosina, timina y uracilo. Este último no forma parte de la estructura del ADN sino del ARN.<smiles>Nc1ncnc2[nH]cnc12</smiles>

Adenina<smiles></smiles>

Guanina<smiles>Nc1cc[nH]c(=O)n1</smiles>

Citosina<smiles>Cc1c[nH]c(=O)[nH]c1=O</smiles>

Timina<smiles>O=c1[nH]c(=O)[nH]c(=O)[nH]1</smiles>

Uracilo

Bases púricas o purinas

Figura 7: Tipos de bases nitrogenadas. 
En 1953 se produjo el descubrimiento por Watson y Crick de la estructura del ADN. La describieron como una doble hélice $\left(3^{`}-5^{\prime}\right)$ formada por dos cadenas complementarias de nucleótidos con bases enfrentadas entre sí; de tal modo que la adenina se encontraba unida a la citosina mediante dos puentes de hidrógeno, y la guanina a la timina por tres puentes de hidrógeno. (Figura 8)

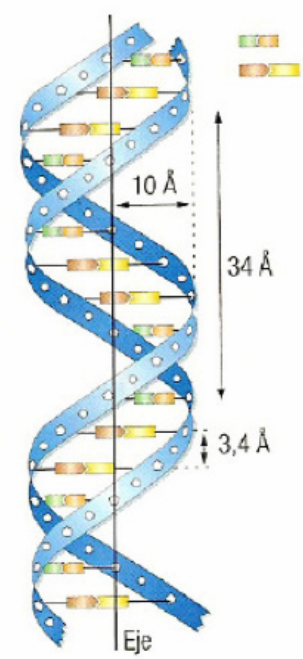

Figura 8: Estructura de la doble hélice del ADN

\section{2.-POLIMORFISMOS}

Se denomina polimorfismo a variaciones en la secuencia de las bases del ADN entre individuos de una población que presentan una frecuencia de al menos un $1 \%$.

Se han estimado más de diez millones de polimorfismos en el genoma humano que aparecen con una frecuencia relativamente alta.

Los polimorfismos, al igual que las mutaciones, pueden consistir en la sustitución de un nucleótido por otro, en la inserción de uno o varios nuevos o en la delección de nucleótidos previamente existentes. Estos procesos pueden afectar a un número variable de bases, pero lo más frecuente es que sólo se afecte un nucleótido. Esto se denomina polimorfismo de un solo nucleótido o SNP (Single Nucleotide Polymorphism) ${ }^{(134)}$. 
Los polimorfismos pueden localizarse en regiones codificantes o no codificantes del ADN. A aquellos que en las regiones codificantes producen un cambio de aminoácido se les denomina no sinónimos. Si este cambio introduce un codón de parada, se llama entonces mutación nonsense, mientras que si codifica un nuevo aminoácido, será una mutación de cambio de sentido (missense). ${ }^{(135)}$ Estos polimorfismos pueden ser patogénicos.

Si la mutación al traducirse no produce ninguna alteración en la secuencia aminoacídica se dice que es sinónima o silente. Las mutaciones de las zonas no codificantes son también muy importantes porque pueden producir una alteración del splicing, o impedir la unión de factores de transcripción (134-135).

Las mutaciones no sinónimas que inducen un cambio de aminoácido son los que en mayor proporción alteran la función de la proteína, y por tanto, son las más estudiadas.

\section{3.- GENES REPARADORES DE ADN}

El ADN puede sufrir alteraciones o mutaciones por las agresiones externas, especialmente por el estrés oxidativo ${ }^{(136)}$. Múltiples estudios han tratado de relacionar el daño en el ADN de las células epiteliales del cristalino producido por diversas causas como la luz y el desarrollo de cataratas ${ }^{(54-57,107,137-139)}$.

Sin embargo, no todas las alteraciones en el ADN desencadenan una respuesta patológica. Esto es debido a que existen enzimas reparadores del $A D N^{(140)}$ que corrigen y eliminan los residuos de nucleótidos dañados por mecanismos como la exposición a componentes citotóxicos o agentes carcinógenos. ${ }^{(140)}$

Existen cuatro mecanismos de reparación del ADN ${ }^{(141)}$ : (Figura 9)

-Mismatch Repair (MMR)

-Reparación por excisión de bases (BER)

-Reparación de rotura de doble cadena (DSBR)

-Reparación por excisión de nucleótidos (NER). ${ }^{(142)}$ 


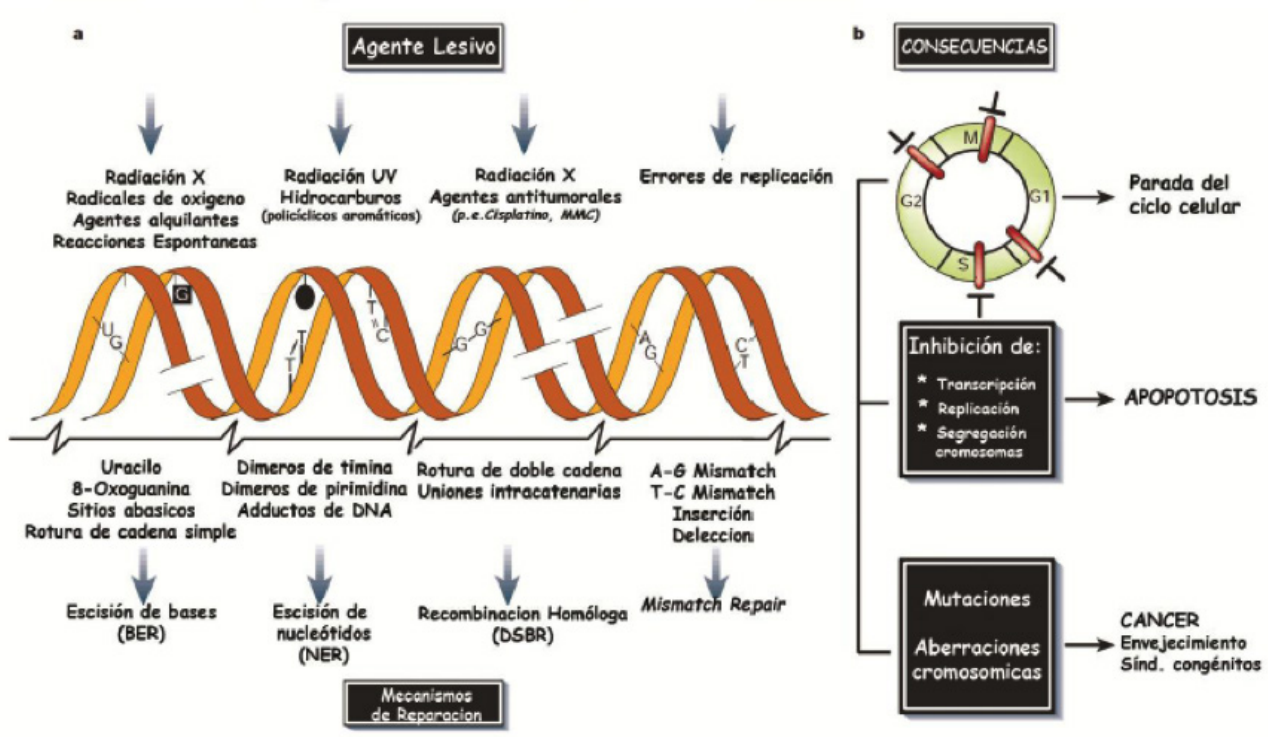

Figura 9: Consecuencias de las diferentes vías de reparación del ADN (137).

A través de este grupo de genes se codifican proteínas que reconocen el daño en el genoma celular y se encargan de repararlo; postergan la replicación celular hasta que las lesiones en su ADN hayan sido reparadas y, en caso contrario, inducen la apoptosis celular para evitar su transmisión ${ }^{(143)}$. Cuando estos mecanismos fallan, el daño se transmite a las células descendientes pudiendo iniciarse procesos como la carcinogénesis.

Se ha propuesto que polimorfismos en los genes reparadores del ADN pueden reducir su capacidad reparadora y, por lo tanto, aumentar el riesgo de sufrir enfermedades como el cáncer o incluso inducir una mayor susceptibilidad al envejecimiento (144-147).

Se han identificado más de 100 genes reparadores de ADN. Una de las primeras enfermedades estudiadas que se relacionó con una alteración en los mecanismos de excisión-reparación de los nucleótidos dañados por la UV-R fue el Xeroderma pigmentoso; la cual entre otros síntomas presenta la aparición de cataratas ${ }^{(148)}$. 
Al haberse propuesto la UV-R como posible factor etio-patogénico de las cataratas preseniles nos centraremos en el estudio de algunos polimorfismos de este grupo de genes reparadores de ADN.

\subsection{1.- Reparación por excisión de nucleótidos}

Los genes que inducen la reparación del ADN mediante la excisión de nucleótidos (NER) son fundamentales en la reparación de las lesiones del ADN inducidas por UV-R.

Estos genes, no sólo reparan las alteraciones en las pirimidinas inducidas por la radiación solar, sino que también resultan vitales en la reparación del ADN dañado por productos químicos como el cisplatino ${ }^{(49-150)}$, el $\mathrm{N}$-acetil-acetoaminofluoreno, el tabaco o el alcohol (151). (Figura 10)
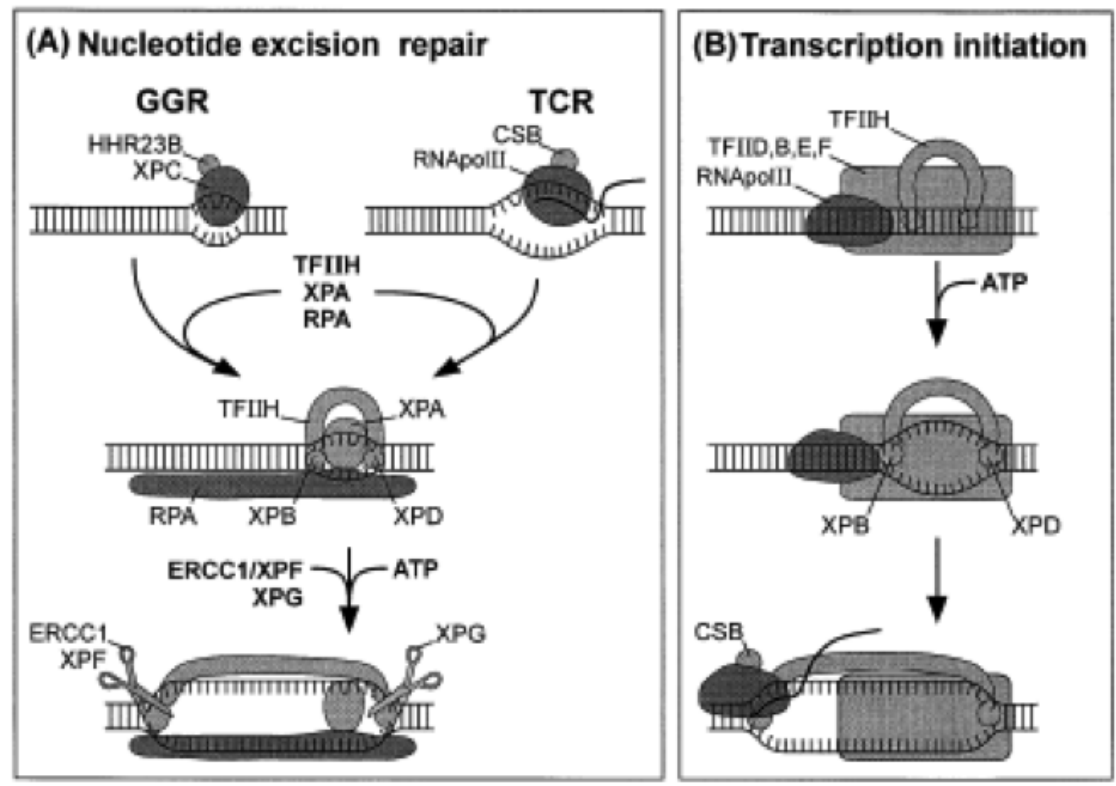

Figura 10: Modelo de reparación por excisión de nucleótidos y papel de la TFIIH en la transcripción. (137) 
Se estima que hasta el $70 \%$ del daño del ADN inducido por factores ambientales puede ser reparado mediante estas vías. Estas alteraciones en la estructura de la doble hélice de ADN interfieren en la unión normal de las bases, por lo que se altera y detiene la replicación celular y la transcripción (142).

Se han descrito tres síndromes asociados a déficits congénitos de la reparación por excisión de nucleótidos (NER): el Xeroderma pigmentoso, el síndrome de Cockayne y la tricotiodistrofia. Todos ellos presentan, entre otros síntomas, una predisposición al desarrollo de cataratas y en todos se ha demostrado una sensibilidad anormal a UV-R. ${ }^{(152)}$ Además se ha comprobado que las diferentes vías de reparación del ADN interactúan entre sí. ${ }^{(153)}$ En la reparación del ADN mediante excisión de nucleótidos (NER) se pueden identificar varias etapas consecutivas. Primero se produce el reconocimiento del daño y verificación de la cadena de DNA, bien por la unión a la región de ADN lesionada por el complejo formado por la proteína XPC y RPA, una proteína de unión al ADN monocatenario, o bien por el complejo formado por XPA y TFIIH.

Posteriormente, se produce la doble incisión de la región de ADN dañada, una incisión tiene lugar 3 a 9 bases en dirección 3'producida por la proteína XPG y otra entre 16 a 25 bases en dirección 5 ' de la lesión y es producida por el heterodímero XPF/ ERCC1 ${ }^{\text {(154). }}$. En total se produce la escisión de unas $25-30$ bases tras lo cual se elimina la zona dañada y se produce una resíntesis de esa región por un enzima que contiene ADN- polimerasa.

\subsubsection{1.- ERCC1}

El excision repair cross-complementing rodent repair deficiency grupo 1 (ERCC1) se encuentra localizado en el brazo largo del cromosoma 19 (19q13.32) (Figura 11).

Codifica la proteína reparadora del ADN ERCC1 que es vital para la reparación mediante la excisión de nucleótidos en lesiones del ADN como las producidas por la radiación ultravioleta (UV-R) o los compuestos electrofílicos como el cisplatino ${ }^{(155)}$. 
Esta proteína se une a la endonucleasa XPF formando un heterodímero que cataliza la incisión en 5' de la lesión del ADN (156-158). "In vitro" estas dos proteínas son inestables en ausencia la una de la otra. ${ }^{(159-160)}$

Recientes estudios de laboratorio han revelado que la actividad nucleasa de heterodímero reside en la subunidad XPF del complejo y que contiene muy conservada la secuencia (dominio) V/IERKX3D. ${ }^{(161-162)}$ El grupo de residuos ácidos permite la coordinación con los iones metálicos necesarios para catalizar la incisión en la cadena de ADN, y las mutaciones de los residuos clave afectan a nucleasa pero no la actividad de unión al ADN.

El heterodímero ERCC1-XPF interactúa específicamente con la proteína XPA a través de los aminoácidos 91-119 de ERCC1 y 75-114 de XPA, interacción necesaria para la funcionalidad de NER, ${ }^{(163-164)}$ siendo suficiente con un pequeño péptido de XPA. ${ }^{(165)}$

La endonucleasa heterodimérica ERCC1-XPF también está implicada en la reparación del ADN y la recombinación en la reparación de los entrecruzamientos inter-cadena.

Las mutaciones en este gen producen el síndrome de Cockayne tipo II el cual se caracteriza por presentar, entre otros síntomas, atrofia óptica y cataratas. Los polimorfismos que alteran su expresión pueden desempeñar un papel importante en la carcinogénesis ${ }^{(166,167)}$.

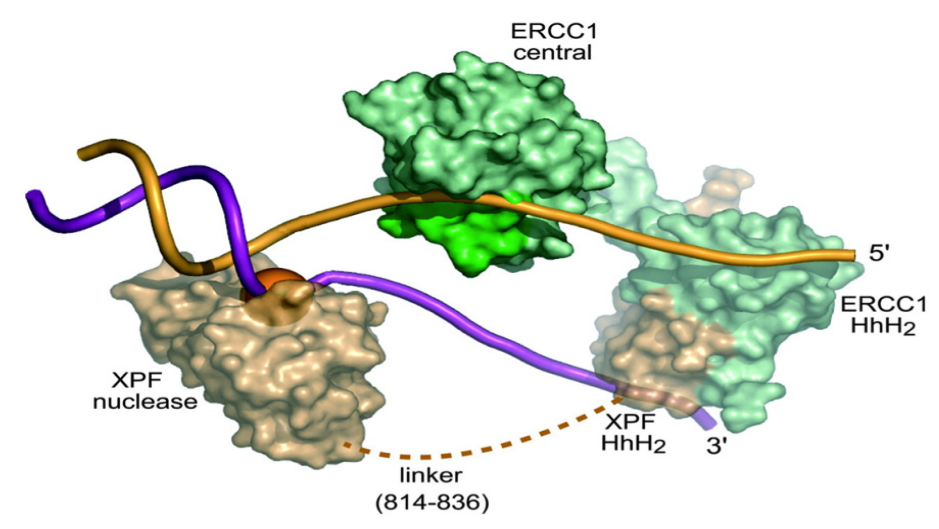

Figura 11: Estructura del gen ERCC1. 


\subsubsection{2.- ERCC2}

El gen XPD, también denominado excision repair cross-complementing rodent repair deficiency grupo 2 (ERCC2), es un gen localizado también en el brazo largo del cromosoma 19 (19q13.32). (Figura 12)

El proceso de reparación del ADN por excisión de nucleótidos (NER) debe actuar de forma simultánea a la transcripción, demostrándose que durante la misma un complejo de la polimerasa de ARN se sitúa frente a la lesión y es desplazado para dar acceso a las enzimas de reparación. ERCC2 codifica una helicasa de 760 aminoácidos, que forma parte del factor de transcripción TF IIH ${ }^{(142,133,168)}$, esencial tanto para iniciar la transcripción mediada por la ARN polimerasa II, como para la NER. ${ }^{(169)}$ Se encarga del procesamiento y verificación del ADN lesionado.

Esta helicasa posee una actividad dependiente de ATP y es la encargada de abrir la hélice de ADN en sentido 5'-3' para que puedan iniciarse los procesos de transcripción y reparación ${ }^{(170)}$.

La pérdida completa de la proteína ERCC2 es incompatible con la vida. Sin embargo, el déficit parcial de su función puede conducir tanto a síndromes con predisposición al cáncer como síndromes que cursan con envejecimiento prematuro, como es el caso del Xeroderma Pigmentoso, el Síndrome de Cockayne o la Tricotiodistrofia (152).

Recientemente se han llevado a cabo estudios que proponen la asociación de ciertos polimorfismos en ERCC2 con ciertas patologías oftalmológicas como degeneración macular asociada a la edad o las cataratas seniles. ${ }^{(171-172)}$

Los llevados a cabo por Ünal y colaboradores demuestran que el genotipo ERCC2-751 GIn/ Gln presentan diferencias estadísticamente significativas entre el grupo con cataratas (12\%) y el grupo control (20\%); diferencias aún mayores entre el grupo con cataratas corticales $(4 \%)$ y el grupo control (20\%). ${ }^{(171)}$

El estudio realizado por Padma y colaboradores demostró la asociación entre el polimorfismo ERCC2-312 Asp/Asn y el desarrollo de cataratas seniles observándose diferencias estadísticamente significativas entre el grupo de pacientes con cataratas $(21,6 \%)$ y controles sanos $(13,2 \%) .{ }^{(172)}$ 


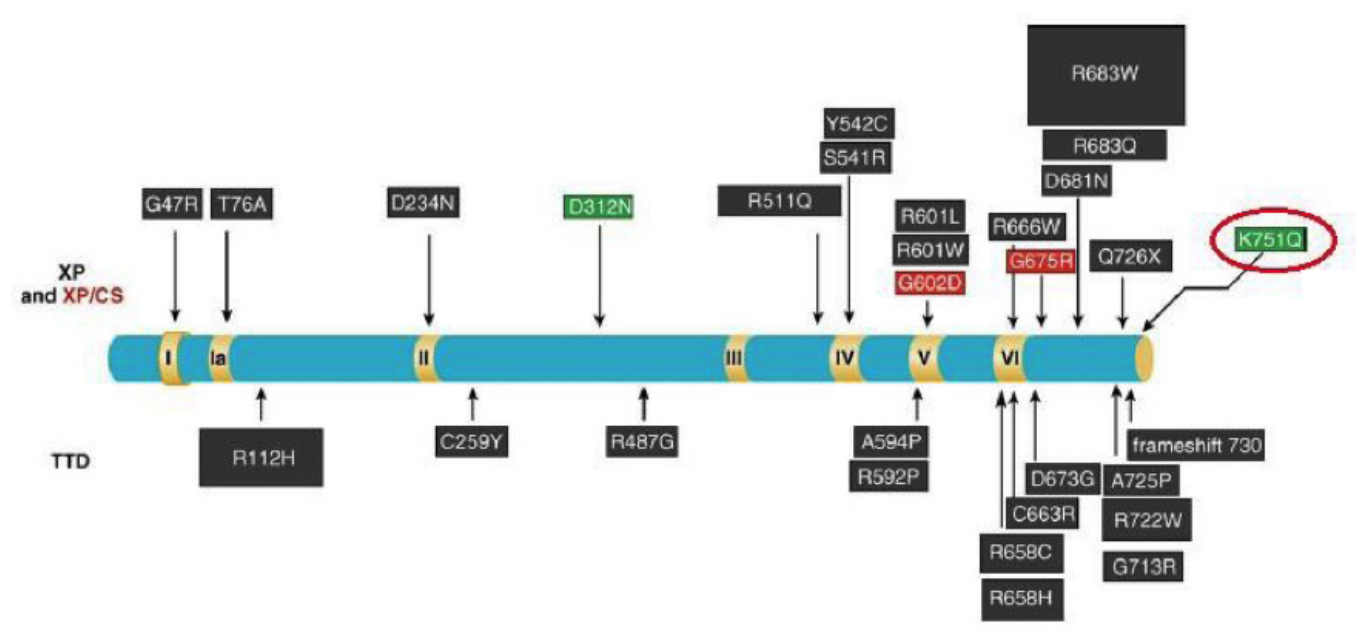

Figura 12: Estructura del gen XPD. (131)

\subsubsection{3.- XPC}

El gen Xeroderma pigmentosum complementation group C (XPC) posee 16 exones y 15 intrones junto a otro intrón de 1,6kb en el exón 5 y está localizado en el brazo pequeño del cromosoma 3 (3p25) (Figura 13).

Codifica la proteína homónima XPC cuya función es primordial en los primeros pasos de reconocimiento del daño del ADN en el proceso de reparación mediante excisión de nucleótidos (NER). ${ }^{(174,175)}$

Podemos diferenciar dos tipos de mecanismos de reparación por excisión de nucleótidos (NER), la reparación global del genoma (GG-NER) y la reparación por pareja de transcripción (TC-NER).

En el caso de XPC, su papel es clave en la reparación global del genoma, destacando su papel en el reconocimiento de los daños en el ADN.

Durante la reparación del ADN, en un primer paso de reconocimiento del daño en el ADN interviene la proteína XPC, al igual que XPA y un complejo de tres proteínas conocidas colectivamente como proteína de replicación A (RPA). 
XPC forma un complejo de iniciación junto con HHRAD23 ${ }^{(176)}$ que se mantiene estable gracias a una proteína denominada centrin2/caltracin $1{ }^{(177)}$. Su función es inducir el reclutamiento y la posterior unión del resto de proteínas al ADN.

Los otros mecanismos de reparación, incluyen al factor de trascripción TFIIH constituido por 6 subunidades que facilitan parcialmente la apertura de las cadenas de ADN.

Al reconocerse el ADN dañado, se produce el cambio de conformación en la proteína XPC, de forma que los restos aromáticos de sus aminoácidos se unen a nucleótidos sin emparejar en frente de la lesión, hecho fundamental para la formación de complejos proteicos abiertos y para la reparación de los mismos. ${ }^{(178)}$

Alteraciones genéticas en XPC impiden la adecuada síntesis de su proteína, por lo que se altera la vía de reparación del ADN mediante NER. El ADN dañado puede sufrir procesos de acumulación y producirse fenómenos de carcinogénesis. ${ }^{(178,179)}$

Se han encontrado más de 40 mutaciones del gen XPC que pueden causar xeroderma pigmentoso, siendo la causa más común de esta enfermedad en los Estados Unidos ${ }^{(180)}$ y Europa.

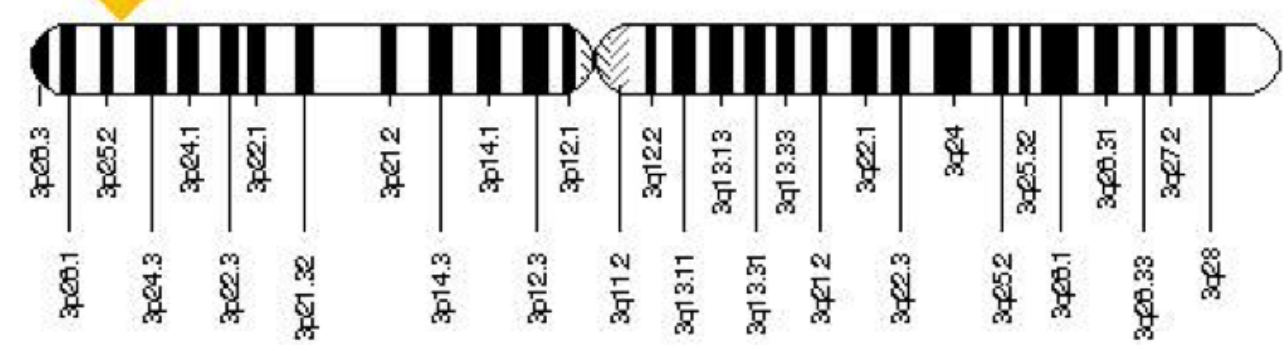

Figura 13: Localización cromosómica del gen XPC. 


\subsection{2.- Reparadores por excisión de bases}

La escisión de bases (BER) es el principal mecanismo de eliminación de bases alteradas o añadidas erróneamente ${ }^{(181-182)}$.

Las principales enzimas implicadas en el reconocimiento de la lesión y la rotura del enlace $\mathrm{N}$-glicosil entre la base nitrogenada y la desoxirribosa-fosfato son las glicosilasas.

La endonucleasa APE1 rompe el enlace fosfodiester en el lugar donde se ha eliminado la base.

Existen dos posibles vías de reparación: (Figura 14)

Long-patch: Cuando se afectan varios nucleótidos; y Short-patch en la que sólo se implica uno. Se trata del mecanismo más frecuente. En esta vía actúa la polimerasa $\beta$, que posee dos dominios y funciones diferentes ${ }^{(135)}$ : Un pequeño dominio terminal $\mathrm{NH} 2$ con actividad AP liasa y que sustrae el residuo de azúcar-fosfato abásico; otro dominio polimerasa propiamente dicho, encargado de añadir el nucleótido correcto. Además, interactúa con el complejo formado por XRCC1 y ADN ligasa III. XRCC1 actúa como proteína estabilizadora permitiendo la unión de la polimerasa y la ligasa al sitio de reparación, al tiempo que se une al ADN por su región amino-terminal ${ }^{(143)}$.

La reparación por escisión de bases (BER) elimina las bases que han sufrido ataques hidrolíticos. Para ello es fundamental la rotura del enlace $\mathrm{N}$-glicosídico que une la base a la estructura desoxi-ribosa-fosfato, la cual se produce gracias al enzima ADN glicosilasa. Esta ruptura deja un lugar AP (apurínico ó apirimidínico) el cual es roto por una AP endonucleasa que cataliza la incisión del enlace fosfodiester en posición 5'. Una desoxi-ribosa-fosfodiesterasa completa la eliminación del residuo desoxi-ribosa-fosfato. Finalmente, se rellena el hueco mediante la acción de ADN polimerasa $B$ y una ADN ligasa. 


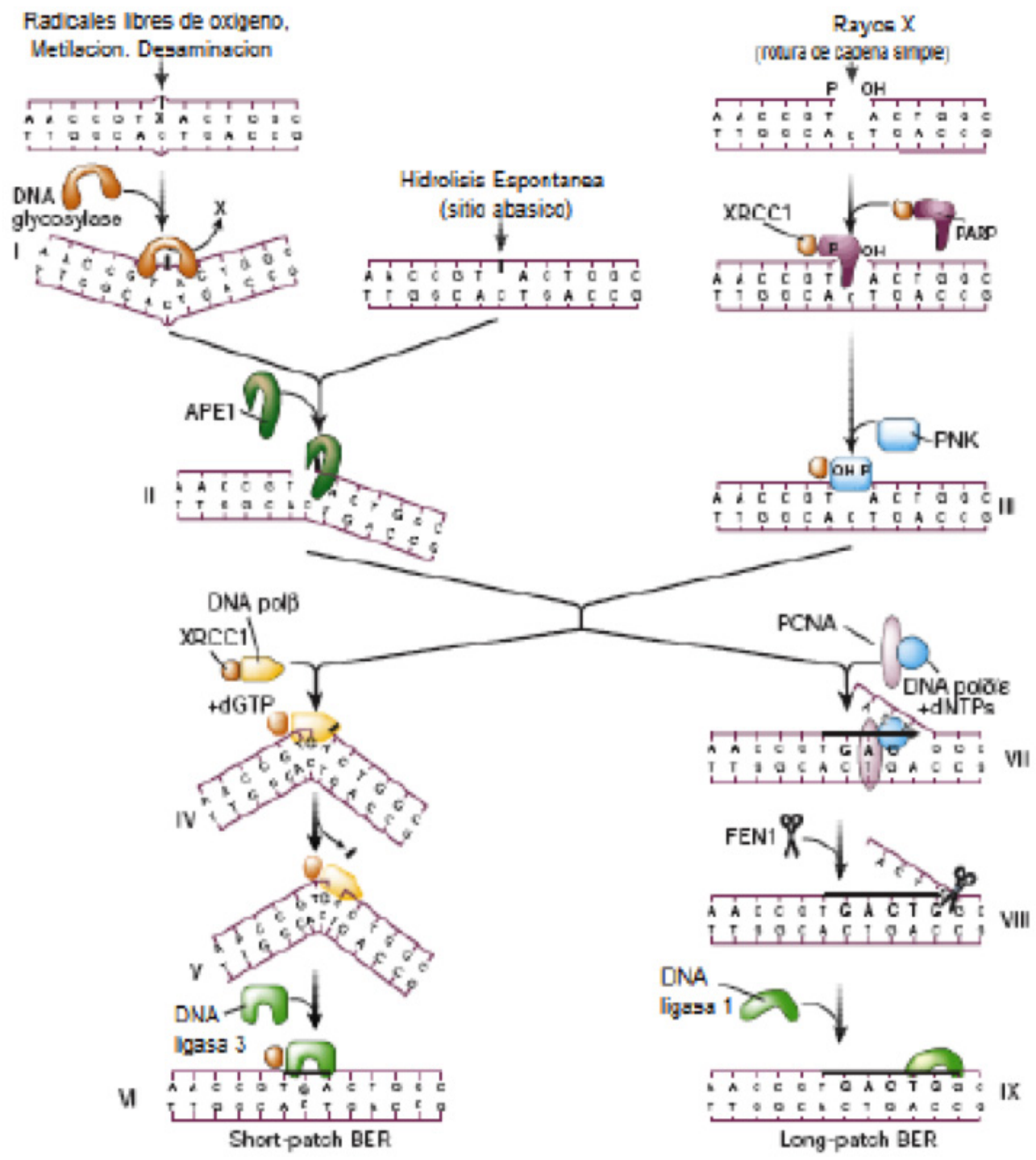

Figura 14: Mecanismo de reparación del ADN por excisión de bases ${ }^{(131)}$. 


\subsubsection{1.- XRCC1}

El gen XRCC1 (X-ray repair cross complementation group 1), tiene un tamaño de $33 \mathrm{~kb}$ y se localiza en el brazo largo del cromosoma 19 (19q13.2-13.3).

Codifica una proteína a la que no se ha atribuido actividad enzimática ${ }^{(183)}$, pero que posee dominios de interacción con otras proteínas, además de una señal de localización nuclear y un sitio de fosforilación ${ }^{(135)}$.

La proteína codificada por este gen resulta fundamental en la reparación del ADN por Escisión de Bases $(\mathrm{BER})^{(184)}$. Interactúa con múltiples glicosilasas y forma complejos con la mayoría de las proteínas que intervienen en este proceso como APE1, POL $\beta$, poli-ADP-ribosa-polimerasa (PARP 1) y ADN ligasa tipo III (LIG3) ${ }^{(171,184)}$, lo que sugiere que es reclutado al lugar de la lesión por las glicosilasas y después coordina los siguientes pasos de BER, modulando la actividad del resto de factores ${ }^{(153)}$ (Figura 15).

Recientemente se ha demostrado que la unión del factor de transcripción E2F1 regula la actividad de XRCC1 y promueve la reparación del ADN ${ }^{(185)}$.

Múltiples estudios han demostrado que la delección de XRCC1 en línea germinal es incompatible con la vida ${ }^{(186)}$, mientras que las líneas celulares con mutaciones inactivantes del gen presentan hipersensibilidad tanto a las radiaciones ionizantes como a los agentes alquilantes ${ }^{(187)}$.

Se ha comprobado, mediante estudios funcionales que analizan el retraso que se produce en el ciclo celular cuando se somete a las células a radiación ionizante y la cantidad y persistencia de aductos de ADN con aumento del número de mutaciones en p53 y alteraciones cromosómicas, que existen más de 60 polimorfismos en este gen que determinan la disminución de la capacidad reparadora del ADN ${ }^{(188-189)}$.

Luo y colaboradores estudiaron la asociación entre el desarrollo de cataratas seniles y polimorfismos en el codón 399 del gen XRCC1 estudiando su distribución en 180 pacientes con cataratas seniles y 174 pacientes sanos. Observaron que los grupos que presentaban al menos un alelo con Adenosina (A), ya fuera con el genotipo $A / A$ o $G / A$, presentaban un riesgo aumentado en 1,68 de desarrollar cataratas respecto a aquellos pacientes con el genotiopo G/G. ${ }^{(190)}$ 


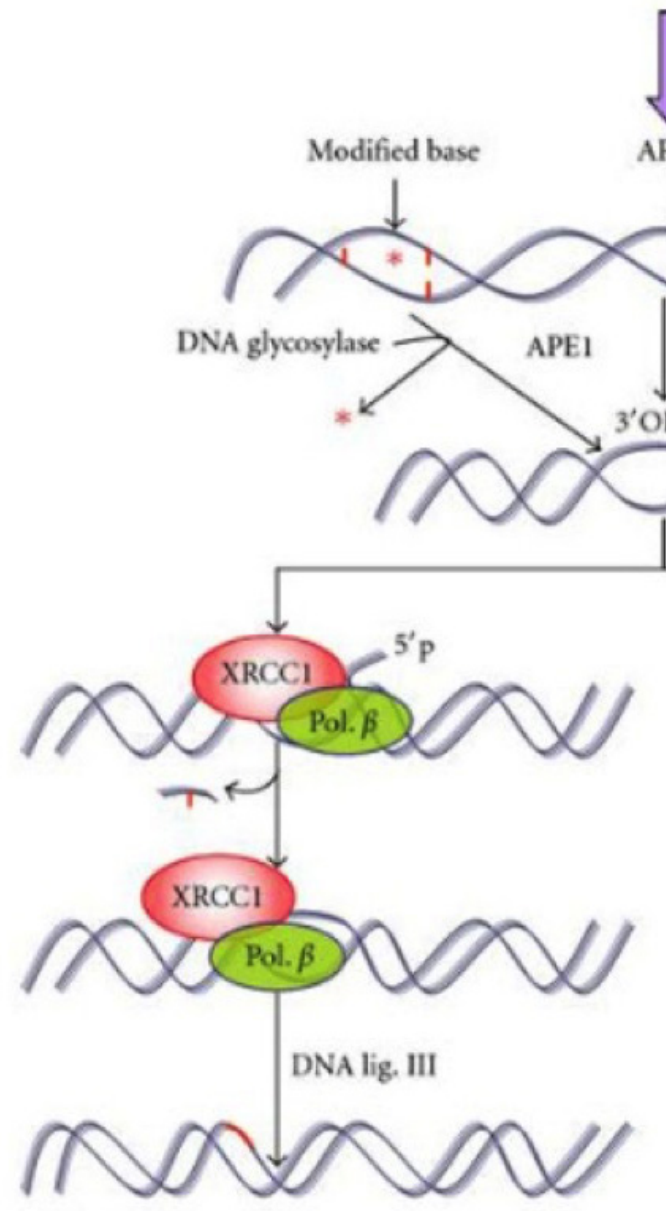

(a) SP-BER
ROS, alkylation, deamination, IR (X-rays, $\gamma$-rays)

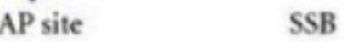

SSB $\mathrm{P} \downarrow \mathrm{P}$ $\checkmark P$<smiles>[AlH2]</smiles>
APE1 $p$ $\infty$

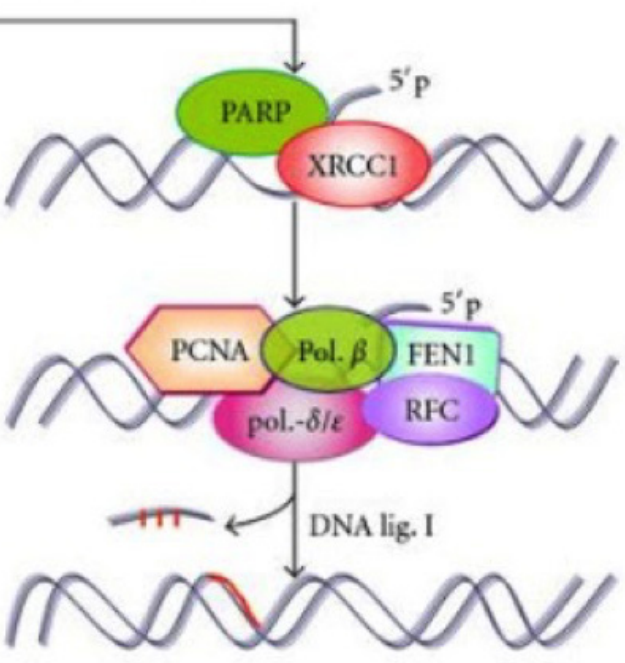

(b) LP-BER 


\section{4.-INDUCTORES DE APOPTOSIS}

La apoptosis fue definida por primera vez por Kerr en el año 1972. Posteriormente se observó que en el último paso de la apoptosis una célula se fragmenta en múltiples células más pequeñas denominadas "cuerpos apoptóticos" (191). En condiciones genéticamente normales se trata de un proceso positivo y controlable de muerte celular.

Este proceso va acompañado de la destrucción de las membranas celulares, condensación de los cromosomas y la transformación de los cuerpos apoptóticos en quistes que serán eliminados por fagocitosis ${ }^{(192)}$.

Estudios experimentales en animales demostraron que la apoptosis causada por la luz ultravioleta (UV-R) alcanza su máximo valor tras 24 horas de exposición (193).

La eliminación de ciertas células puede ser beneficiosa para un organismo; sin embargo, en ciertas condiciones la apoptosis puede eliminar a células que aún son funcionales. En el caso del cristalino, ciertas proteasas como las caspasas están implicadas en la muerte celular activándose cuando se produce daño oxidativo ${ }^{(194)}$.

La rapidez en la muerte de las células epiteliales cristalinianas por apoptosis después de la irradiación UV eliminaría el control homeostático que estas células epiteliales ejercen en las células de las fibras subyacentes, lo que conlleva un deterioro de la integridad de estas fibras. Estas reacciones, además de daños directos en el ADN y las rupturas de membrana, pueden conducir a la pérdida observada de la viabilidad celular en el epitelio ${ }^{(195)}$. La muerte de las células epiteliales junto al daño inducido por UV a las proteínas de las células de fibra puede dar lugar a opacificación del cristalino y la formación de catarata. 


\subsection{1.- p53}

p53 es uno de los genes más estudiados en la apoptosis, y se ha comprobado que puede parar la proliferación celular e inducir su apoptosis. Sin embargo, una vez que el gen p53 está dañado, se pierde la capacidad de la apoptosis celular, lo que puede resultar fatal en ciertos cánceres al no poderse evitar la proliferación de células tumorales. (196) (Figura16)

El gen p53 o TP53 se encuentra en el brazo corto del cromosoma 17 (17p13) y codifica un factor de transcripción nuclear. Codifica la proteína p53, fosfoproteína nuclear de 53 KDa, que actúa sobre genes que codifican proteínas que regulan el ciclo celular, de forma que, en situaciones de daño al ADN, detiene el ciclo celular hasta que el ADN es reparado o hasta la muerte celular, evitando la proliferación de células mutadas (197).

La proteína p53 consta de cuatro dominios funcionales encargados de regular la respuesta celular frente a daños en el DNA ${ }^{(198,199)}$. El dominio de activación transcripcional que se encuentra en el extremo amino terminal y sus funciones principales son reclutar cofactores de transcripción y proteínas modificadoras como CBP o p300 e interaccionar con el regulador negativo MDM2. En este extremo también se localiza una región rica en residuos de prolina importante para los procesos apoptóticos mediados por p53 ${ }^{(200)}$. El dominio de unión al DNA se encuentra en la región central de la proteína. A través de él, p53 se une a secuencias específicas de respuesta a p53, presentes en la región promotora de sus genes diana ${ }^{(201)}$. Esta unión con el DNA es imprescindible para la actividad transcripcional de p53 y para su actividad como supresor tumoral. El extremo carboxilo terminal se encuentran los dos dominios restantes; el dominio de regulación y el dominio de oligomerización a través del cual se forma un tetrámero simétrico que es activo como factor de transcripción ${ }^{(198,199)}$. 
Para la regulación de p53 la proteína ubiquitina quinasa MDM2 ejerce un control negativo ${ }^{(202,203)}$. En condiciones normales, MDM2 interacciona con p53 inhibiendo su actividad transcripcional .Sin embargo, en condiciones de estrés se producen diversas modificaciones postraduccionales en p53 como fosforilaciones o acetilaciones que generan cambios conformacionales en la proteína ${ }^{(203,204)}$. Todo ello interrumpe la interacción entre p53 y MDM2, y a produce la estabilización, acumulación y activación de p53 (205).

La proteína p53 funciona regulando la trascripción y modulando el ciclo celular en los puntos de control G1/S y G2/M, permitiendo detener el crecimiento celular y reparar el ADN ó activando la apoptosis si el daño es irreparable. Induce la detención del ciclo celular en múltiples puntos mediante la inducción de p21, inhibidor de la progresión del ciclo, y la inhibición catalítica de PCNA, proteína promotora de la replicación del ADN (206-207). La expresión de oncogenes como Myc o Ras también provoca una parada del ciclo celular al aumentar los niveles de p16 y ARF ${ }^{(208)}$. Ante situaciones de estrés o ante daños que no pueden ser reparados, p53 puede inducir senescencia celular, una parada irreversible del ciclo celular, a través de la activación de la expresión de PAI-1 (inhibidor del activador de plasminógeno 1) y p21 (209).

La inducción de la apoptosis por p53 puede llevarse a cabo mediante la activación de la transcripción de genes proapoptóticos ${ }^{(210)}$ de manera independiente de su actividad transcripcional al traslocarse a la mitocondria e interaccionar directamente con las proteínas antiapoptóticas BCL-XL y BCL-2, antagonizando su actividad (211, 212).

El que una célula sufra una parada del ciclo celular o sufra un proceso de apoptosis en respuesta a una señal de estrés dependerá de múltiples factores como el tipo celular, la eficiencia de los mecanismos de reparación del DNA, la composición oncogénica de la célula, los estímulos extracelulares o la intensidad de las condiciones de estrés (201, 209). La proteína p53 también participa en la reparación de daños en el DNA activando la transcripción de diversos genes como la ribonucleótido reductasa p53R2, XPC o GADD45, inhibiendo así la síntesis de DNA y estimulando la reparación por escisión de

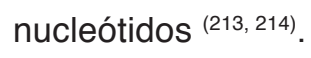


La mutación de una copia del gen TP53 y la deleción o inactivación del otro alelo origina la pérdida de la función de la proteína p53. La mutación origina una proteína con cambio de conformación, una vida media más larga y una función desordenada ${ }^{(215)}$.

La inactivación del gen TP53 puede ocurrir por mutación, pérdida alélica, secuestro de la proteína mediante unión con productos virales, como las proteínas del adenovirus E1b y la proteína E6 del virus del papiloma humano, o por interacción con la proteína MDM2.

Se han identificado aproximadamente 10.000 mutaciones del gen TP53 en tumores humanos ${ }^{(216)}$. La cuarta parte de estas mutaciones son sustituciones en pares de bases $\mathrm{G}$ : C. El $87 \%$ de las mutaciones caracterizadas se encuentran en los exones $5-8$ y el $8 \%$ en el exón 4. Además, se han hallado diferencias en la presentación de mutaciones por etnias.

Las mutaciones en la región central del gen suelen ser del tipo "missense" -por cambio de sentido-, mientras que las que se producen en las regiones amino y carboxilo terminal, mucho menos frecuentes, suelen ser del tipo "nonsense" -producen un codón sin sentido-, mutaciones que cambian la fase de lectura, mutaciones en las secuencias de procesamiento o mutaciones silenciosas ${ }^{(217)}$.

Las mutaciones por cambio de sentido (missense) además de producir pérdida de la función supresora de tumores, pueden favorecer funciones oncogénicas al modificar la expresión de genes que están controlados por este factor de trascripción, lo que se denomina efecto de ganancia de función ${ }^{(209,218)}$.

La ganancia de función se consigue estimulando factores de crecimiento o receptores de factores de crecimiento, como el receptor del factor de crecimiento epidérmico 136 y el factor de crecimiento vascular endotelial (VEGF).

Otros genes que pueden aumentar su expresión cuando p53 está mutado son c-myc, c-fos, II-6, isoformas de mdm2, MDR... entre otros ${ }^{(219) .}$ 
En ciertos estudios se observó su asociación con la apoptosis del epitelio cristaliniano comprobándose el aumento de su expresión en modelos experimentales con animales expuestos a UV-R ${ }^{(220) \text {. }}$

A nivel ocular, recientes estudios de Pastor y colaboradores, se han centrado en la posible asociación entre polimorfismos del codón 72 de p53 y el desarrollo de proliferación vítreo retiniana (PVR) en población con desprendimiento de retina; demostrando que existe un riesgo aumentado de desarrollar proliferación vítreo retiniana en los pacientes que presentaban el alelo pro-apoptótico de dicho polimorfismo ${ }^{(221)}$.

\section{Structural organization of TP53 gene and p53 protein}

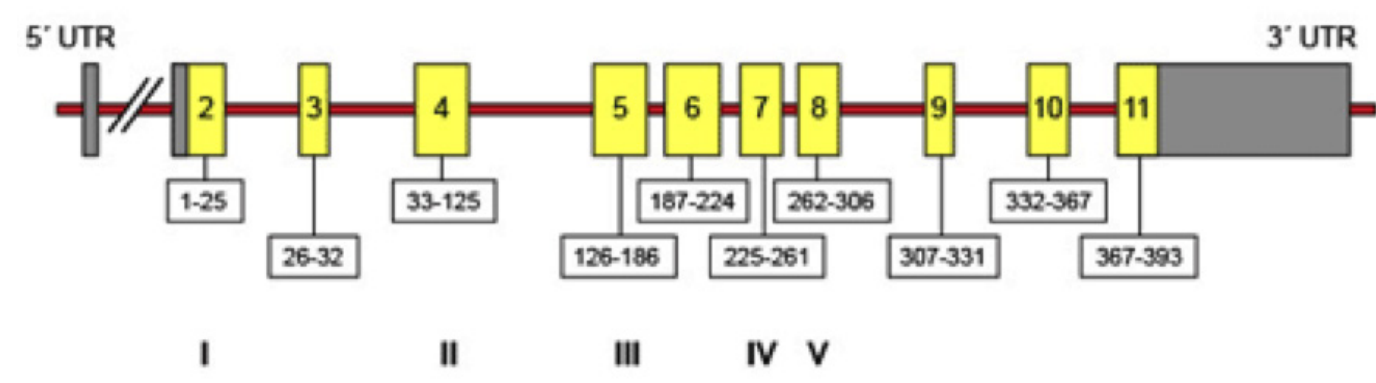

\begin{tabular}{|c|c|c|}
\hline N-terminal Domain & Central Domain & C-terminal Domain \\
\hline $\begin{array}{l}\text { Transcriptonal } \\
\text { Activation Domain }\end{array}$ & $\begin{array}{l}\text { Sequence-specific } \\
\text { DNA-binding Domain }\end{array}$ & $\begin{array}{l}\text { Negative } \\
\text { regulation Domain }\end{array}$ \\
\hline $\begin{array}{l}\text { Proline-rich } \\
\text { Domaln }\end{array}$ & & $\begin{array}{l}\text { Tetramerization } \\
\text { Domain }\end{array}$ \\
\hline
\end{tabular}

Coding region of TP53 gene (exons 2 to 11)

UTR region (untranslated region)

1-393 aminoacids residues (represented at each exon)

Figura 16: Estructura del gen y de la proteína p53. 


Hipótesis y objetivos 



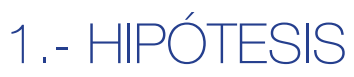

Múltiples estudios relacionan la aparición de cataratas con la radiación ultravioleta (R-UVA). Puesto que los genes reparadores del DNA son los encargados de reparar los posibles fallos inducidos en nuestro DNA por condicionantes externos, como las radiaciones ionizantes, resultará útil estudiar si ciertos polimorfismos en estos genes se encuentran asociados al desarrollo precoz de cataratas. De la misma manera, se puede considerar que el polimorfismo en el codón 72 de p53 implicado en procesos de envejecimiento y apoptosis, puede estar así mismo relacionado con el riesgo de desarrollar cataratas.

Por todo ello enunciamos para nuestro estudio la siguiente hipótesis:

"Diversas diferencias a nivel genómico podrían condicionar el desarrollo de cataratas y su aparición en edades más tempranas".

\section{2.- OBJETIVOS \\ 2.1.- GENERALES}

-Analizar si ciertos factores de riesgo ambientales pueden condicionar al desarrollo de cataratas preseniles.

- Analizar si existen diferencias a nivel genético entre personas con cataratas preseniles y sujetos sanos.

-Analizar si la presencia de cataratas preseniles está relacionada con factores genéticos asociados al envejecimiento prematuro.

- Analizar si existen diferencias a nivel genético entre personas con cataratas preseniles y pacientes con cataratas seniles. 


\section{2.- ESPECÍFICOS}

- Analizar las diferencias en la distribución de los factores de riesgo HTA, DM, consumo de tabaco o alcohol en los diferentes grupos de estudio.

- Analizar las diferencias en la distribución de genotipos del gen ERCC1, que regula la reparación del DNA, en personas con catarata presenil, sujetos con cataratas seniles y sujetos mayores de 55 años sin cataratas.

- Analizar las diferencias en la distribución de genotipos del gen ERCC2 en pacientes con cataratas preseniles, pacientes con cataratas seniles y sujetos mayores de 55 años sin cataratas.

- Analizar las diferencias en la distribución de genotipos del gen XPC en personas con cataratas preseniles, pacientes con cataratas seniles y sujetos mayores de 55 años sin cataratas.

- Analizar las diferencias en la distribución de genotipos del gen XRCC1 en personas cataratas preseniles, pacientes con cataratas seniles y sujetos mayores de 55 años sin cataratas.

- Analizar las diferencias en la distribución de genotipos del gen p53 en personas con cataratas preseniles, pacientes con cataratas seniles y sujetos mayores de 55 años sin cataratas. 


Pacientes y métodos 



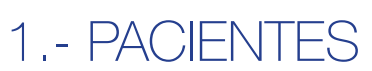

Para este estudio se han seleccionado, de manera secuencial, tres grupos de estudio, todos ellos diagnosticados y tratados en el Servicio de Oftalmología del Complejo Asistencial Universitario de Salamanca.

Como primer grupo de estudio se escogieron 72 pacientes que han desarrollado cualquier tipo de cataratas antes de los 55 años (cataratas preseniles) desde enero de 2007 hasta diciembre de 2012, excluyendo aquellas secundarias a factores de riesgo conocidos como la toma de corticoides o las secundarias a traumatismos o cirugía vítreo-retiniana y a los pacientes con enfermedades sistémicas que han demostrado su asociación con las cataratas como el síndrome de Steinert, la galactosemia, el síndrome de Lowe, la homocistinuria, el síndrome de Alport, el síndrome de Marfan, el síndrome de Weil Marchesani, la anomalía de Peters, enfermedades del tejido conectivo como el síndrome de Ehlers-Danlos, el síndrome de Down y el síndrome de Cockayne entre otras.

Así mismo se han seleccionado individuos que no han desarrollado cataratas en edades tempranas, consignándose dos grupos diferentes: 101 pacientes mayores de 55 años operados de cataratas excluyendo aquellos sujetos que presentaban alguno de los factores de riesgo de formación de cataratas antes mencionados y 42 pacientes mayores de 55 años que no han desarrollado cataratas y que han sido examinados por un oftalmólogo en el mismo centro.

Se extrajeron muestras de sangre periférica de todos los individuos a estudio, previa firma del consentimiento informado (anexo1) siguiendo las normas legales para Estudios Clínicos en España y las del Comité de Ética del Complejo Asistencial Universitario de Salamanca. Las muestras de sangre se recogieron en tubos con EDTA de $10 \mathrm{~mL}$ y se conservaron a $-4{ }^{\circ} \mathrm{C}$ hasta su procesamiento. 
A todos los pacientes se les realizó una exploración oftalmológica completa en la consulta, consistente en:

1.- Toma de datos:

-Datos demográficos: edad, sexo.

-Factores de riesgo de desarrollar cataratas: posibles enfermedades asociadas (hipertensión arterial, diabetes, toma de psicofármacos...), antecedentes de hábitos tóxicos (consumo de tabaco de por lo menos 10 cigarrillos al día durante al menos 5 años, ingesta de alcohol de por lo menos una unidad de alcohol (UMA) dos o más veces a la semana o ingesta drogas), tratamientos o intervenciones quirúrgicas.

\section{2.- Pruebas:}

Al acudir por primera vez a consulta se realizaron las siguientes pruebas:

-Medida de la refracción: Tomada por el auto-refractómetro modelo KR 8800 marca Topcon®. Con ella también obtenemos los valores de queratometría que utilizaremos para el cálculo de la potencia de la lente intraocular (LIO).

- Medida de la presión intraocular (PIO) neumática: Tomada con el CT 80 computerized tonometer marca Topcon® ${ }^{\circledR}$. Nos da un valor levemente hiperestimado de la presión intraocular. En aquellos pacientes cuyo valor salga por encima de $20 \mathrm{~mm}$ de $\mathrm{Hg}$ (valor establecido como límite superior de la normalidad), debemos realizar una segunda toma de la presión intraocular con un tonómetro de contacto tipo Perkins.

-Agudeza visual: Se realiza la prueba de agudeza visual con optotipos de la ETDRS, con los defectos refractivos corregidos y a una distancia de 4 metros. Tomando la agudeza visual de cada uno de los ojos por separado.

La agudeza visual (AV) por debajo de la cual se incluye al paciente en la lista de espera quirúrgica de catarata es de 0,5. 
-Biomicroscopía por lámpara de hendidura: Se realiza en dos fases:

a) Exploración de la amplitud de la cámara anterior del paciente, previa a la midriasis.

b) Exploración de la presencia y grado de madurez de las cataratas bajo midriasis. Por trasluminación y aplicando el sistema de clasificación de cataratas LOCS tipo III $(40,41)$ determinamos la presencia de cataratas y el grado de madurez y opacidad de las mismas. En este sistema se emplean una serie de fotografías para graduar la opacidad y opalescencia nuclear, otra serie de imágenes tomadas por retroiluminación en la lámpara de hendidura para graduar las cataratas corticales y una tercera serie de imágenes también tomadas por retroiluminación para graduar las cataratas subcapsulares posteriores.

Así, en función de estas imágenes, podemos clasificar las cataratas según la gradación que presente a nivel:

-Nuclear: Existen hasta 6 niveles de opacidad nuclear. Se escriben con las iniciales NO o NC y el número del 1 al 6 según su coloración, siendo uno las cataratas más incipientes y reservándose el 6 para las más brunescentes.

-Cortical: Se definen con la letra C y hasta 5 niveles de gradación.

-Opacidades posteriores: también existen 5 tipos que se denominan con la letra P seguida del número del 1 al 5 en función de la intensidad de la opacidad.

- Oftalmoscopia indirecta: Se hace un estudio del fondo de ojo de todos los pacientes para descartar patologías asociadas. Realizada a la lámpara de hendidura con lente de 90 dioptrías o con el oftalmoscopio indirecto binocular con casco frontal, como el popularizado por Schepens, utilizando una lente de 20 dioptrías.

-Biometría ultrasónica de contacto: En el caso de los pacientes que presentaban cataratas con criterios quirúrgicos, previa a la intervención, es necesaria realizar la medida de la lente intraocular (LIO) que sustituirá al cristalino tras la intervención por facoemulsificación. 
Como grupo control obtuvimos sangre de 143 pacientes con edades superiores a los 55 años. En este grupo incluimos a aquellos sujetos que habían desarrollado cataratas seniles ya que nuestra enfermedad a estudio es la catarata presenil y, por tanto, estos sujetos eran sanos de jóvenes. Así obtuvimos 101 con cataratas seniles y 42 sujetos mayores de 55 años que no habían desarrollado cataratas. Se les tomó una muestra de sangre periférica, previa firma del consentimiento informado, y fueron sometidos a las mismas pruebas de exploración que los pacientes con cataratas preseniles.

\section{2.- DISEÑO DEL ESTUDIO}

Realizamos un estudio analítico observacional retrospectivo de casos y controles con tres grupos de estudio.

En cada uno de los genes de estudio se analizó un polimorfismo por cambio de un solo nucleótido (SNP) (tabla 3). 
Tabla 3: Polimorfismos (SNP) de genes reparadores del ADN en nuestro estudio

\begin{tabular}{|c|c|c|c|c|c|c|}
\hline $\begin{array}{l}\text { Vía de } \\
\text { reparación }\end{array}$ & Gen & SNP & Bases & $\begin{array}{l}\text { Localización } \\
\text { del gen }\end{array}$ & $\begin{array}{l}\text { Localización en } \\
\text { el cromosoma }\end{array}$ & ID del ensayo \\
\hline NER & ERCC1 & $\begin{array}{l}\text { rs11615 } \\
\text { Asn118Asn }\end{array}$ & $\mathrm{T} / \mathrm{C}$ & Exón 4 & $19 q 13.32$ & C_2532959 \\
\hline NER & ERCC2 & $\begin{array}{l}\text { rs13181 } \\
\text { Lys751Gln }\end{array}$ & $\mathrm{A} / \mathrm{C}$ & Exón 23 & $19 q 13.32$ & C_3145033 \\
\hline NER & $\mathrm{XPC}$ & $\begin{array}{l}\text { rs2228000 } \\
\text { Ala499Val }\end{array}$ & $\mathrm{T} / \mathrm{C}$ & Exón 8 & $3 p 25$ & C_16018061_10 \\
\hline BER & XRCC1 & $\begin{array}{l}\text { rs25487 } \\
\text { Gln399Arg }\end{array}$ & $\mathrm{A} / \mathrm{G}$ & Exón 10 & 19q13.31 & C_622564 \\
\hline $\begin{array}{l}\text { Inductor de } \\
\text { apoptosis }\end{array}$ & P53 & $\begin{array}{l}\text { rs1042522 } \\
\text { Pro72Arg }\end{array}$ & $\mathrm{C} / \mathrm{G}$ & Exón 4 & $17 \mathrm{p} 13$ & PCR \\
\hline
\end{tabular}




\section{3. - MÉTODOS \\ 3.1.- AISLAMIENTO DEL ADN DE ALTO PESO MOLECULAR 222 3.1.1.- Obtención de muestras de sangre periférica}

Las muestras de sangre periférica se obtuvieron por venopunción antecubital, previa firma del consentimiento informado por parte del paciente (anexo1), y se conservaron a $4{ }^{\circ} \mathrm{C}$ hasta su procesamiento.

\subsection{2.- Obtención de células mononucleadas de sangre periférica}

Se obtuvieron $10 \mathrm{~mL}$ de sangre periférica por venopunción. Las células nucleadas de la sangre se aislaron mediante centrifugación repetida y lisis eritrocitaria con solución hipotónica (centrifugación de la sangre total en $50 \mathrm{~mL}$ de ddH2O durante 30 minutos, 1500 rpm, a $\left.4^{\circ} \mathrm{C}\right)$.

Tras la recuperación de la interfase, las células mononucleadas se lavaron en tampón Fornace y se precipitaron mediante centrifugación a $580 \mathrm{~g}$ durante 20 minutos. El botón de células nucleadas de la sangre se resuspendió de nuevo en tampón Fornace a una concentración estimada de 5×106 células/mL, tras lo cuál se añadió mezcla se incubó a $55{ }^{\circ} \mathrm{C}$ durante 8-16 horas. Tras la incubación, se procedió a purificar el ADN con fenol y cloroformo.

\subsection{3.- Aislamiento del ADN total de alto peso molecular}

A la muestra obtenida en el paso anterior se añade EDTA (ácido etilendiaminotetraacético, concentración final $10 \mathrm{mM}$ ), SDS (Dodecil sulfato sódico, concentración final 1\%) y Proteinasa K (Boehringer Mannheim, concentración final $50 \mu \mathrm{g} / \mathrm{mL}$ ). Esta mezcla se incuba $55^{\circ} \mathrm{C}$ durante 8-16 $\mathrm{h}$. 


\subsection{4.- Purificación del ADN}

Tras la incubación anterior se purifica el ADN mediante extracción con fenol-CIAA

(cloroformo/alcohol isoamílico 24:1 v/V), y se centrifuga durante 10 minutos a 1800rpm.

Se recupera la fase acuosa sobrenadante superior (contiene el ADN en solución) evitando la interfase proteica, y se añade el mismo volumen obtenido de fenol-CIAA.

Nuevamente se centrifuga a 1800 rpm durante 10 minutos.

Una vez recuperada de nuevo la fase acuosa, el ADN en solución se precipita mediante la adición de 2,5 volúmenes de etanol absoluto al $100 \%$ frío $\left(-20^{\circ} \mathrm{C}\right)$. EI ADN extraído se lava con etanol al $70 \%$ y, tras una breve centrifugación a $16600 \mathrm{~g}$, se deja evaporar el etanol residual y se disuelve el ADN en tampón TE (Tris- $\mathrm{HCl} 10 \mathrm{mM}$ pH 7,5; EDTA 1mM) o en agua destilada.

\subsection{5.- Cuantificación del ADN}

La concentración y el grado de contaminación proteica del ADN así obtenido, se calculan tras medir su absorbancia a 260 y $280 \mathrm{~nm}$, respectivamente, en un espectrofotómetro (GeneQuant, Pharmacia) por medio de la siguiente fórmula:

$\mu \mathrm{g}$ de $\mathrm{ADN} / \mathrm{mL}=(\mathrm{D} .0 .260) \times$ (factor de dilución) $\times(50)$

DO: densidad óptica

50 es un factor de corrección introducido ya que una unidad de densidad óptica con una luz incidente de $260 \mathrm{~nm}$ es el valor de absorbancia que tienen $50 \mu g$ de ADN/mL. 
El cociente D.0.260/D. 0.280 se utiliza para determinar el grado de contaminación proteica, considerando como valores adecuados un cociente entre 1.65 y 2.0. Valores inferiores a los señalados indican contaminación por proteínas o por solventes orgánicos, realizándose en estos casos una nueva purificación del ADN. Valores superiores parecen indicar un exceso de ARN, el cuál se eliminó tratando la solución de ADN con RNAsa y purificando nuevamente según el método antes descrito.

La muestra de ADN con una concentración aproximada entre 1,000 y $1,500 \mu \mathrm{g} / \mathrm{mL}$, se almacena en tubos Eppendorf $\circledast$ a $-20^{\circ} \mathrm{C}$, con el fin de evitar tanto la degradación progresiva del ADN como su posible contaminación por microorganismos.

\section{2.- AMPLIFICACIÓN DE FRAGMENTOS DE ADN MEDIANTE RE- ACCIÓN EN CADENA DE LA POLIMERASA (PCR)}

Las reacciones de amplificación se realizaron con los productos comerciales PCR:

Supermix (Gibco-BRL) y Master Mix (Promega) y se emplearon entre $1 \mu \mathrm{L}$ y $4 \mu \mathrm{L}$ de la mezcla de los dos oligonucleótidos flanqueantes y $1 \mu \mathrm{L}$ del ADN obtenido por el método anteriormente descrito (concentración = 0,1-0,2 $\mu \mathrm{g} / \mathrm{mL}$ ) 261 .

Para asegurar que no existía contaminación y que las reacciones eran específicas, para cada muestra de partida se preparó como control una reacción conteniendo todos los reactivos antes citados excepto ADN molde. Todas las reacciones de amplificación se llevaron a cabo en un termociclador automático y la manipulación post-PCR se realizó en un laboratorio distinto de donde se llevó a cabo la extracción del ADN y se preparó la reacción de amplificación. 


\section{3.- DISCRIMINACIÓN ALÉLICA DE POLIMORFISMOS}

Se emplearon dos métodos para la discriminación alélica de los polimorfismos a estudio.

\subsection{1.- Discriminación alélica mediante PCR con sondas taqman}

En la PCR con sondas Taqman los procesos de amplificación y detección se producen de manera simultánea en el mismo vial cerrado, sin necesidad de ninguna acción posterior.

Además, mediante detección por fluorescencia se puede medir durante la amplificación la cantidad de ADN sintetizado en cada momento, ya que la emisión de fluorescencia producida en la reacción es proporcional a la cantidad de ADN formado. Esto permite conocer y registrar en todo momento la cinética de la reacción de amplificación. Los termocicladores para llevar a cabo la PCR con sondas Taqman incorporan un lector de fluorescencia y están diseñados para poder medir, en cualquier momento, la fluorescencia emitida en cada uno de los viales donde se realice la amplificación. Los sistemas de detección por fluorescencia empleados en la PCR con sondas Taqman pueden ser de dos tipos: agentes intercalantes y sondas específicas marcadas con fluorocromos.

Para la discriminación alélica empleamos sondas específicas marcadas con fluorocromos: Un donador en el extremo 5', que emite fluorescencia al ser excitado y un aceptor en el extremo 3', que absorbe la fluorescencia liberada por el donador. Para que esto ocurra, las moléculas donadora y aceptora deben estar espacialmente próximas. Además, el espectro de emisión de la primera se ha de solapar con el espectro de absorción de la segunda.

En todos nuestros ensayos de discriminación alélica mediante PCR con sondas Taqman los fluorocromos empleados fueron VIC y FAM. 
Mientras la sonda está intacta, la fluorescencia emitida por el donador es absorbida por el aceptor. Sin embargo, durante la amplificación del ADN diana, la sonda se hibrida con su cadena complementaria. Al desplazarse a lo largo de la cadena, en su acción de síntesis, la ADN polimerasa de Thermus aquaticus, que tiene actividad 5' exonucleasa, hidroliza el extremo libre 5' de la sonda, produciéndose la liberación del fluorocromo donador. Como donador y aceptor están, espacialmente alejados, la fluorescencia emitida por el primero es captada por el lector (Figura 17).

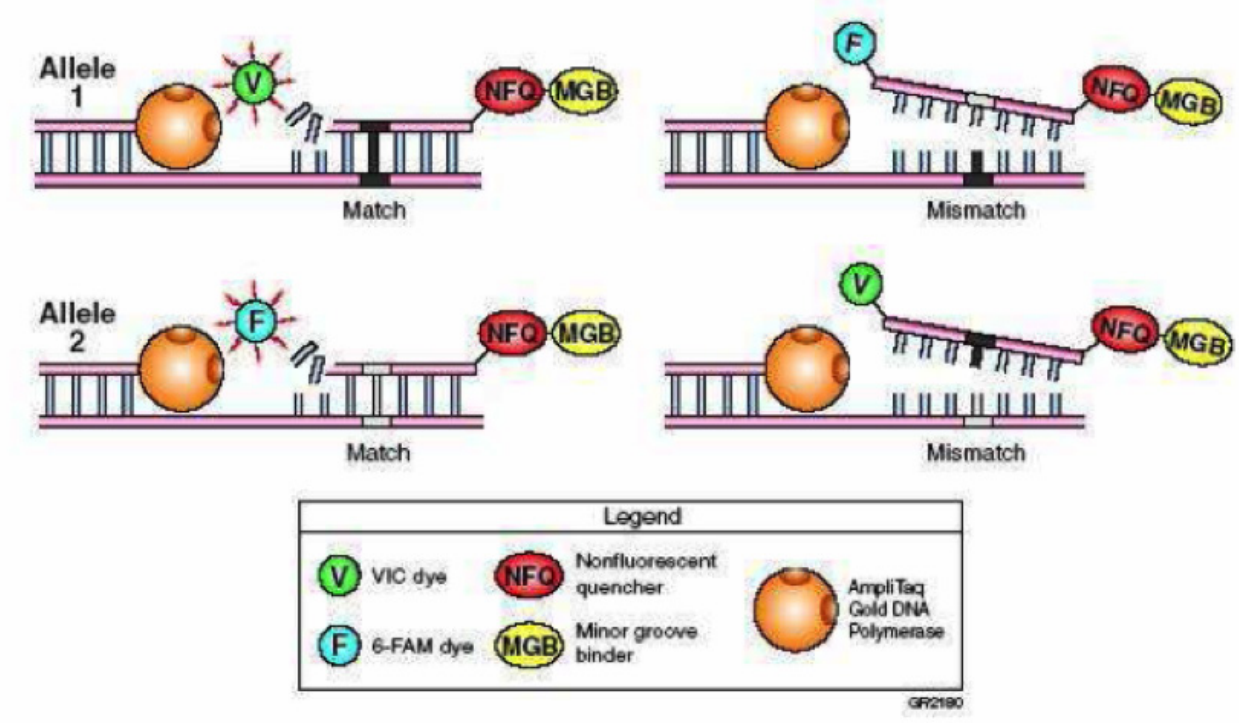

Figura 17: Mecanismo de la PCR con sondas Taqman.

El incremento de ADN en cada ciclo se corresponde con un aumento de hibridación de las sondas, lo que conlleva un aumento en la misma proporción de fluorescencia emitida. El empleo de estas sondas garantiza la especificidad de la detección y permite identificar polimorfismos o mutaciones puntuales. 
Realizamos nuestro estudio en un termociclador de Applied Biosystems ${ }^{\circledR}$ que dispone de varios canales de lectura y permite detectar la emisión de distintos fluorocromos a la vez. De esa manera, se pueden usar varias sondas marcadas con distintos fluorocromos, para identificar los diferentes alelos descritos en cada uno de los genes estudiados. (Figura 18)

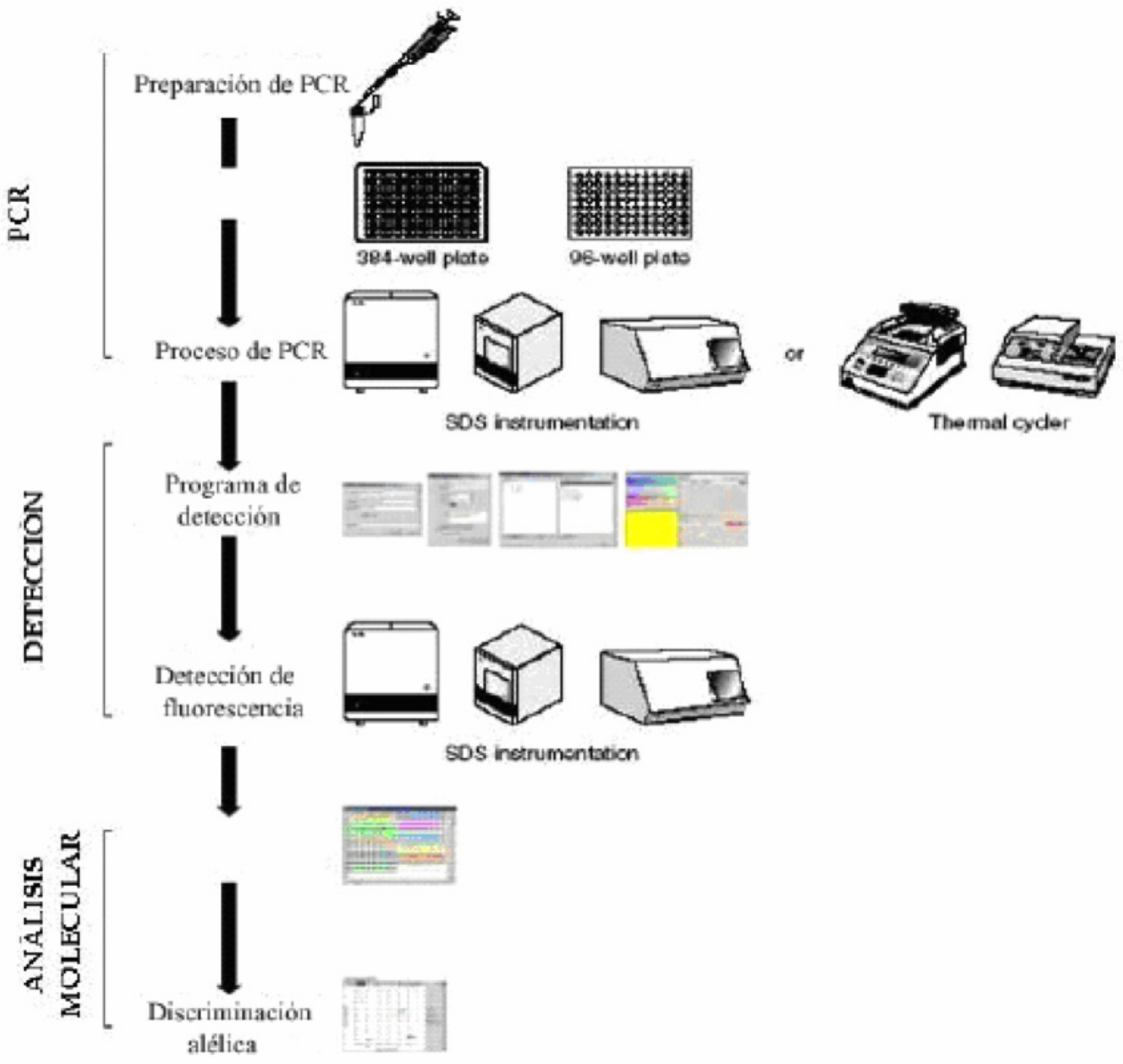

Figura 18: Discriminación alélica mediante PCR con sondas Taqman 
La reacción de amplificación se lleva a cabo en el termociclador automático (Biosystem Step one $\left.{ }^{\circledR}\right)$, siguiendo el mismo esquema para los distintos SNP's:

a) Realización del sustrato:

Se realiza una placa de 96 celdas, en la que ponemos como sustrato en cada una de ellas: $-5 \mathrm{ml}$ del compuesto comercial PCR Taqman ${ }^{\circledR}$, que proporciona la enzima necesaria para la amplificación (polimerasa Taq)

$-0,25 \mathrm{ml}$ del compuesto comercial que contiene oligonucleótido cebador primer forward, oligonucleótido cebador primer "reverse" y las sondas marcadas con fluorocromo de VIC y FAM.

$-4,25 \mathrm{ml}$ de agua destilada.

$-0,5 \mathrm{ml}=5 \mathrm{ng}$ de ADN (concentración = 10-20 $\mu \mathrm{g} / \mathrm{ml}$ ).

Como control se rellenan ocho celdillas de cada placa con el mismo sustrato, pero sin ADN.

b) Fases del programa:

Se coloca la placa realizada en el step one $\AA$ de applied biosystems ${ }^{\circledR}$ en el que nuestras muestras pasan por las siguientes fases (tabla 4): 
Tabla 4: fases realizadas por el step one applied biosystems ${ }^{\circledR}$.

\begin{tabular}{cccc}
\hline No de Ciclos & Temperatura & Tiempo & Proceso \\
\hline 1 & $50^{\circ} \mathrm{C}$ & 3 minutos & Desnaturalización \\
& $92^{\circ} \mathrm{C}$ & 30 segundos & Desnaturalización \\
& $60^{\circ} \mathrm{C}$ & 30 segundos & Anillamiento \\
& $72^{\circ} \mathrm{C}$ & 1 minutos & Extensión \\
& $72^{\circ} \mathrm{C}$ & 10 minutos & Extensión \\
\hline
\end{tabular}

c) Análisis:

Se realiza un análisis de la detección de fluoresceína que nos da una representación gráfica en la que se muestran los resultados de la discriminación alélica realizada y su distribución en nuestros tres grupos de estudio. 


\subsubsection{1.- Análisis de polimorfismos en el gen ERCC1}

La nomenclatura de las mutaciones y polimorfismos se han descrito siguiendo la nomenclatura recomendada por el grupo de trabajo de nomenclatura genética humana.

Se estudió un SNP (rs 11615) del gen que produce un cambio de una alanina (A) por una guanina $(G)$.

Para la realización de PCR a tiempo real empleamos como cebadores los siguientes oligonucleótidos:

5’ GGGAATTACGTCGCCAAATTCCCAGGGCAC 3’

5' TTGCGCACGAACTTCAGTACGGGATTGCCC 3'

Las sondas marcadas con fluorocromos utilizadas fueron:

VIC: GGCACATTGCG

FAM: GGCACGTTGCG

Después de realizar la discriminación alélica obtenemos la representación gráfica (figura 19) de los resultados en los tres grupos de estudio. 


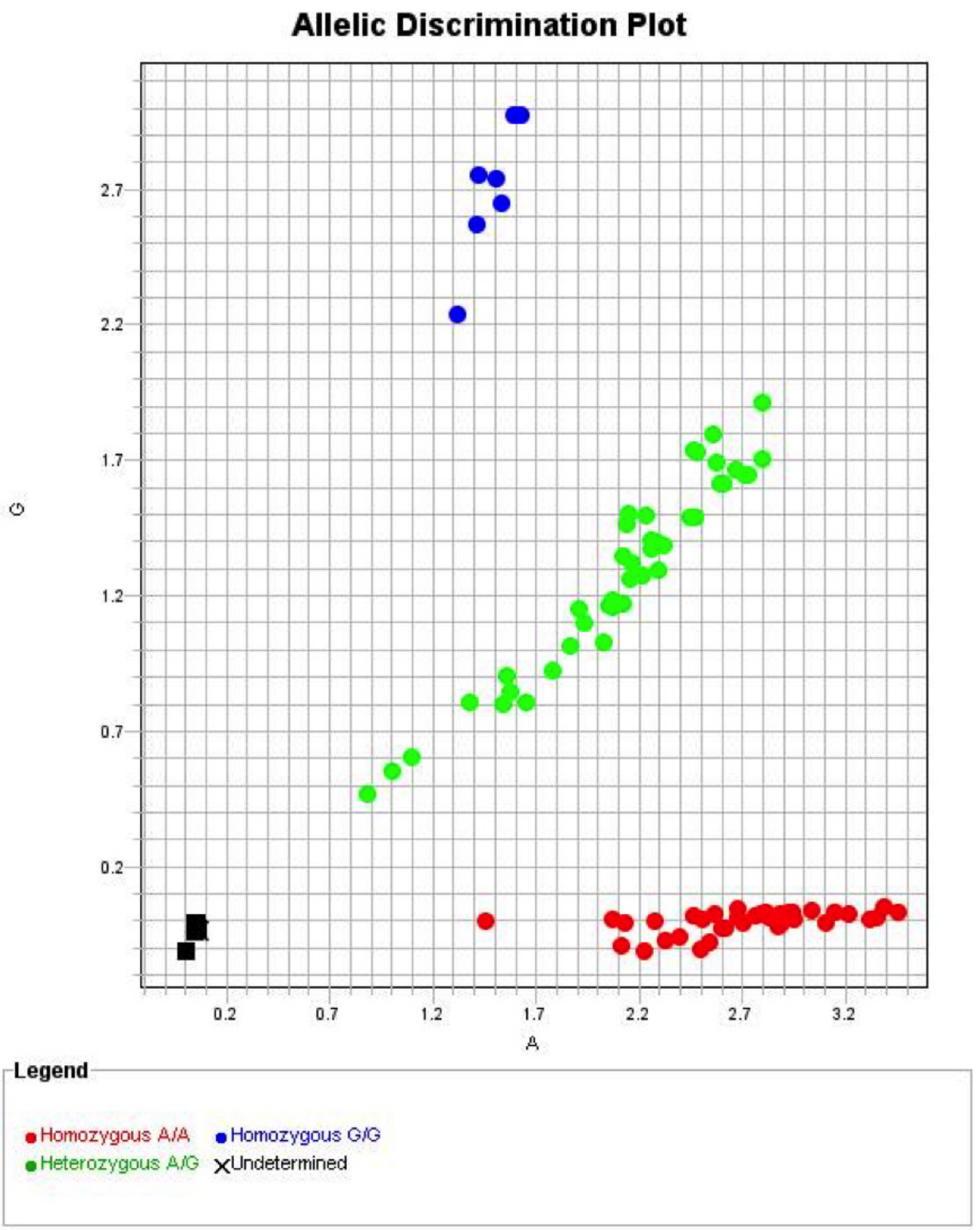

Figura 19: Representación gráfica según la distribución alélica del polimorfismo rs 11615 en el grupo de pacientes con cataratas preseniles. 


\subsubsection{2.- Análisis de polimorfismos en el gen ERCC2}

El gen XPD, también denominado ERCC2, es un gen localizado también en el brazo largo del cromosoma 19 (19q13.32). Se estudió un SNP (rs 13181) del gen que produce un cambio de una guanina $(G)$ por una timina $(T)$.

Para la realización de la PCR a tiempo real empleamos como cebadores los siguientes oligonucleótidos:

\section{5' AGAGCTGCTGAGCAATCTGCTCTATCCTCT 3'}

\section{5' CAGCGTCTCCTCTGATTCTAGCTGCTCCAG 3'}

Las sondas marcadas con fluorocromos utilizadas fueron:

VIC: CTCTGCAGC

\section{FAM: CTCTTCACG}

La reacción de amplificación se llevó a cabo en el termociclador automático (Biosystem Step one ${ }^{\circledR}$ ), obteniendo la representación gráfica (Figura 20 ) de los resultados en los tres grupos de estudio. 


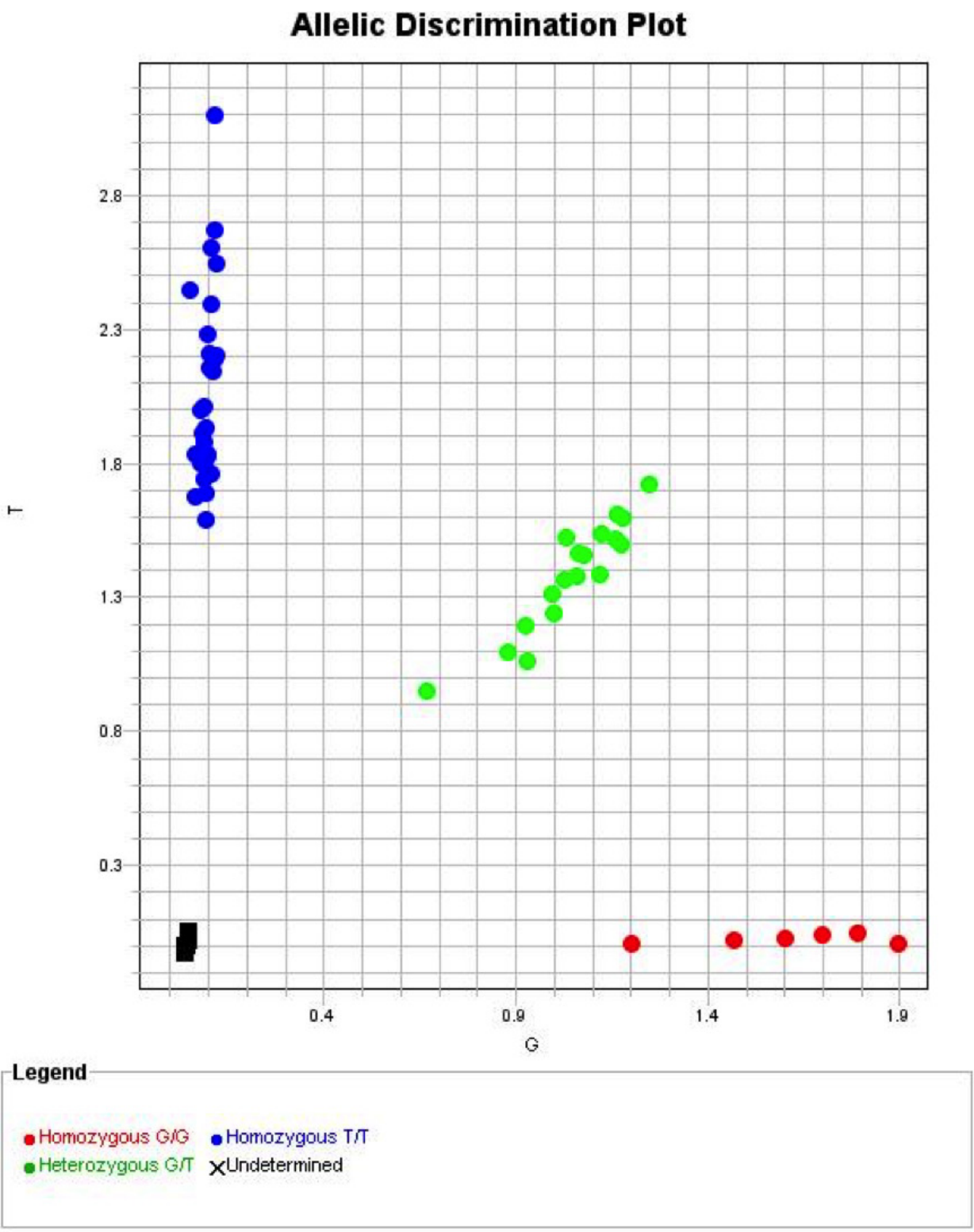

Figura 20: Representación gráfica de la distribución alélica del polimorfismo rs 13181 de ERCC2 en el grupo de mayores de 55 años con cataratas. 


\subsubsection{3.- Análisis de polimorfismos en el gen XPC:}

El Gen XPC está localizado en el brazo corto del cromosoma 3 (3p25). Estudiamos un SNP (rs 2228000) del gen en el que se produce un cambio de una adenina (A) por una guanina $(G)$.

Para la realización de PCR a tiempo real empleamos como cebadores los siguientes oligonucleótidos:

5' CTTTTACTGCTTGAAGAGCTTGAGGATGCC 3'

5' CTGGCAAGCTTGGGTCCTTACGATGGCTCC 3'

Las sondas marcadas con fluorocromos utilizadas fueron:

VIC: TGCCACTGG

FAM: TGCCGCTGG

La reacción de amplificación se llevó a cabo en el termociclador automático (Biosystem Step one $\left.{ }^{\circledR}\right)$, obteniendo la configuración alélica de los tres grupos de estudio para el polimorfismo (Figura 21). 


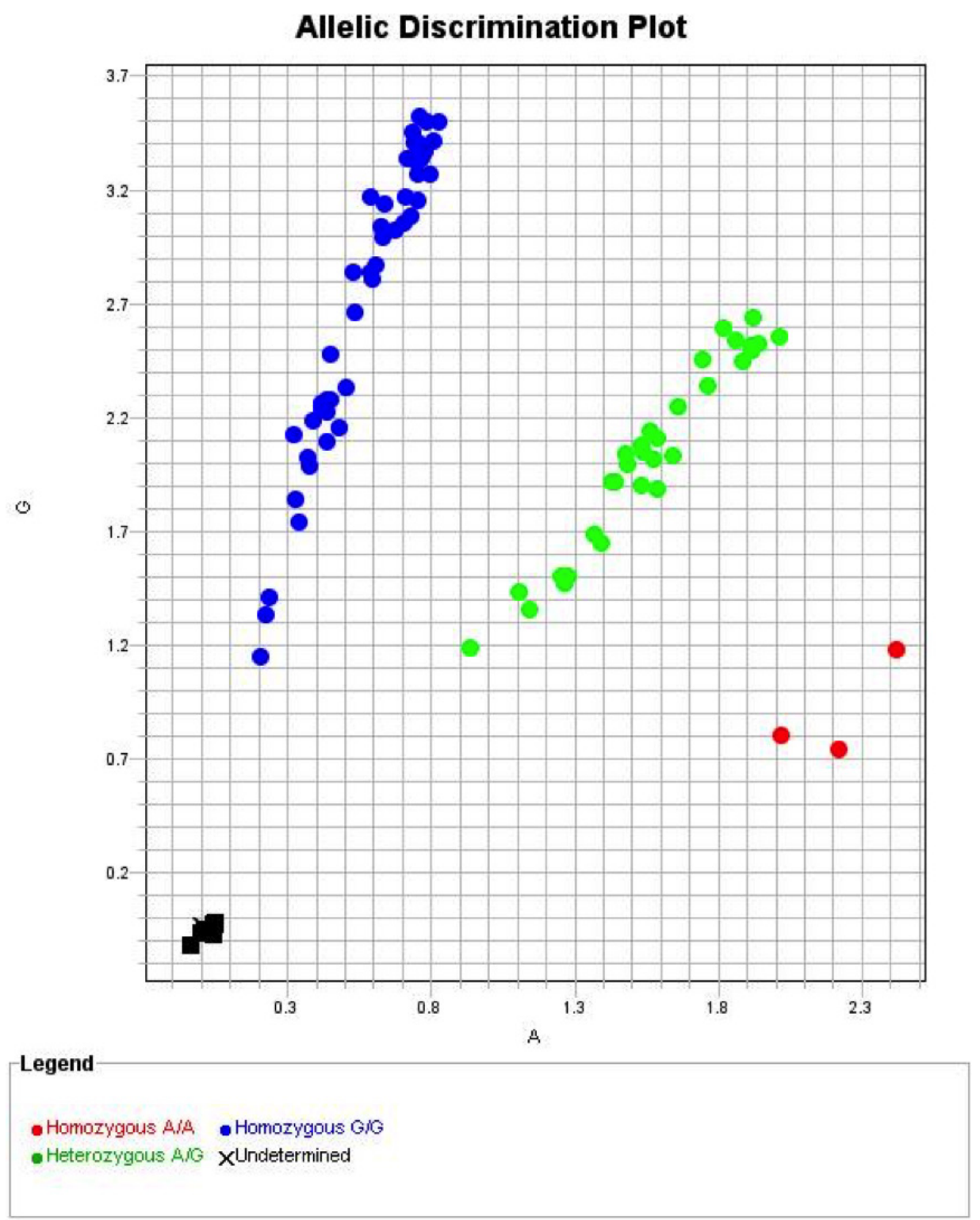

Figura 21: Representación gráfica de la distribución alélica del polimorfismo rs 2228000 del gen XPC en el grupo de mayores de 55 años con cataratas. 


\subsubsection{4.- Análisis de polimorfismos del gen XRCC1}

El gen XRCC1 (X-ray repair cross complementation group 1), tiene un tamaño de 33kb y se localiza en el brazo largo del cromosoma 19 (19q13.2-13.3).

Hemos estudiado un SNP (rs 25487) en el que se produce un cambio de una guanina (G) por una adenosina $(A)$.

Para la realización de PCR a tiempo real empleamos como cebadores los siguientes oligonucleótidos:

\section{5' GAGGCAGGGAGTGGGTTGAGGAAGGAGAGG 3'}

\section{5’ GAGGCAAGACACGGGGGCAGCAGTGACCCC 3'}

Las sondas marcadas con fluorocromos utilizadas fueron:

VIC: GAGGGGAGG

FAM: GAGGAGAGG

La reacción de amplificación se llevó a cabo de acuerdo al esquema ya explicado (ver 3.3.1) obteniendo la configuración alélica de los tres grupos de estudio para ambos polimorfismos mediante una representación gráfica (Figura 22). 


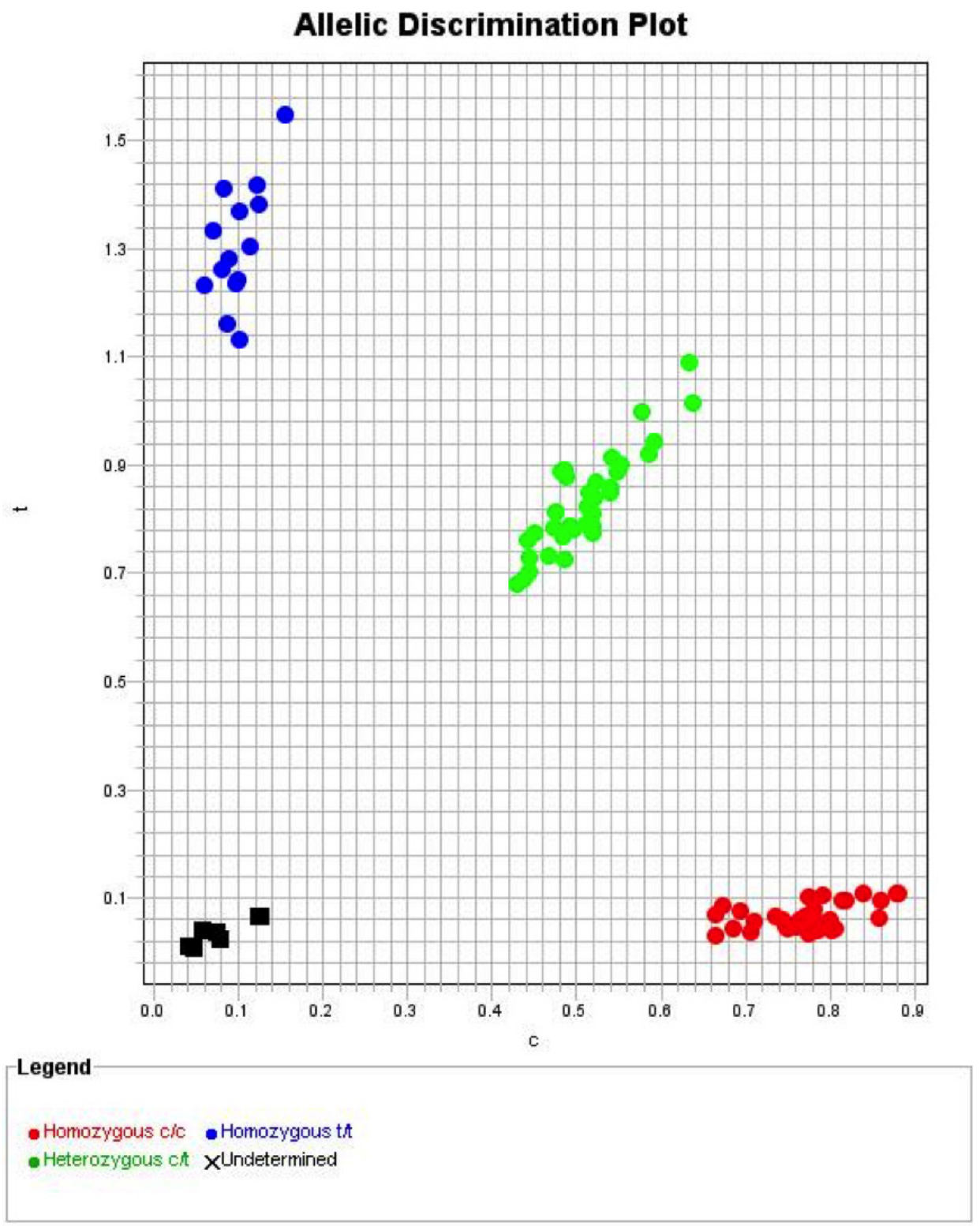

Figura 22: representación gráfica de la distribución alélica del polimorfismo rs 25478 del gen XRCC1 para el grupo de mayores de 55 años con cataratas. 


\subsection{2. - DISCRIMINACIÓN ALÉLICA MEDIANTE DIGESTIÓN CON NUCLEASAS DE RESTRICCIÓN}

Las endonucleasas de restricción reconocen secuencias específicas de ADN y lo escinden en ese punto. El estudio de los polimorfismos de la longitud de los fragmentos de restricción (restriction fragment lenght polymorphism- RFLP) es una técnica que permite discriminar distintos alelos de un gen, analizando el tamaño de los fragmentos generados tras la digestión del ADN con enzimas de restricción.

Las digestiones se llevan a cabo incubando $12 \mu \mathrm{L}$ del producto de PCR con $1 \mu \mathrm{L}$ de la endonucleasa de restricción seleccionada, BstUI (Bsh12361, Fermentas) en nuestro caso, y $7 \mu \mathrm{L}$ de agua , utilizando como tampón de digestión el específico para cada endonucleasa o un tampón universal. Se coloca a la temperatura específica durante un tiempo que varía entre 5 y 7 horas.

Los fragmentos obtenidos tras la digestión fueron separados mediante electroforesis en geles de agarosa al $1 \%$ o $3 \%$ teñidos con syber-safe ${ }^{\circledR}$. En todos los geles incluímos el marcador de tamaño.

Para monitorizar la migración del ADN en el gel se incluyen dos colorantes en el tampón de carga: xileno-cianol y azul de bromofenol. Posteriormente realizamos una fotografía digital bajo iluminación ultravioleta, usando el programa Kodak Science ID (Kodak,SA). (Figura 23) 


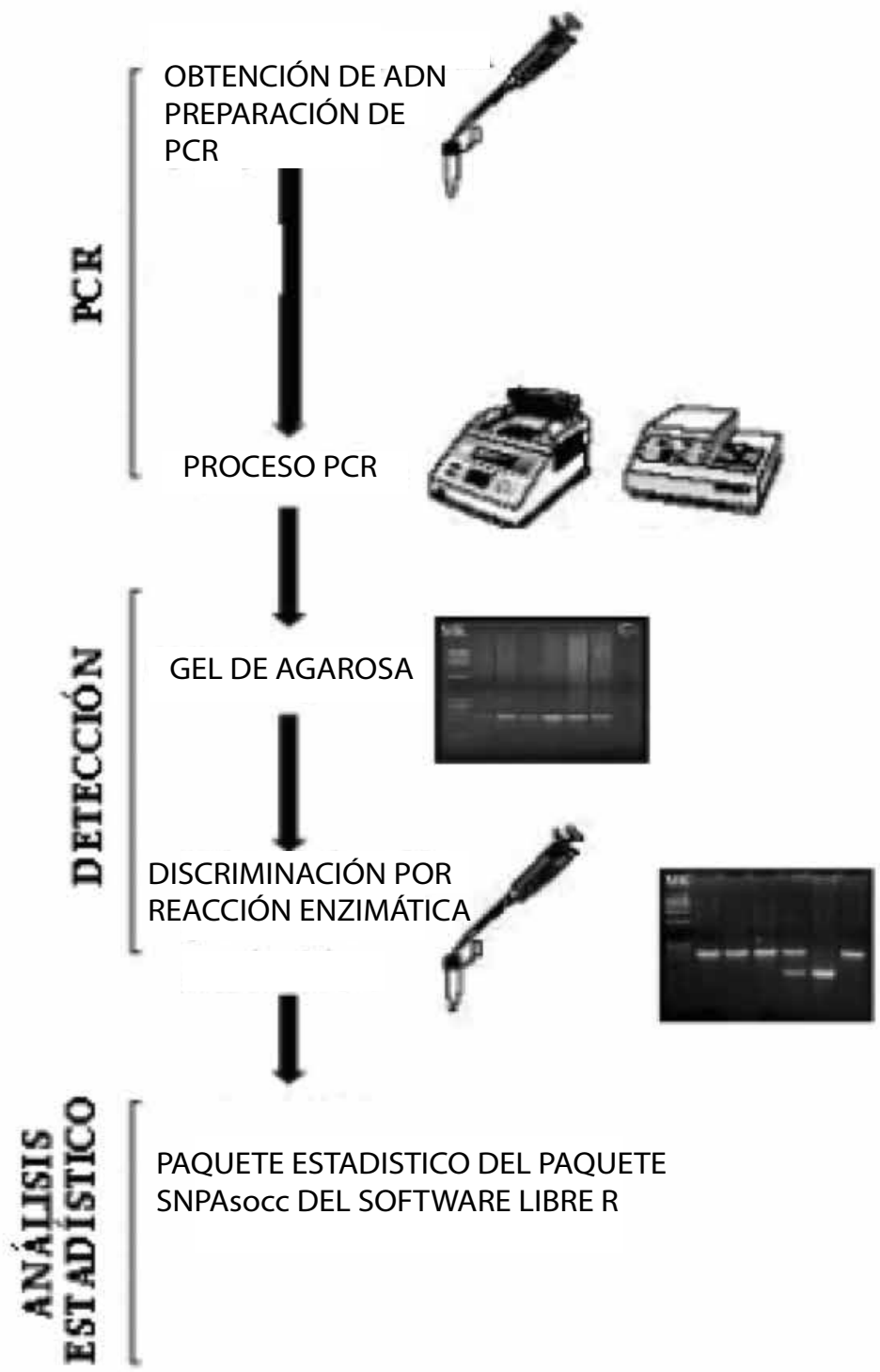

Figura 23: Discriminación alélica mediante digestión con enzimas de restricción. 


\subsubsection{1.- Análisis del polimorfismo en el gen p53}

El gen p53 o tp53 se encuentra en el brazo corto del cromosoma 17 (17p13) y codifica un factor de transcripción nuclear.

En el exón 4 del gen p53, existe un polimorfismo por cambio de un solo nucleótido, single nucleotide polymorphism (SNP), ampliamente estudiado (rs1042522), consistente en el cambio de una citosina $(C)$ por una guanina $(G)$. Esto a su vez produce un cambio de Prolina (Pro) por Argina (Arg) en el codón 72 de la proteína.

La secuencia reconocida por la endonucleasa BstUI (Tabla 5) actúa sobre el fragmento de 291 (pb) pares de bases amplificado previamente por la PCR (Figura 24).

Tabla 5: Secuencia reconocida por la enzima BstUl:

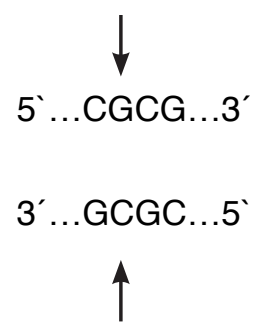

Los genotipos generados por este polimorfismo son:

- Genotipo C/C (homocigoto Prolina): un fragmento de 291 pares de bases (pb)

- Genotipo G/G (homocigoto Arginina): dos fragmentos de 165 y 126 pb

- Genotipo C/G (heterocigoto Arginina/Prolina): tres fragmentos de 291 pb, 165 pb y 126 pb 


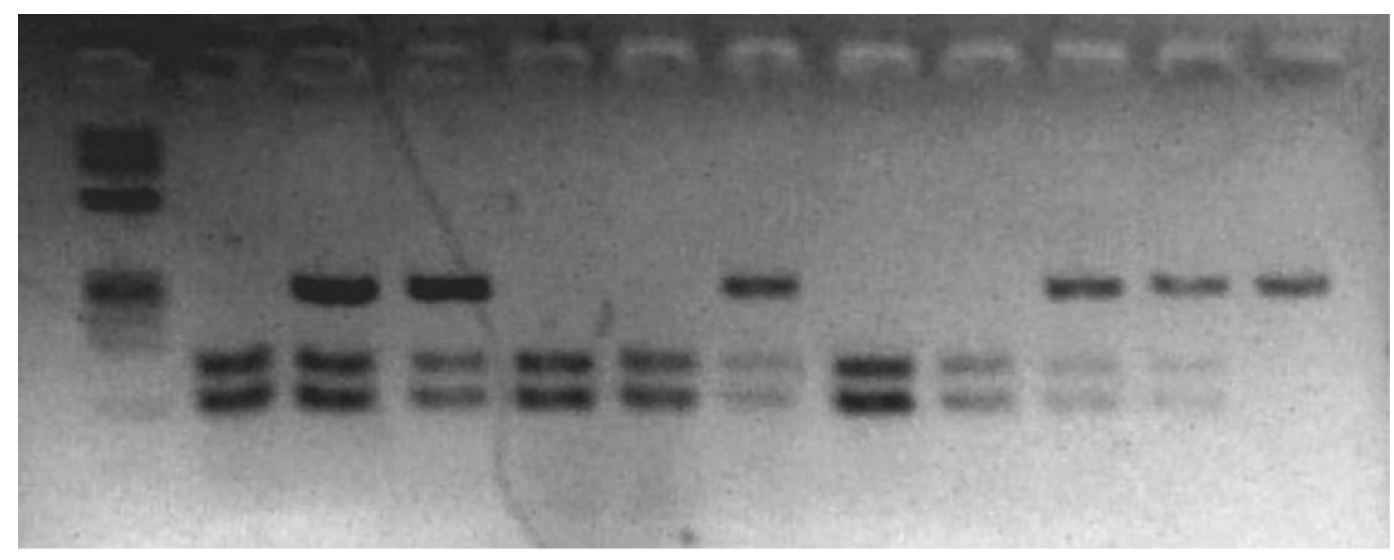

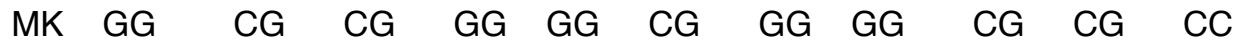

Figura 24: Genotipos del polimorfismo (MK =marcador)

\section{4.- ANÁLISIS ESTADISTICO}

Para el análisis descriptivo de los datos, se calcularon la distribución de frecuencias de los porcentajes de cada categoría para cada variable cualitativa y para la variable edad se calcularon indicadores de tendencia central (media o mediana) y de dispersión (desviación estándar o percentiles).

La asociación entre los factores y los grupos de comparación (Casos - Control) establecidos se investigó mediante pruebas de contraste de hipótesis, con comparación de proporciones. 
Para el Análisis de Asociación Genética: Antes de realizar el análisis de asociación se comprobó si los Polimorfismos cumplían el principio de equilibrio de Hardy-Weinberg en la muestra de controles (como representantes de la población general). Se cuantificó la magnitud de la asociación de un polimorfismo con la enfermedad mediante el cálculo de odds ratios de cada genotipo respecto del grupo de referencia (grupo control), ajustándose modelos de regresión logística por los factores de riesgo con significación estadística en el análisis bidimensional, y según los modelos de herencia dominante, recesivo, aditivo y codominante.

Este análisis se realizó con el paquete SNPAsocc ${ }^{(223)}$ del Sofware libre $\mathrm{R}$ (The R Proyect. Disponible en: http://www.r-proyect.org) por una persona independiente al estudio.

\section{5.- ASPECTOS ÉTICOS Y LEGALES}

El estudio fue presentado y aceptado por el comité ético del Hospital Universitario de Salamanca. Todas las muestras se obtuvieron, previo consentimiento informado (anexo1), siguiendo las normas legales para Estudios Clínicos en España y las del comité ético del Hospital Universitario de Salamanca. 


Resultados 



\section{RESULTADOS}

Para este estudio se han establecido tres grupos de sujetos: los menores de 55 años diagnosticados e intervenidos de cataratas preseniles; aquellos que de jóvenes no presentaron catarata, pero la desarrollaron después de los 55 años y los sujetos mayores de 55 años que aún no presentaban cataratas.

La edad media del grupo de sujetos menores de 55 años con cataratas resultó 49,01 años; en el grupo de mayores de 55 años con cataratas 73,79 años y en el grupo de mayores de 55 años que no habían desarrollado cataratas 67,10 años. Se observó que mientras que en el grupo de menores de 55 años con cataratas predominaba el género masculino, en el grupo de sujetos mayores de 55 años sin cataratas predominaba el género femenino, no hallándose diferencias entre sexos en el grupo de mayores de 55 años con catarata (tabla 6).

Tabla 6: Edad y sexo de los tres grupo de estudio.

\begin{tabular}{cccc}
\hline & GRUPO 1 & GRUPO 2 & GRUP0 3 \\
& $<$ 55 años con & $>$ 55 años con & $>$ 55 años sin \\
& cataratas & cataratas & cataratas \\
\hline EDAD & $49,01+/-7,268$ & $73,79+/-6,532$ & $67,10+/-4,642$ \\
& & & $11(26,2 \%)$ \\
\hline HOMBRES & $47(65,28 \%)$ & $54(53,5 \%)$ & $31(73,8 \%)$ \\
& & & \\
\hline
\end{tabular}


En la tabla 7 se muestra la distribución de los factores de riesgo del grupo de menores de 55 años con cataratas preseniles.

Tabla 7: Presencia de factores de riesgo en el grupo de individuos menores de 55 años con cataratas (HTA: hipertensión arterial; DM: diabetes mellitus).

FACTORES DE RIESGO

\begin{tabular}{ccccc}
\hline & HTA & DM & TABACO & ALCOHOL \\
\hline SI & $12(16,67 \%)$ & $12(16,67 \%)$ & $35(48,61 \%)$ & $32(44,4 \%)$ \\
& & & & \\
NO & $60(83,33 \%)$ & $60(83,33 \%)$ & $37(51,39 \%)$ & $40(55,6 \%)$
\end{tabular}

Las características de los grupos de sujetos mayores de 55 años, se muestran en las tablas 8 y 9 .

Tabla 8: Presencia de factores de riesgo en el grupo de mayores de 55 años con cataratas (HTA: hipertensión arterial; DM: diabetes mellitus).

FACTORES DE RIESGO

\begin{tabular}{ccccc}
\hline & HTA & DM & TABACO & ALCOHOL \\
\hline SI & $60(59,4 \%)$ & $16(15,8 \%)$ & $18(17,8 \%)$ & $10(9,9 \%)$ \\
NO & $41(40,6 \%)$ & $85(84,2 \%)$ & $83(82,2 \%)$ & $91(90,1 \%)$ \\
\hline
\end{tabular}


Tabla 9: Presencia de factores de riesgo en el grupo de mayores de 55 años sin cataratas (HTA: hipertensión arterial; DM: diabetes mellitus).

FACTORES DE RIESGO

\begin{tabular}{ccccc}
\hline & HTA & DM & TABACO & ALCOHOL \\
\hline SI & $21(50 \%)$ & $11(26,2 \%)$ & $3(7,1 \%)$ & $0(0 \%)$ \\
NO & $21(50 \%)$ & $31(73,8 \%)$ & $39(92,9 \%)$ & $42(100 \%)$
\end{tabular}

Al comparar el grupo de sujetos menores de 55 años con catarata y el grupo de mayores de 55 años con catarata, no encontramos diferencias en cuanto a la distribución del factor de riesgo DM entre ambos grupos; sin embargo sí se observó una mayor frecuencia de HTA en el grupo de mayores de 55 años con cataratas y una mayor frecuencia estadísticamente significativa en el consumo de tabaco y alcohol en el grupo de jóvenes con cataratas (tabla 10).

Tabla 10: Distribución de los factores de riesgo en el grupo de menores de 55 años con cataratas comparado con el grupo de mayores de 55 años con cataratas.

\begin{tabular}{|c|c|c|c|c|c|c|c|c|c|}
\hline & & HTA & $p$ & DM & $p$ & TABACO & $p$ & ALCOHOL & $p$ \\
\hline \multirow{2}{*}{$\begin{array}{l}<55 \text { años } \\
\text { con } \\
\text { cataratas }\end{array}$} & $\mathrm{SI}$ & $\begin{array}{c}12 \\
(16,66 \%)\end{array}$ & $<0,001$ & $\begin{array}{c}12 \\
(16,66 \%)\end{array}$ & $>0,005$ & $\begin{array}{c}35 \\
(48,61 \%)\end{array}$ & $<0,001$ & $\begin{array}{c}32 \\
(44,44 \%)\end{array}$ & $<0,001$ \\
\hline & NO & $\begin{array}{l}60 \\
(83,33 \%)\end{array}$ & & $\begin{array}{c}60 \\
(83,33 \%)\end{array}$ & & $\begin{array}{c}37 \\
(51,39 \%)\end{array}$ & & $\begin{array}{c}40 \\
(55,55 \%)\end{array}$ & \\
\hline \multirow{2}{*}{$\begin{array}{l}>55 \text { años } \\
\text { con } \\
\text { cataratas }\end{array}$} & $\mathrm{SI}$ & $\begin{array}{c}60 \\
(59,4 \%)\end{array}$ & & $\begin{array}{c}16 \\
(15,8 \%)\end{array}$ & & $\begin{array}{c}18 \\
(17,8 \%)\end{array}$ & & $\begin{array}{c}10 \\
(9,9 \%)\end{array}$ & \\
\hline & NO & $\begin{array}{c}41 \\
(40,6 \%)\end{array}$ & & $\begin{array}{c}85 \\
(84,2 \%)\end{array}$ & & $\begin{array}{c}83 \\
(82,2 \%)\end{array}$ & & $\begin{array}{c}91 \\
(90,1 \%)\end{array}$ & \\
\hline
\end{tabular}


Al analizar el grupo de menores de 55 años con catarata y el grupo de mayores de 55 años sin catarata, no encontramos diferencias en cuanto a la distribución de los factores de riesgo DM e HTA entre ambos grupos; sin embargo sí se observó una mayor frecuencia estadísticamente significativa en el consumo de tabaco y alcohol en el grupo de pacientes jóvenes con cataratas (tabla 11).

Tabla 11: Distribución de los factores de riesgo en el grupo de menores de 55 años con cataratas comparado con el grupo de mayores de 55 años sin cataratas.

\begin{tabular}{|c|c|c|c|c|c|c|c|c|c|}
\hline & \multirow{2}{*}{\multicolumn{2}{|c|}{$\begin{array}{|cc|}\text { HTA } & \mathbf{p} \\
12 & >0,005 \\
\end{array}$}} & \multirow{2}{*}{\multicolumn{2}{|c|}{$\begin{array}{|cc|}\text { DM } & \mathbf{p} \\
12 & >0,005 \\
\end{array}$}} & \multirow{3}{*}{\multicolumn{2}{|c|}{$\begin{array}{|cc|}\text { TABACO } & p \\
35 & \leq 0,001 \\
\end{array}$}} & \multirow{3}{*}{\multicolumn{2}{|c|}{$\begin{array}{|cc|}\text { ALCOHOL } & p \\
32 & <0,001 \\
\end{array}$}} \\
\hline & & & & & & & & & \\
\hline \multirow{2}{*}{$\begin{array}{l}<55 \text { años } \\
\text { con } \\
\text { cataratas }\end{array}$} & $\mathrm{SI}$ & $\begin{array}{c}12 \\
(16,66 \%)\end{array}$ & $>0,005$ & $\begin{array}{c}12 \\
(16,66 \%)\end{array}$ & $>0,005$ & & & & \\
\hline & NO & $\begin{array}{c}60 \\
(83,33 \%)\end{array}$ & & $\begin{array}{c}60 \\
(83,33 \%)\end{array}$ & & $\begin{array}{c}37 \\
(51,39 \%)\end{array}$ & & $\begin{array}{c}40 \\
(55,55 \%)\end{array}$ & \\
\hline \multirow{2}{*}{$\begin{array}{l}>55 \text { años } \\
\text { sin } \\
\text { cataratas }\end{array}$} & $\mathrm{SI}$ & $\begin{array}{c}21 \\
(50 \%)\end{array}$ & & $\begin{array}{c}11 \\
(26,2 \%)\end{array}$ & & $\begin{array}{c}3 \\
(7,1 \%)\end{array}$ & & $\begin{array}{c}0 \\
(0 \%)\end{array}$ & \\
\hline & NO & $\begin{array}{c}21 \\
(50 \%)\end{array}$ & & $\begin{array}{c}31 \\
(73,8 \%)\end{array}$ & & $\begin{array}{c}39 \\
(92,9 \%)\end{array}$ & & $\begin{array}{c}42 \\
(100 \%)\end{array}$ & \\
\hline
\end{tabular}

Así mismo, decidimos analizar la distribución de los factores de riesgo entre el grupo de mayores de 55 años con catarata y el grupo de mayores de 55 años sin catarata. En ellos, no encontramos diferencias en cuanto a la distribución de los factores de riesgo DM, HTA ni tabaco entre ambos grupos; sin embargo sí se observó una mayor frecuencia estadísticamente significativa en el consumo de alcohol en el grupo de pacientes con cataratas (tabla 12). 
Tabla 12: Distribución de los factores de riesgo en el grupo de mayores de 55 años con cataratas comparado con el grupo de mayores de 55 años sin cataratas.

\begin{tabular}{|c|c|c|c|c|c|c|c|c|c|}
\hline & & HTA & $p$ & DM & $p$ & TABACO & $p$ & ALCOHOL & $\mathbf{p}$ \\
\hline \multirow{2}{*}{$\begin{array}{l}>55 \text { años } \\
\text { con } \\
\text { cataratas }\end{array}$} & $\mathrm{SI}$ & $\begin{array}{c}60 \\
(59,4 \%)\end{array}$ & $>0,005$ & $\begin{array}{c}16 \\
(15,8 \%)\end{array}$ & $>0,005$ & $\begin{array}{c}18 \\
(17,8 \%)\end{array}$ & $>0,005$ & $\begin{array}{c}10 \\
(9,9 \%)\end{array}$ & $<0,027$ \\
\hline & NO & $\begin{array}{c}41 \\
(40,6 \%)\end{array}$ & & $\begin{array}{c}85 \\
(84,2 \%)\end{array}$ & & $\begin{array}{c}83 \\
(82,2 \%)\end{array}$ & & $\begin{array}{c}91 \\
(90,1 \%)\end{array}$ & \\
\hline \multirow{2}{*}{$\begin{array}{l}>55 \text { años } \\
\text { sin } \\
\text { cataratas }\end{array}$} & $\mathrm{SI}$ & $\begin{array}{c}21 \\
(50 \%)\end{array}$ & & $\begin{array}{c}11 \\
(26,2 \%)\end{array}$ & & $\begin{array}{c}3 \\
(7,1 \%)\end{array}$ & & $\begin{array}{c}0 \\
(0 \%)\end{array}$ & \\
\hline & NO & $\begin{array}{c}21 \\
(50 \%)\end{array}$ & & $\begin{array}{c}31 \\
(73,8 \%)\end{array}$ & & $\begin{array}{c}39 \\
(92,9 \%)\end{array}$ & & $\begin{array}{c}42 \\
(100 \%)\end{array}$ & \\
\hline
\end{tabular}




\section{2.- ESTUDIO GENÉTICO DE LA SUSCEPTIBILIDAD AL DESARROLLO DE CATARATAS PRESENILES}

Antes de realizar el análisis de asociación genética se comprobó que los polimorfismos a estudio cumplían el equilibrio de Hardy-Weinberg (Tabla 13).

Tabla 13: Distribución del coeficiente de Hardy-Weinberg en los distintos polimorfismos al comparar los tres grupos a estudio:

\begin{tabular}{|c|c|c|c|c|}
\hline Polimorfismos & $\begin{array}{l}\text { Valor p HWE } \\
\text { en todos los } \\
\text { grupos }\end{array}$ & $\begin{array}{l}\text { Valor p HWE } \\
\text { en los }>55 \\
\text { años con } \\
\text { cataratas }\end{array}$ & $\begin{array}{l}\text { Valor p HWE } \\
\text { en los }<55 \\
\text { años con } \\
\text { cataratas }\end{array}$ & $\begin{array}{l}\text { Valor p HWE } \\
\text { en los }>55 \\
\text { años sin } \\
\text { cataratas }\end{array}$ \\
\hline ERCC1 & 0.6585 & 0.4996 & 0.3231 & 0.5056 \\
\hline ERCC2 & 0.7679 & 0.3903 & 0.4452 & 0.1810 \\
\hline XPC & 0.5906 & 0.4241 & 1.0000 & 0.6558 \\
\hline XRCC1 & 0.8605 & 0.2637 & 0.1320 & 1.0000 \\
\hline P53 & 0.7677 & 0.8290 & 1.0000 & 0.1604 \\
\hline
\end{tabular}




\section{1.- ESTUDIO DEL GEN ERCC1}

Estudiamos un SNP (rs 11615; c.354 A>G) del gen que produce un cambio de una alanina (A) por una guanina $(G)$

La comparación de la distribución de los genotipos y alelos del polimorfismo rs 11615 del gen ERCC1 entre los pacientes con cataratas preseniles y el grupo de mayores de 55 años con cataratas mostró que no existen diferencias significativas en la distribución genotípica entre ambos grupos. (tabla 14).

Tabla 14: Distribución de los genotipos del polimorfismo (rs 11615) del gen ERCC1 en menores de 55 años con cataratas y sujetos mayores de 55 años con cataratas.

ERCC1 (rs 11615)

\begin{tabular}{|c|c|c|c|c|c|c|c|c|}
\hline Modelos & $\begin{array}{c}>55 \text { años con } \\
\text { cataratas }\end{array}$ & $\%$ & $\begin{array}{c}<55 \text { años con } \\
\text { cataratas }\end{array}$ & $\%$ & OR & inferior & superior & $p$ \\
\hline \multicolumn{9}{|c|}{ Codominante } \\
\hline$A / A$ & 43 & 42.6 & 29 & 40.3 & 1.00 & & & 0.20176 \\
\hline$A / G$ & 49 & 48.5 & 30 & 41.7 & 0.91 & 0.47 & 1.75 & \\
\hline $\mathrm{G} / \mathrm{G}$ & 9 & 8.9 & 13 & 18.1 & 2.14 & 0.81 & 5.66 & \\
\hline \multicolumn{9}{|l|}{ Dominante } \\
\hline$A / A$ & 43 & 42.6 & 29 & 40.3 & 1.00 & & & 0.76250 \\
\hline$A / G-G / G$ & 58 & 57.4 & 43 & 59.7 & 1.10 & 0.59 & 2.03 & \\
\hline \multicolumn{9}{|l|}{ Recesivo } \\
\hline$A / A-A / G$ & 92 & 91.1 & 59 & 81.9 & 1.00 & & & 0.07746 \\
\hline $\mathrm{G} / \mathrm{G}$ & 9 & 8.9 & 13 & 18.1 & 2.25 & 0.91 & 5.60 & \\
\hline \multicolumn{9}{|l|}{ log-Aditivo } \\
\hline $0,1,2$ & 101 & 58.4 & 72 & 41.6 & 1.28 & 0.82 & 2.00 & 0.27435 \\
\hline
\end{tabular}


Así mismo, realizamos el análisis según el modelo de regresión ajustando por los factores de riesgo hipertensión (HTA), tabaco y alcohol; tampoco encontramos diferencias estadísticamente significativas en la distribución de los genotipos al comparar los grupos de pacientes menores de 55 años con cataratas y mayores de 55 años con cataratas (Tabla 15).

Tabla 15: Distribución de los genotipos del polimorfismo (rs 11615) del gen ERCC1 en menores de 55 años con cataratas y mayores de 55 años con cataratas según el modelo de regresión ajustado por los factores de riesgo HTA, tabaco y alcohol.

ERCC1 (rs 11615)

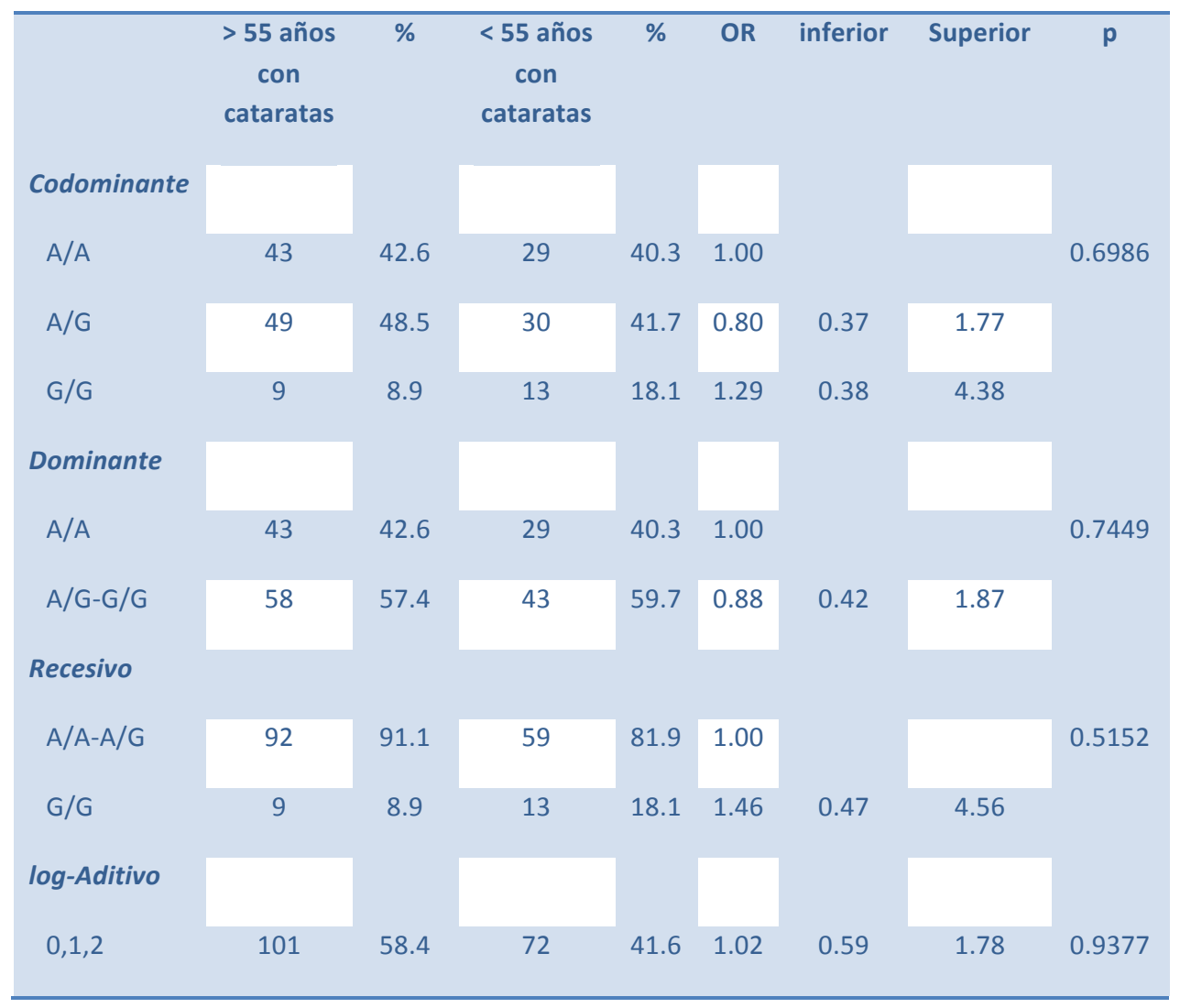

Ajustado por los factores de riesgo HTA, tabaco y alcohol. 
La comparación de la distribución de los genotipos del polimorfismo rs 11615 del gen ERCC1 entre los pacientes con cataratas preseniles y el grupo de mayores de 55 años sin cataratas tampoco mostró diferencias significativas. Tampoco se observaron diferencias al realizar el análisis por agrupación de alelos (tabla 16).

Tabla 16: Distribución de los genotipos del polimorfismo (rs 11615) del gen ERCC1 en menores de 55 años con cataratas y mayores de 55 años sin cataratas.

ERCC1 (rs 11615)

\begin{tabular}{|c|c|c|c|c|c|c|c|c|}
\hline & $\begin{array}{l}\text { >55 años } \\
\text { sin } \\
\text { cataratas }\end{array}$ & $\%$ & $\begin{array}{c}<55 \text { años } \\
\text { con } \\
\text { cataratas }\end{array}$ & $\%$ & OR & inferior & superior & $p$ \\
\hline \multicolumn{9}{|c|}{ Codominante } \\
\hline$A / A$ & 18 & 42.9 & 29 & 40.3 & 1.00 & & & 0.9603 \\
\hline$A / G$ & 17 & 40.5 & 30 & 41.7 & 1.10 & 0.47 & 2.53 & \\
\hline $\mathrm{G} / \mathrm{G}$ & 7 & 16.7 & 13 & 18.1 & 1.15 & 0.39 & 3.43 & \\
\hline \multicolumn{9}{|c|}{ Dominante } \\
\hline $\mathrm{A} / \mathrm{A}$ & 18 & 42.9 & 29 & 40.3 & 1.00 & & & 0.7874 \\
\hline$A / G-G / G$ & 24 & 57.1 & 43 & 59.7 & 1.11 & 0.51 & 2.41 & \\
\hline \multicolumn{9}{|l|}{ Recesivo } \\
\hline$A / A-A / G$ & 35 & 83.3 & 59 & 81.9 & 1.00 & & & 0.8504 \\
\hline $\mathrm{G} / \mathrm{G}$ & 7 & 16.7 & 13 & 18.1 & 1.10 & 0.40 & 3.02 & \\
\hline \multicolumn{9}{|c|}{ log-Aditivo } \\
\hline $0,1,2$ & 42 & 36.8 & 72 & 63.2 & 1.08 & 0.64 & 1.82 & 0.7790 \\
\hline
\end{tabular}


Así mismo, realizamos el análisis según el modelo de regresión ajustando por los factores de riesgo HTA, tabaco y alcohol; no encontrando diferencias estadísticamente significativas en la distribución de los genotipos al comparar los sujetos menores de 55 años con cataratas y los mayores de 55 años sin cataratas (Tabla 17).

Tabla 17: Distribución de los genotipos del polimorfismo (rs 11615) del gen ERCC1 en menores de 55 años con cataratas y mayores de 55 años sin cataratas según el modelo de regresión ajustado por los factores de riesgo HTA, tabaco y alcohol.

ERCC1 (rs 11615)

\begin{tabular}{|c|c|c|c|c|c|c|c|c|}
\hline & $\begin{array}{c}>55 \text { años sin } \\
\text { cataratas }\end{array}$ & $\%$ & $\begin{array}{c}<55 \text { años } \\
\text { con } \\
\text { cataratas }\end{array}$ & $\%$ & OR & inferior & superior & p \\
\hline \multicolumn{9}{|c|}{ Codominante } \\
\hline $\mathrm{A} / \mathrm{A}$ & 18 & 42.9 & 29 & 40.3 & 1.00 & & & 0.8782 \\
\hline A/G & 17 & 40.5 & 30 & 41.7 & 1.03 & 0.35 & 3.04 & \\
\hline G/G & 7 & 16.7 & 13 & 18.1 & 1.44 & 0.34 & 6.13 & \\
\hline \multicolumn{9}{|c|}{ Dominante } \\
\hline $\mathrm{A} / \mathrm{A}$ & 18 & 42.9 & 29 & 40.3 & 1.00 & & & 0.8072 \\
\hline A/G-G/G & 24 & 57.1 & 43 & 59.7 & 1.13 & 0.42 & 3.08 & \\
\hline \multicolumn{9}{|l|}{ Recesivo } \\
\hline $\mathrm{A} / \mathrm{A}-\mathrm{A} / \mathrm{G}$ & 35 & 83.3 & 59 & 81.9 & 1.00 & & & 0.6128 \\
\hline $\mathrm{G} / \mathrm{G}$ & 7 & 16.7 & 13 & 18.1 & 1.41 & 0.37 & 5.43 & \\
\hline \multicolumn{9}{|c|}{ log-Aditivo } \\
\hline $0,1,2$ & 42 & 36.8 & 72 & 63.2 & 1.16 & 0.58 & 2.32 & 0.6687 \\
\hline
\end{tabular}

Ajustado por los factores de riesgo HTA, tabaco y alcohol. 
Cuando comparamos la distribución del polimorfismo entre los individuos mayores de 55 años que presentan catarata y los que no la presentan no encontramos diferencias significativas. Tampoco encontramos diferencias al agrupar a los pacientes por alelos (Tabla 18).

Tabla 18: Distribución de los genotipos del polimorfismo (rs 11615) del gen ERCC1 en mayores de 55 años con cataratas y mayores de 55 años sin cataratas.

ERCC1 (rs 11615)

\begin{tabular}{|c|c|c|c|c|c|c|c|c|}
\hline & $\begin{array}{l}>55 \text { años } \\
\text { sin } \\
\text { cataratas }\end{array}$ & $\%$ & $\begin{array}{l}>55 \text { años } \\
\text { con } \\
\text { cataratas }\end{array}$ & $\%$ & OR & inferior & superior & $p$ \\
\hline \multicolumn{9}{|c|}{ Codominante } \\
\hline$A / A$ & 18 & 42.9 & 43 & 42.6 & 1.00 & & & 0.3852 \\
\hline$A / G$ & 17 & 40.5 & 49 & 48.5 & 1.21 & 0.55 & 2.63 & \\
\hline G/G & 7 & 16.7 & 9 & 8.9 & 0.54 & 0.17 & 1.67 & \\
\hline \multicolumn{9}{|c|}{ Dominante } \\
\hline $\mathrm{A} / \mathrm{A}$ & 18 & 42.9 & 43 & 42.6 & 1.00 & & & 0.9752 \\
\hline A/G-G/G & 24 & 57.1 & 58 & 57.4 & 1.01 & 0.49 & 2.09 & \\
\hline \multicolumn{9}{|l|}{ Recesivo } \\
\hline$A / A-A / G$ & 35 & 83.3 & 92 & 91.1 & 1.00 & & & 0.1943 \\
\hline G/G & 7 & 16.7 & 9 & 8.9 & 0.49 & 0.17 & 1.41 & \\
\hline \multicolumn{9}{|c|}{ log-Aditivo } \\
\hline $0,1,2$ & 42 & 29.4 & 101 & 70.6 & 0.84 & 0.49 & 1.45 & 0.5404 \\
\hline
\end{tabular}


El análisis según el modelo de regresión ajustando por los factores de riesgo no mostró diferencias estadísticamente significativas en la distribución de los genotipos (Tabla 19).

Tabla 19: Distribución de los genotipos del polimorfismo (rs 11615) del gen ERCC1 en mayores de 55 años con cataratas y mayores de 55 años sin cataratas según el modelo de regresión ajustado por los factores de riesgo HTA, tabaco y alcohol.

ERCC1 (rs 11615)

\begin{tabular}{|c|c|c|c|c|c|c|c|c|}
\hline & $\begin{array}{l}>55 \text { años sin } \\
\text { cataratas }\end{array}$ & $\%$ & $\begin{array}{c}>55 \text { años con } \\
\text { catarata }\end{array}$ & $\%$ & OR & inferior & superior & $p$ \\
\hline \multicolumn{9}{|c|}{ Codominante } \\
\hline$A / A$ & 18 & 42.9 & 43 & 42.6 & 1.00 & & & 0.2411 \\
\hline A/G & 17 & 40.5 & 49 & 48.5 & 1.34 & 0.61 & 2.97 & \\
\hline $\mathrm{G} / \mathrm{G}$ & 7 & 16.7 & 9 & 8.9 & 0.49 & 0.15 & 1.60 & \\
\hline \multicolumn{9}{|c|}{ Dominante } \\
\hline$A / A$ & 18 & 42.9 & 43 & 42.6 & 1.00 & & & 0.8111 \\
\hline A/G-G/G & 24 & 57.1 & 58 & 57.4 & 1.09 & 0.52 & 2.30 & \\
\hline \multicolumn{9}{|l|}{ Recesivo } \\
\hline$A / A-A / G$ & 35 & 83.3 & 92 & 91.1 & 1.00 & & & 0.1290 \\
\hline G/G & 7 & 16.7 & 9 & 8.9 & 0.42 & 0.14 & 1.28 & \\
\hline \multicolumn{9}{|c|}{ log-Aditivo } \\
\hline $0,1,2$ & 42 & 29.4 & 101 & 70.6 & 0.85 & 0.49 & 1.49 & 0.5776 \\
\hline
\end{tabular}

Ajustado por los factores de riesgo HTA, tabaco y alcohol. 


\section{2.- ESTUDIO DEL GEN ERCC2}

Se estudió un SNP (rs 13181; c.2179 T>G) del gen que produce un cambio de una guanina $(G)$ por una timina $(T)$.

La comparación de la distribución de genotipos y alelos del polimorfismo rs 13181 del gen ERCC2 entre los pacientes con cataratas preseniles y el grupo de mayores de 55 años con cataratas no mostró diferencias significativas (Tabla 20).

Tabla 20: Distribución de los genotipos del polimorfismo (rs 13181) del gen ERCC2 en menores de 55 años con cataratas y mayores de 55 años con cataratas.

ERCC2 (rs 13181)

\begin{tabular}{|c|c|c|c|c|c|c|c|c|}
\hline & $\begin{array}{c}>55 \text { años con } \\
\text { cataratas }\end{array}$ & $\%$ & $\begin{array}{c}<55 \text { años con } \\
\text { cataratas }\end{array}$ & $\%$ & OR & inferior & superior & $p$ \\
\hline \multicolumn{9}{|c|}{ Codominante } \\
\hline $\mathrm{T} / \mathrm{T}$ & 38 & 37.6 & 31 & 43.1 & 1.00 & & & 0.4061 \\
\hline $\mathrm{T} / \mathrm{G}$ & 52 & 51.5 & 30 & 41.7 & 0.71 & 0.37 & 1.36 & \\
\hline $\mathrm{G} / \mathrm{G}$ & 11 & 10.9 & 11 & 15.3 & 1.23 & 0.47 & 3.20 & \\
\hline \multicolumn{9}{|c|}{ Dominante } \\
\hline $\mathrm{T} / \mathrm{T}$ & 38 & 37.6 & 31 & 43.1 & 1.00 & & & 0.4724 \\
\hline $\mathrm{T} / \mathrm{G}-\mathrm{G} / \mathrm{G}$ & 63 & 62.4 & 41 & 56.9 & 0.80 & 0.43 & 1.48 & \\
\hline \multicolumn{9}{|l|}{ Recesivo } \\
\hline $\mathrm{T} / \mathrm{T}-\mathrm{T} / \mathrm{G}$ & 90 & 89.1 & 61 & 84.7 & 1.00 & & & 0.3961 \\
\hline $\mathrm{G} / \mathrm{G}$ & 11 & 10.9 & 11 & 15.3 & 1.48 & 0.60 & 3.62 & \\
\hline \multicolumn{9}{|c|}{ log-Aditivo } \\
\hline $0,1,2$ & 101 & 58.4 & 72 & 41.6 & 0.98 & 0.62 & 1.53 & 0.9197 \\
\hline
\end{tabular}


El análisis según el modelo de regresión ajustando por los factores de riesgo HTA, tabaco y alcohol; tampoco mostró diferencias estadísticamente significativas en la distribución de los genotipos en ninguno de los grupos (Tabla 21).

Tabla 21: Distribución de los genotipos del polimorfismo (rs 13181) del gen ERCC2 en menores de 55 años con cataratas y mayores de 55 años con cataratas según el modelo de regresión ajustado por los factores de riesgo HTA, tabaco y alcohol.

ERCC2 (rs 13181)

\begin{tabular}{|c|c|c|c|c|c|c|c|c|}
\hline & $\begin{array}{c}>55 \text { años } \\
\text { con } \\
\text { cataratas }\end{array}$ & $\%$ & $\begin{array}{c}<55 \text { años } \\
\text { con } \\
\text { catarata }\end{array}$ & $\%$ & OR & inferior & superior & $p$ \\
\hline \multicolumn{9}{|c|}{ Codominante } \\
\hline $\mathrm{T} / \mathrm{T}$ & 38 & 37.6 & 31 & 43.1 & 1.00 & & & 0.5324 \\
\hline$T / G$ & 52 & 51.5 & 30 & 41.7 & 0.68 & 0.31 & 1.49 & \\
\hline $\mathrm{G} / \mathrm{G}$ & 11 & 10.9 & 11 & 15.3 & 1.11 & 0.34 & 3.58 & \\
\hline \multicolumn{9}{|l|}{ Dominante } \\
\hline $\mathrm{T} / \mathrm{T}$ & 38 & 37.6 & 31 & 43.1 & 1.00 & & & 0.4518 \\
\hline $\mathrm{T} / \mathrm{G}-\mathrm{G} / \mathrm{G}$ & 63 & 62.4 & 41 & 56.9 & 0.75 & 0.36 & 1.58 & \\
\hline \multicolumn{9}{|l|}{ Recesivo } \\
\hline $\mathrm{T} / \mathrm{T}-\mathrm{T} / \mathrm{G}$ & 90 & 89.1 & 61 & 84.7 & 1.00 & & & 0.5762 \\
\hline G/G & 11 & 10.9 & 11 & 15.3 & 1.37 & 0.46 & 4.08 & \\
\hline \multicolumn{9}{|l|}{ log-Aditivo } \\
\hline $0,1,2$ & 49 & 48.5 & 42 & 58.3 & 1.00 & & & 0.2670 \\
\hline
\end{tabular}

Ajustado por los factores de riesgo HTA, tabaco y alcohol. 
La comparación de la distribución de genotipos y alelos del polimorfismo rs 13181 del gen ERCC2 entre los individuos menores de 55 años con cataratas y el grupo de mayores de 55 años sin cataratas tampoco mostró diferencias significativas entre ambos grupos (Tabla 22).

Tabla 22: Distribución de los genotipos del polimorfismo (rs 13181) del gen ERCC2 en menores de 55 años con cataratas y mayores de 55 años sin cataratas.

ERCC2 (rs 13181)

\begin{tabular}{|c|c|c|c|c|c|c|c|c|}
\hline & $\begin{array}{l}>55 \text { años } \\
\text { sin } \\
\text { cataratas }\end{array}$ & $\%$ & $\begin{array}{c}<55 \text { años } \\
\text { con } \\
\text { catarata }\end{array}$ & $\%$ & OR & inferior & superior & $p$ \\
\hline \multicolumn{9}{|c|}{ Codominante } \\
\hline$T / T$ & 20 & 47.6 & 31 & 43.1 & 1.00 & & & 0.8203 \\
\hline $\mathrm{G} / \mathrm{T}$ & 15 & 35.7 & 30 & 41.7 & 1.29 & 0.56 & 2.98 & \\
\hline G/G & 7 & 16.7 & 11 & 15.3 & 1.01 & 0.34 & 3.05 & \\
\hline \multicolumn{9}{|c|}{ Dominante } \\
\hline$T / T$ & 20 & 47.6 & 31 & 43.1 & 1.00 & & & 0.6366 \\
\hline $\mathrm{G} / \mathrm{T}-\mathrm{G} / \mathrm{G}$ & 22 & 52.4 & 41 & 56.9 & 1.20 & 0.56 & 2.58 & \\
\hline \multicolumn{9}{|l|}{ Recesivo } \\
\hline $\mathrm{T} / \mathrm{T}-\mathrm{G} / \mathrm{T}$ & 35 & 83.3 & 61 & 84.7 & 1.00 & & & 0.8449 \\
\hline G/G & 7 & 16.7 & 11 & 15.3 & 0.90 & 0.32 & 2.54 & \\
\hline \multicolumn{9}{|c|}{ log-Aditivo } \\
\hline $0,1,2$ & 42 & 36.8 & 72 & 63.2 & 1.06 & 0.63 & 1.80 & 0.8207 \\
\hline
\end{tabular}


Así mismo, realizamos el análisis según el modelo de regresión ajustando por los factores de riesgo HTA, tabaco y alcohol; no encontrando diferencias estadísticamente significativas en la distribución de los genotipos en ninguno de los grupos analizados (Tabla 23).

Tabla 23: Distribución de los genotipos del polimorfismo (rs 13181) del gen ERCC2 en menores de 55 años y mayores de 55 años sin cataratas según el modelo de regresión ajustado por los factores de riesgo HTA, tabaco y alcohol.

ERCC2 (rs 13181)

\begin{tabular}{|c|c|c|c|c|c|c|c|c|}
\hline & $\begin{array}{c}>55 \text { años sin } \\
\text { cataratas }\end{array}$ & $\%$ & $\begin{array}{l}<55 \text { años } \\
\text { con } \\
\text { cataratas }\end{array}$ & $\%$ & OR & inferior & superior & $p$ \\
\hline \multicolumn{9}{|c|}{ Codominante } \\
\hline $\mathrm{T} / \mathrm{T}$ & 20 & 47.6 & 31 & 43.1 & 1.00 & & & 0.5836 \\
\hline $\mathrm{G} / \mathrm{T}$ & 15 & 35.7 & 30 & 41.7 & 0.57 & 0.18 & 1.74 & \\
\hline G/G & 7 & 16.7 & 11 & 15.3 & 0.95 & 0.23 & 3.87 & \\
\hline \multicolumn{9}{|c|}{ Dominante } \\
\hline $\mathrm{T} / \mathrm{T}$ & 20 & 47.6 & 31 & 43.1 & 1.00 & & & 0.4308 \\
\hline $\mathrm{G} / \mathrm{T}-\mathrm{G} / \mathrm{G}$ & 22 & 52.4 & 41 & 56.9 & 0.67 & 0.25 & 1.82 & \\
\hline \multicolumn{9}{|l|}{ Recesivo } \\
\hline $\mathrm{T} / \mathrm{T}-\mathrm{G} / \mathrm{T}$ & 35 & 83.3 & 61 & 84.7 & 1.00 & & & 0.7923 \\
\hline $\mathrm{G} / \mathrm{G}$ & 7 & 16.7 & 11 & 15.3 & 1.19 & 0.32 & 4.48 & \\
\hline \multicolumn{9}{|c|}{ log-Aditivo } \\
\hline $0,1,2$ & 42 & 36.8 & 72 & 63.2 & 0.87 & 0.45 & 1.71 & 0.6905 \\
\hline
\end{tabular}

Ajustado por los factores de riesgo HTA, tabaco y alcohol. 
La tabla 24 muestra la comparación de la distribución de los genotipos y alelos del polimorfismo entre los sujetos mayores de 55 años que presentan catarata y los que no la presentan, no encontrando diferencias significativas.

Tabla 24: Distribución de los genotipos del polimorfismo (rs 13181) del gen ERCC2 en mayores de 55 años con cataratas y mayores de 55 años sin cataratas.

ERCC2 (rs 13181)

\begin{tabular}{|c|c|c|c|c|c|c|c|c|}
\hline & $\begin{array}{l}>55 \text { años } \\
\sin \\
\text { cataratas }\end{array}$ & $\%$ & $\begin{array}{c}>55 \text { años } \\
\text { con } \\
\text { catarata }\end{array}$ & $\%$ & OR & inferior & superior & $p$ \\
\hline \multicolumn{9}{|c|}{ Codominante } \\
\hline$T / T$ & 20 & 47.6 & 38 & 37.6 & 1.00 & & & 0.21071 \\
\hline $\mathrm{G} / \mathrm{T}$ & 15 & 35.7 & 52 & 51.5 & 1.82 & 0.83 & 4.02 & \\
\hline $\mathrm{G} / \mathrm{G}$ & 7 & 16.7 & 11 & 10.9 & 0.83 & 0.28 & 2.46 & \\
\hline \multicolumn{9}{|c|}{ Dominante } \\
\hline$T / T$ & 20 & 47.6 & 38 & 37.6 & 1.00 & & & 0.26945 \\
\hline G/T-G/G & 22 & 52.4 & 63 & 62.4 & 1.51 & 0.73 & 3.12 & \\
\hline \multicolumn{9}{|l|}{ Recesivo } \\
\hline $\mathrm{T} / \mathrm{T}-\mathrm{G} / \mathrm{T}$ & 35 & 83.3 & 90 & 89.1 & 1.00 & & & 0.35382 \\
\hline G/G & 7 & 16.7 & 11 & 10.9 & 0.61 & 0.22 & 1.70 & \\
\hline \multicolumn{9}{|c|}{ log-Aditivo } \\
\hline $0,1,2$ & 42 & 29.4 & 101 & 70.6 & 1.10 & 0.64 & 1.88 & 0.73232 \\
\hline
\end{tabular}


El análisis según el modelo de regresión ajustando por los factores de riesgo, tampoco mostró diferencias estadísticamente significativas en la distribución de los genotipos (Tabla 25).

Tabla 25: Distribución de los genotipos del polimorfismo (rs 13181) del gen ERCC2 en mayores de 55 años con cataratas y mayores de 55 años sin cataratas según el modelo de regresión ajustado por los factores de riesgo HTA, tabaco y alcohol.

ERCC2 ( rs 13181)

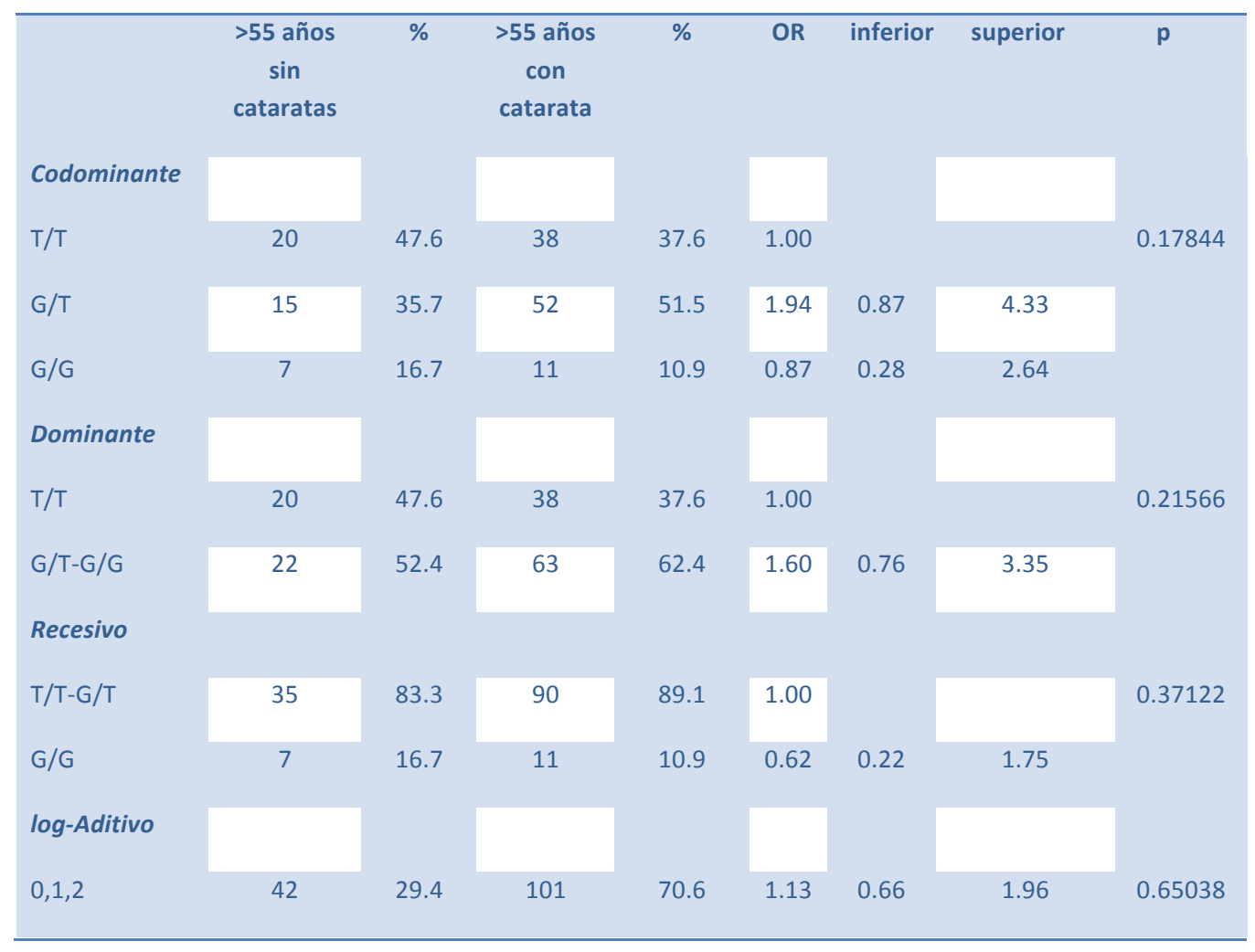

Ajustado por los factores de riesgo HTA, tabaco y alcohol. 


\section{3.- ESTUDIO DEL GEN XPC}

Nosotros estudiamos un SNP (rs 2228000; c.1385 G>A) del gen en el que se produce un cambio de una adenina $(A)$ por una guanina $(G)$.

Al comparar la distribución de los genotipos y alelos de este polimorfismo entre los pacientes jóvenes con cataratas preseniles y el grupo de mayores de 55 años con cataratas no observamos diferencias significativas (Tabla 26).

Tabla 26: Distribución de los genotipos del polimorfismo (rs 2228000) del gen XPC en menores de 55 años con cataratas y mayores de 55 años con cataratas.

XPC (rs 2228000)

\begin{tabular}{|c|c|c|c|c|c|c|c|c|}
\hline & $\begin{array}{c}>55 \text { años con } \\
\text { cataratas }\end{array}$ & $\%$ & $\begin{array}{c}<55 \text { años } \\
\text { con } \\
\text { cataratas }\end{array}$ & $\%$ & OR & inferior & superior & p \\
\hline \multicolumn{9}{|c|}{ Codominante } \\
\hline G/G & 57 & 56.4 & 35 & 48.6 & 1.00 & & & 0.2605 \\
\hline $\mathrm{G} / \mathrm{A}$ & 40 & 39.6 & 30 & 41.7 & 1.22 & 0.65 & 2.30 & \\
\hline$A / A$ & 4 & 4.0 & 7 & 9.7 & 2.85 & 0.78 & 10.44 & \\
\hline \multicolumn{9}{|l|}{ Dominante } \\
\hline G/G & 57 & 56.4 & 35 & 48.6 & 1.00 & & & 0.3093 \\
\hline $\mathrm{G} / \mathrm{A}-\mathrm{A} / \mathrm{A}$ & 44 & 43.6 & 37 & 51.4 & 1.37 & 0.75 & 2.51 & \\
\hline \multicolumn{9}{|l|}{ Recesivo } \\
\hline G/G-G/A & 97 & 96.0 & 65 & 90.3 & 1.00 & & & 0.1288 \\
\hline$A / A$ & 4 & 4.0 & 7 & 9.7 & 2.61 & 0.73 & 9.28 & \\
\hline \multicolumn{9}{|l|}{ log-Aditivo } \\
\hline $0,1,2$ & 101 & 58.4 & 72 & 41.6 & 1.43 & 0.87 & 2.35 & 0.1517 \\
\hline
\end{tabular}


Así mismo, realizamos el análisis según el modelo de regresión ajustando por los factores de riesgo HTA, tabaco y alcohol; y tampoco encontramos diferencias estadísticamente significativas (Tabla 27).

Tabla 27: Distribución de los genotipos del polimorfismo (rs 2228000) del gen XPC en menores de 55 años con cataratas y mayores de 55 años con cataratas) según el modelo de regresión ajustado por los factores de riesgo HTA, tabaco y alcohol.

XPC (rs 2228000)

\begin{tabular}{|c|c|c|c|c|c|c|c|c|}
\hline & $\begin{array}{c}>55 \text { años } \\
\text { con } \\
\text { cataratas }\end{array}$ & $\%$ & $\begin{array}{c}<55 \text { años } \\
\text { con } \\
\text { cataratas }\end{array}$ & $\%$ & OR & inferior & superior & $p$ \\
\hline \multicolumn{9}{|c|}{ Codominante } \\
\hline G/G & 57 & 56.4 & 35 & 48.6 & 1.00 & & & 0.3726 \\
\hline $\mathrm{G} / \mathrm{A}$ & 40 & 39.6 & 30 & 41.7 & 1.31 & 0.61 & 2.83 & \\
\hline$A / A$ & 4 & 4.0 & 7 & 9.7 & 2.96 & 0.58 & 15.04 & \\
\hline \multicolumn{9}{|l|}{ Dominante } \\
\hline G/G & 57 & 56.4 & 35 & 48.6 & 1.00 & & & 0.3108 \\
\hline G/A-A/A & 44 & 43.6 & 37 & 51.4 & 1.46 & 0.70 & 3.04 & \\
\hline \multicolumn{9}{|l|}{ Recesivo } \\
\hline G/G-G/A & 97 & 96.0 & 65 & 90.3 & 1.00 & & & 0.2231 \\
\hline$A / A$ & 4 & 4.0 & 7 & 9.7 & 2.64 & 0.54 & 13.00 & \\
\hline \multicolumn{9}{|l|}{ log-Aditivo } \\
\hline $0,1,2$ & 61 & 60.4 & 42 & 58.3 & 1.00 & & & 0.6563 \\
\hline
\end{tabular}

Ajustado por los factores de riesgo HTA, tabaco y alcohol. 
La comparación de la distribución de genotipos y alelos del polimorfismo rs 2228000 del gen XPC entre los pacientes con cataratas preseniles y el grupo de mayores de 55 años sin cataratas tampoco mostró diferencias significativas (Tabla 28).

Tabla 28: Distribución de los genotipos del polimorfismo (rs 2228000) del gen XPC en menores de 55 años con cataratas y mayores de 55 años sin cataratas.

XPC (rs 2228000)

\begin{tabular}{|c|c|c|c|c|c|c|c|c|}
\hline & $\begin{array}{l}>55 \text { años } \\
\text { sin } \\
\text { cataratas }\end{array}$ & $\%$ & $\begin{array}{c}<55 \text { años } \\
\text { con } \\
\text { cataratas }\end{array}$ & $\%$ & OR & inferior & superior & $p$ \\
\hline \multicolumn{9}{|c|}{ Codominante } \\
\hline G/G & 25 & 59.5 & 35 & 48.6 & 1.00 & & & 0.2147 \\
\hline $\mathrm{G} / \mathrm{A}$ & 16 & 38.1 & 30 & 41.7 & 1.34 & 0.60 & 2.96 & \\
\hline$A / A$ & 1 & 2.4 & 7 & 9.7 & 5.00 & 0.58 & 43.24 & \\
\hline \multicolumn{9}{|c|}{ Dominante } \\
\hline G/G & 25 & 59.5 & 35 & 48.6 & 1.00 & & & 0.2592 \\
\hline G/A-A/A & 17 & 40.5 & 37 & 51.4 & 1.55 & 0.72 & 3.36 & \\
\hline \multicolumn{9}{|l|}{ Recesivo } \\
\hline G/G-G/A & 41 & 97.6 & 65 & 90.3 & 1.00 & & & 0.1100 \\
\hline$A / A$ & 1 & 2.4 & 7 & 9.7 & 4.42 & 0.52 & 37.21 & \\
\hline \multicolumn{9}{|c|}{ log-Aditivo } \\
\hline $0,1,2$ & 42 & 36.8 & 72 & 63.2 & 1.64 & 0.86 & 3.12 & 0.1262 \\
\hline
\end{tabular}


Así mismo, realizamos el análisis según el modelo de regresión ajustando por los factores de riesgo HTA, tabaco y alcohol; no encontrando diferencias estadísticamente significativas en la distribución de los genotipos (Tabla 29).

Tabla 29: Distribución de los genotipos del polimorfismo (rs 2228000) del gen XPC en menores de 55 años con cataratas y mayores de 55 años sin cataratas según el modelo de regresión ajustado por los factores de riesgo HTA, tabaco y alcohol.

XPC (rs 2228000)

\begin{tabular}{|c|c|c|c|c|c|c|c|c|}
\hline & $\begin{array}{c}>55 \text { años sin } \\
\text { cataratas }\end{array}$ & $\%$ & $\begin{array}{c}<55 \text { años con } \\
\text { cataratas }\end{array}$ & $\%$ & OR & inferior & superior & $p$ \\
\hline \multicolumn{9}{|c|}{ Codominante } \\
\hline $\mathrm{G} / \mathrm{G}$ & 25 & 59.5 & 35 & 48.6 & 1.00 & & & 0.3678 \\
\hline $\mathrm{G} / \mathrm{A}$ & 16 & 38.1 & 30 & 41.7 & 1.54 & 0.55 & 4.36 & \\
\hline$A / A$ & 1 & 2.4 & 7 & 9.7 & 4.70 & 0.37 & 59.68 & \\
\hline \multicolumn{9}{|c|}{ Dominante } \\
\hline $\mathrm{G} / \mathrm{G}$ & 25 & 59.5 & 35 & 48.6 & 1.00 & & & 0.2730 \\
\hline G/A-A/A & 17 & 40.5 & 37 & 51.4 & 1.75 & 0.64 & 4.77 & \\
\hline \multicolumn{9}{|l|}{ Recesivo } \\
\hline G/G-G/A & 41 & 97.6 & 65 & 90.3 & 1.00 & & & 0.2503 \\
\hline$A / A$ & 1 & 2.4 & 7 & 9.7 & 3.90 & 0.32 & 47.14 & \\
\hline \multicolumn{9}{|c|}{ log-Aditivo } \\
\hline $0,1,2$ & 42 & 36.8 & 72 & 63.2 & 1.77 & 0.76 & 4.15 & 0.1803 \\
\hline
\end{tabular}

Ajustado por los factores de riesgo HTA, tabaco y alcohol. 
Cuando comparamos la distribución del polimorfismo entre los sujetos mayores de 55 años que presentan catarata y los que no la presentan no encontramos diferencias significativas. Tampoco encontramos diferencias al agrupar a los pacientes por alelos (Tabla $30)$.

Tabla 30: Distribución de los genotipos del polimorfismo (rs 2228000) del gen XPC en mayores de 55 años con cataratas y mayores de 55 años sin cataratas.

XPC (rs 2228000)

\begin{tabular}{|c|c|c|c|c|c|c|c|c|}
\hline & $\begin{array}{c}>55 \text { años sin } \\
\text { cataratas }\end{array}$ & $\%$ & $\begin{array}{l}>55 \text { años } \\
\text { con } \\
\text { cataratas }\end{array}$ & $\%$ & OR & inferior & superior & $p$ \\
\hline \multicolumn{9}{|c|}{ Codominante } \\
\hline G/G & 25 & 59.5 & 57 & 56.4 & 1.00 & & & 0.8631 \\
\hline $\mathrm{G} / \mathrm{A}$ & 16 & 38.1 & 40 & 39.6 & 1.10 & 0.52 & 2.31 & \\
\hline$A / A$ & 1 & 2.4 & 4 & 4.0 & 1.75 & 0.19 & 16.50 & \\
\hline \multicolumn{9}{|c|}{ Dominante } \\
\hline G/G & 25 & 59.5 & 57 & 56.4 & 1.00 & & & 0.7334 \\
\hline $\mathrm{G} / \mathrm{A}-\mathrm{A} / \mathrm{A}$ & 17 & 40.5 & 44 & 43.6 & 1.14 & 0.55 & 2.36 & \\
\hline \multicolumn{9}{|l|}{ Recesivo } \\
\hline G/G-G/A & 41 & 97.6 & 97 & 96.0 & 1.00 & & & 0.6273 \\
\hline$A / A$ & 1 & 2.4 & 4 & 4.0 & 1.69 & 0.18 & 15.59 & \\
\hline \multicolumn{9}{|c|}{ log-Aditivo } \\
\hline $0,1,2$ & 42 & 29.4 & 101 & 70.6 & 1.16 & 0.61 & 2.22 & 0.6509 \\
\hline
\end{tabular}


En estos grupos también realizamos el análisis según el modelo de regresión ajustando por los factores de riesgo. En la tabla 31 se observa que no existen encontramos diferencias estadísticamente significativas en la distribución de los genotipos.

Tabla 31: Distribución de los genotipos del polimorfismo (rs 2228000) del gen XPC en mayores de 55 años con cataratas y mayores de 55 años sin cataratas según el modelo de regresión ajustado por los factores de riesgo HTA, tabaco y alcohol.

XPC (rs 2228000)

\begin{tabular}{|c|c|c|c|c|c|c|c|c|}
\hline & $\begin{array}{l}>55 \text { años } \\
\text { sin } \\
\text { cataratas }\end{array}$ & $\%$ & $\begin{array}{l}>55 \text { años } \\
\text { con } \\
\text { cataratas }\end{array}$ & $\%$ & OR & inferior & superior & $p$ \\
\hline \multicolumn{9}{|c|}{ Codominante } \\
\hline $\mathrm{G} / \mathrm{G}$ & 25 & 59.5 & 57 & 56.4 & 1.00 & & & 0.9228 \\
\hline $\mathrm{G} / \mathrm{A}$ & 16 & 38.1 & 40 & 39.6 & 1.16 & 0.55 & 2.48 & \\
\hline$A / A$ & 1 & 2.4 & 4 & 4.0 & 0.98 & 0.08 & 11.33 & \\
\hline \multicolumn{9}{|c|}{ Dominante } \\
\hline G/G & 25 & 59.5 & 57 & 56.4 & 1.00 & & & 0.7058 \\
\hline G/A-A/A & 17 & 40.5 & 44 & 43.6 & 1.15 & 0.55 & 2.42 & \\
\hline \multicolumn{9}{|l|}{ Recesivo } \\
\hline G/G-G/A & 41 & 97.6 & 97 & 96.0 & 1.00 & & & 0.9475 \\
\hline$A / A$ & 1 & 2.4 & 4 & 4.0 & 0.92 & 0.08 & 10.45 & \\
\hline \multicolumn{9}{|c|}{ log-Aditivo } \\
\hline $0,1,2$ & 42 & 29.4 & 101 & 70.6 & 1.12 & 0.57 & 2.21 & 0.7433 \\
\hline
\end{tabular}

Ajustado por los factores de riesgo HTA, tabaco y alcohol. 


\section{4.- ESTUDIO DEL GEN XRCC1}

Hemos estudiado un SNP ( $r s 25487 ; c .1196$ A $>$ G) en el que se produce un cambio de una guanina $(G)$ por una adenosina $(A)$.

La comparación de la distribución de genotipos y alelos de este polimorfismo entre los pacientes con cataratas preseniles y el grupo de mayores de 55 años con cataratas mostró que no existen diferencias significativas entre ambos grupos. (Tabla 32 ).

Tabla 32: Distribución de los genotipos del polimorfismo (rs 25487) del gen XRCC1 en menores de 55 años con cataratas y mayores de 55 años con cataratas.

XRCC1 (rs 25487)

\begin{tabular}{|c|c|c|c|c|c|c|c|c|}
\hline & $\begin{array}{c}>55 \text { años con } \\
\text { cataratas }\end{array}$ & $\%$ & $\begin{array}{c}<55 \text { años con } \\
\text { cataratas }\end{array}$ & $\%$ & OR & inferior & superior & $p$ \\
\hline \multicolumn{9}{|c|}{ Codominante } \\
\hline G/G & 42 & 41.6 & 29 & 40.3 & 1.00 & & & 0.9838 \\
\hline$G / A$ & 45 & 44.6 & 33 & 45.8 & 1.06 & 0.55 & 2.04 & \\
\hline $\mathrm{A} / \mathrm{A}$ & 14 & 13.9 & 10 & 13.9 & 1.03 & 0.40 & 2.65 & \\
\hline \multicolumn{9}{|l|}{ Dominante } \\
\hline G/G & 42 & 41.6 & 29 & 40.3 & 1.00 & & & 0.8633 \\
\hline $\mathrm{G} / \mathrm{A}-\mathrm{A} / \mathrm{A}$ & 59 & 58.4 & 43 & 59.7 & 1.06 & 0.57 & 1.95 & \\
\hline \multicolumn{9}{|l|}{ Recesivo } \\
\hline $\mathrm{G} / \mathrm{G}-\mathrm{G} / \mathrm{A}$ & 87 & 86.1 & 62 & 86.1 & 1.00 & & & 0.9959 \\
\hline $\mathrm{A} / \mathrm{A}$ & 14 & 13.9 & 10 & 13.9 & 1.00 & 0.42 & 2.40 & \\
\hline \multicolumn{9}{|l|}{ log-Aditivo } \\
\hline $0,1,2$ & 101 & 58.4 & 72 & 41.6 & 1.03 & 0.66 & 1.59 & 0.9002 \\
\hline
\end{tabular}


Así mismo, realizamos el análisis según el modelo de regresión ajustando por los factores de riesgo HTA, tabaco y alcohol; la tabla 33 muestra que no existen diferencias significativas en la distribución de los genotipos en ninguno de los grupos.

Tabla 33: Distribución de los genotipos del polimorfismo (rs 25487) del gen XRCC1 en menores de 55 años con cataratas y mayores de 55 años con cataratas según el modelo de regresión ajustado por los factores de riesgo HTA, tabaco y alcohol.

XRCC1 (rs 25487)

\begin{tabular}{|c|c|c|c|c|c|c|c|c|}
\hline & $\begin{array}{l}\text { >55 años } \\
\text { con } \\
\text { cataratas }\end{array}$ & $\%$ & $\begin{array}{c}<55 \text { años } \\
\text { con } \\
\text { cataratas }\end{array}$ & $\%$ & OR & inferior & superior & p \\
\hline \multicolumn{9}{|c|}{ Codominante } \\
\hline G/G & 42 & 41.6 & 29 & 40.3 & 1.00 & & & 0.4230 \\
\hline $\mathrm{G} / \mathrm{A}$ & 45 & 44.6 & 33 & 45.8 & 1.64 & 0.73 & 3.71 & \\
\hline$A / A$ & 14 & 13.9 & 10 & 13.9 & 1.73 & 0.55 & 5.45 & \\
\hline \multicolumn{9}{|l|}{ Dominante } \\
\hline G/G & 42 & 41.6 & 29 & 40.3 & 1.00 & & & 0.1907 \\
\hline $\mathrm{G} / \mathrm{A}-\mathrm{A} / \mathrm{A}$ & 59 & 58.4 & 43 & 59.7 & 1.66 & 0.77 & 3.60 & \\
\hline \multicolumn{9}{|l|}{ Recesivo } \\
\hline $\mathrm{G} / \mathrm{G}-\mathrm{G} / \mathrm{A}$ & 87 & 86.1 & 62 & 86.1 & 1.00 & & & 0.6071 \\
\hline$A / A$ & 14 & 13.9 & 10 & 13.9 & 1.32 & 0.46 & 3.75 & \\
\hline \multicolumn{9}{|l|}{ log-Aditivo } \\
\hline $0,1,2$ & 101 & 58.4 & 72 & 41.6 & 1.39 & 0.81 & 2.38 & 0.2346 \\
\hline
\end{tabular}

Ajustado por los factores de riesgo HTA, tabaco y alcohol. 
La comparación de la distribución de genotipos y alelos entre los pacientes con cataratas preseniles y el grupo de mayores de 55 años sin cataratas tampoco mostró diferencias significativas entre ambos grupos (Tabla 34).

Tabla 34: Distribución de los genotipos del polimorfismo (rs 25487) del gen XRCC1 en menores de 55 años con cataratas y mayores de 55 años sin cataratas.

XRCC1 (rs 25487)

\begin{tabular}{|c|c|c|c|c|c|c|c|c|}
\hline & $\begin{array}{l}>55 \text { años } \\
\text { sin } \\
\text { cataratas }\end{array}$ & $\%$ & $\begin{array}{c}<55 \text { años } \\
\text { con } \\
\text { catarata }\end{array}$ & $\%$ & OR & inferior & superior & $p$ \\
\hline \multicolumn{9}{|c|}{ Codominante } \\
\hline G/G & 17 & 40.5 & 29 & 40.3 & 1.00 & & & 0.2471 \\
\hline $\mathrm{G} / \mathrm{A}$ & 23 & 54.8 & 33 & 45.8 & 0.84 & 0.38 & 1.87 & \\
\hline$A / A$ & 2 & 4.8 & 10 & 13.9 & 2.93 & 0.57 & 14.99 & \\
\hline \multicolumn{9}{|c|}{ Dominante } \\
\hline G/G & 17 & 40.5 & 29 & 40.3 & 1.00 & & & 0.9834 \\
\hline $\mathrm{G} / \mathrm{A}-\mathrm{A} / \mathrm{A}$ & 25 & 59.5 & 43 & 59.7 & 1.01 & 0.46 & 2.19 & \\
\hline \multicolumn{9}{|l|}{ Recesivo } \\
\hline G/G-G/A & 40 & 95.2 & 62 & 86.1 & 1.00 & & & 0.1058 \\
\hline$A / A$ & 2 & 4.8 & 10 & 13.9 & 3.23 & 0.67 & 15.50 & \\
\hline \multicolumn{9}{|c|}{ log-Aditivo } \\
\hline $0,1,2$ & 42 & 36.8 & 72 & 63.2 & 1.25 & 0.69 & 2.27 & 0.4570 \\
\hline
\end{tabular}


Así mismo, realizamos el análisis según el modelo de regresión ajustando por los factores de riesgo HTA, tabaco y alcohol; no encontrando diferencias estadísticamente significativas en la distribución de los genotipos en la mayoría de los modelos de herencia. No obstante, en el modelo recesivo (agrupando por el alelo $\mathrm{G}$ ) observamos una mayor frecuencia, estadísticamente significativa, del genotipo AA en el grupo de pacientes con cataratas preseniles, aumentando el riesgo de padecerlas 6,45 veces $(p=0,02951$; OR 1,02-40,67) (Tabla 35).

Tabla 35: Distribución de los genotipos del polimorfismo (rs 25487) del gen XRCC1 en menores de 55 años con cataratas y mayores de 55 años sin cataratas según el modelo de regresión ajustado por los factores de riesgo HTA, tabaco y alcohol.

XRCC1 (rs 25487)

\begin{tabular}{|c|c|c|c|c|c|c|c|c|}
\hline & $\begin{array}{c}>55 \text { años } \sin \\
\text { cataratas }\end{array}$ & $\%$ & $\begin{array}{c}<55 \text { años con } \\
\text { cataratas }\end{array}$ & $\%$ & OR & inferior & superior & $p$ \\
\hline \multicolumn{9}{|c|}{ Codominante } \\
\hline $\mathrm{G} / \mathrm{G}$ & 17 & 40.5 & 29 & 40.3 & 1.00 & & & \multirow[t]{4}{*}{0.09360} \\
\hline $\mathrm{G} / \mathrm{A}$ & 23 & 54.8 & 33 & 45.8 & 1.00 & 0.35 & 2.89 & \\
\hline $\mathrm{A} / \mathrm{A}$ & 2 & 4.8 & 10 & 13.9 & 6.46 & 0.94 & 44.50 & \\
\hline \multicolumn{8}{|c|}{ Dominante } & \\
\hline G/G & 17 & 40.5 & 29 & 40.3 & 1.00 & & & \multirow[t]{2}{*}{0.54673} \\
\hline $\mathrm{G} / \mathrm{A}-\mathrm{A} / \mathrm{A}$ & 25 & 59.5 & 43 & 59.7 & 1.36 & 0.50 & 3.72 & \\
\hline \multicolumn{9}{|l|}{ Recesivo } \\
\hline $\mathrm{G} / \mathrm{G}-\mathrm{G} / \mathrm{A}$ & 40 & 95.2 & 62 & 86.1 & 1.00 & & & \multirow[t]{3}{*}{0.02951} \\
\hline $\mathrm{A} / \mathrm{A}$ & 2 & 4.8 & 10 & 13.9 & 6.45 & 1.02 & 40.67 & \\
\hline \multicolumn{8}{|c|}{ log-Aditivo } & \\
\hline $0,1,2$ & 42 & 36.8 & 72 & 63.2 & 1.78 & 0.82 & 3.85 & 0.13598 \\
\hline
\end{tabular}

Ajustado por los factores de riesgo HTA, tabaco y alcohol. 
Cuando comparamos la distribución del polimorfismo entre los mayores de 55 años que presentan catarata y los que no la presentan no encontramos diferencias significativas entre ambos grupos. Tampoco encontramos diferencias al agrupar a los pacientes por alelos (Tabla 36).

Tabla 36: Distribución de los genotipos del polimorfismo (rs 25487) del gen XRCC1 en mayores de 55 años con cataratas y mayores de 55 años sin cataratas.

XRCC1 (rs 25487)

\begin{tabular}{|c|c|c|c|c|c|c|c|c|}
\hline & $\begin{array}{c}>55 \text { años } \sin \\
\text { cataratas }\end{array}$ & $\%$ & $\begin{array}{c}>55 \text { años con } \\
\text { cataratas }\end{array}$ & $\%$ & OR & inferior & superior & $p$ \\
\hline \multicolumn{9}{|c|}{ Codominante } \\
\hline G/G & 17 & 40.5 & 42 & 41.6 & 1.00 & & & 0.19972 \\
\hline $\mathrm{G} / \mathrm{A}$ & 23 & 54.8 & 45 & 44.6 & 0.79 & 0.37 & 1.68 & \\
\hline$A / A$ & 2 & 4.8 & 14 & 13.9 & 2.83 & 0.58 & 13.83 & \\
\hline \multicolumn{9}{|c|}{ Dominante } \\
\hline G/G & 17 & 40.5 & 42 & 41.6 & 1.00 & & & 0.90239 \\
\hline $\mathrm{G} / \mathrm{A}-\mathrm{A} / \mathrm{A}$ & 25 & 59.5 & 59 & 58.4 & 0.96 & 0.46 & 1.99 & \\
\hline \multicolumn{9}{|l|}{ Recesivo } \\
\hline G/G-G/A & 40 & 95.2 & 87 & 86.1 & 1.00 & & & 0.09119 \\
\hline$A / A$ & 2 & 4.8 & 14 & 13.9 & 3.22 & 0.70 & 14.84 & \\
\hline \multicolumn{9}{|c|}{ log-Aditivo } \\
\hline $0,1,2$ & 42 & 29.4 & 101 & 70.6 & 1.21 & 0.69 & 2.10 & 0.50708 \\
\hline
\end{tabular}


El análisis según el modelo de regresión ajustando por los factores de riesgo no mostró diferencias estadísticamente significativas en la distribución de los genotipos (Tabla 37).

Tabla 37: Distribución de los genotipos del polimorfismo (rs 25487) del gen XRCC1 en mayores de 55 años con cataratas y mayores de 55 años sin cataratas según el modelo de regresión ajustado por los factores de riesgo HTA, tabaco y alcohol.

XRCC1 (rs 25487)

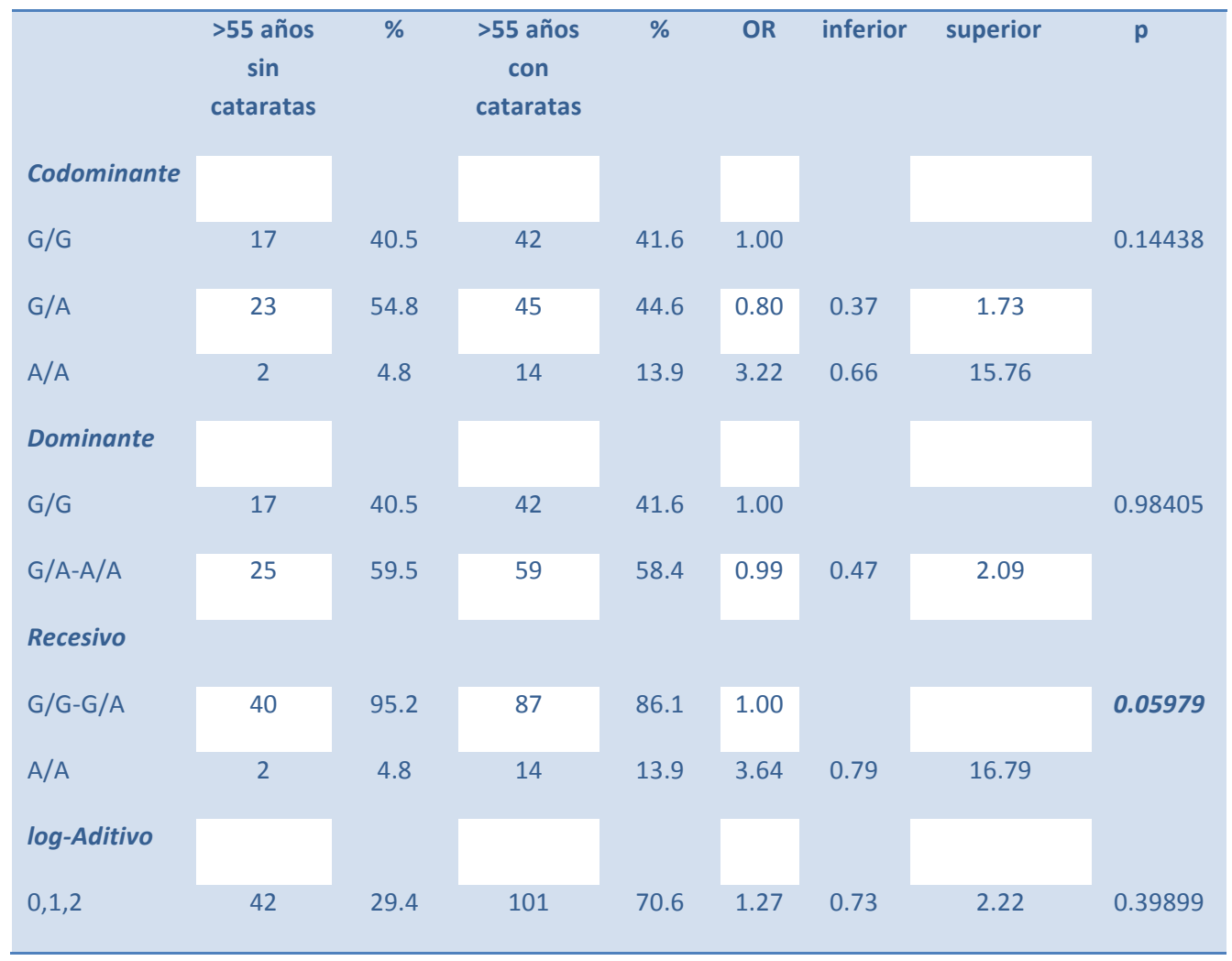

Ajustado por los factores de riesgo HTA, tabaco y alcohol. 


\section{5.- ESTUDIO DEL GEN p53}

Estudiamos un SNP localizado en el exón 4 del gen p53, el (rs1042522), que consiste en el cambio de una citosina $(C)$ por una guanina $(G)(c .215 C>G)$ y que produce un cambio de Prolina (Pro) por Argina (Arg) en el codón 72 de la proteína.

La comparación de la distribución de genotipos y alelos de este polimorfismo entre los sujetos con cataratas preseniles y el grupo de mayores de 55 años con cataratas mostró que no existen diferencias significativas en la distribución genotípica entre ambos grupos. En la tabla 38 se observa una mayor frecuencia del genotipo $\mathrm{CC}$ en el grupo de menores de 55 años con cataratas en el modelo de herencia recesivo; ( $p=0,03082$; OR 1,02-15,97). En el resto de grupos no se hallaron diferencias estadísticamente significativas al agrupar por alelos.

Tabla 38: Distribución de los genotipos del polimorfismo (rs 1042522) del gen p53 en menores de 55 años con cataratas y mayores de 55 años con cataratas.

P53 (rs 1042522)

\begin{tabular}{|c|c|c|c|c|c|c|c|c|}
\hline & $\begin{array}{l}>55 \text { años } \\
\text { con } \\
\text { cataratas }\end{array}$ & $\%$ & $\begin{array}{c}<55 \text { años } \\
\text { con } \\
\text { cataratas }\end{array}$ & $\%$ & OR & inferior & superior & $p$ \\
\hline \multicolumn{9}{|c|}{ Codominante } \\
\hline G/G & 57 & 56.4 & 41 & 56.9 & 1.00 & & & 0.07319 \\
\hline $\mathrm{G} / \mathrm{C}$ & 41 & 40.6 & 23 & 31.9 & 0.78 & 0.41 & 1.49 & \\
\hline $\mathrm{C} / \mathrm{C}$ & 3 & 3.0 & 8 & 11.1 & 3.71 & 0.93 & 14.83 & \\
\hline \multicolumn{9}{|l|}{ Dominante } \\
\hline $\mathrm{G} / \mathrm{G}$ & 57 & 56.4 & 41 & 56.9 & 1.00 & & & 0.94692 \\
\hline $\mathrm{G} / \mathrm{C}-\mathrm{C} / \mathrm{C}$ & 44 & 43.6 & 31 & 43.1 & 0.98 & 0.53 & 1.80 & \\
\hline \multicolumn{9}{|l|}{ Recesivo } \\
\hline G/G-G/C & 98 & 97.0 & 64 & 88.9 & 1.00 & & & 0.03082 \\
\hline $\mathrm{c} / \mathrm{C}$ & 3 & 3.0 & 8 & 11.1 & 4.08 & 1.04 & 15.97 & \\
\hline \multicolumn{9}{|l|}{ log-Aditivo } \\
\hline $0,1,2$ & 101 & 58.4 & 72 & 41.6 & 1.22 & 0.75 & 2.00 & 0.42135 \\
\hline
\end{tabular}


Así mismo, realizamos el análisis según el modelo de regresión ajustando por los factores de riesgo HTA, tabaco y alcohol; y dicha diferencia, aunque se pierde, roza la significación estadística $(p=0,05614)$ (Tabla 39).

Tabla 39: Distribución de los genotipos del polimorfismo (rs 1042522) del gen p53 en menores de 55 años con cataratas y mayores de 55 años con cataratas según el modelo de regresión ajustado por los factores de riesgo HTA, tabaco y alcohol.

P53 (rs 1042522)

\begin{tabular}{|c|c|c|c|c|c|c|c|c|}
\hline & $\begin{array}{c}>55 \text { años } \\
\text { con } \\
\text { cataratas }\end{array}$ & $\%$ & $\begin{array}{c}<55 \text { años } \\
\text { con } \\
\text { cataratas }\end{array}$ & $\%$ & OR & inferior & superior & $p$ \\
\hline \multicolumn{9}{|c|}{ Codominante } \\
\hline $\mathrm{G} / \mathrm{G}$ & 57 & 56.4 & 41 & 56.9 & 1.00 & & & 0.14116 \\
\hline $\mathrm{G} / \mathrm{C}$ & 41 & 40.6 & 23 & 31.9 & 0.81 & 0.37 & 1.77 & \\
\hline $\mathrm{C} / \mathrm{C}$ & 3 & 3.0 & 8 & 11.1 & 4.55 & 0.80 & 25.86 & \\
\hline \multicolumn{9}{|l|}{ Dominante } \\
\hline $\mathrm{G} / \mathrm{G}$ & 57 & 56.4 & 41 & 56.9 & 1.00 & & & 0.95907 \\
\hline $\mathrm{G} / \mathrm{C}-\mathrm{C} / \mathrm{C}$ & 44 & 43.6 & 31 & 43.1 & 1.02 & 0.49 & 2.13 & \\
\hline \multicolumn{9}{|l|}{ Recesivo } \\
\hline G/G-G/C & 98 & 97.0 & 64 & 88.9 & 1.00 & & & 0.05614 \\
\hline $\mathrm{C} / \mathrm{C}$ & 3 & 3.0 & 8 & 11.1 & 4.93 & 0.89 & 27.37 & \\
\hline \multicolumn{9}{|l|}{ log-Aditivo } \\
\hline $0,1,2$ & 60 & 59.4 & 49 & 68.1 & 1.00 & & & 0.39048 \\
\hline
\end{tabular}

Ajustado por los factores de riesgo HTA, tabaco y alcohol. 
La comparación de la distribución de los genotipos y alelos entre los pacientes con cataratas preseniles y el grupo de mayores de 55 años sin cataratas no mostró diferencias significativas en la distribución genotípica entre ambos grupos (Tabla 40).

Tabla 40: Distribución de los genotipos del polimorfismo (rs 1042522) del gen p53 en menores de 55 años con cataratas y mayores de 55 años sin cataratas.

P53 (rs 1042522)

\begin{tabular}{|c|c|c|c|c|c|c|c|c|}
\hline & $\begin{array}{l}>55 \text { años } \\
\quad \sin \\
\text { cataratas }\end{array}$ & $\%$ & $\begin{array}{c}<55 \text { años } \\
\text { con } \\
\text { cataratas }\end{array}$ & $\%$ & OR & inferior & superior & $p$ \\
\hline Codominante & 20 & 47.6 & 41 & 56.9 & 1.00 & & & 0.5062 \\
\hline G/G & 18 & 42.9 & 23 & 31.9 & 0.62 & 0.28 & 1.41 & \\
\hline $\mathrm{G} / \mathrm{C}$ & 4 & 9.5 & 8 & 11.1 & 0.98 & 0.26 & 3.63 & \\
\hline \multicolumn{9}{|l|}{$\mathrm{C} / \mathrm{C}$} \\
\hline Dominante & 20 & 47.6 & 41 & 56.9 & 1.00 & & & 0.3357 \\
\hline G/G & 22 & 52.4 & 31 & 43.1 & 0.69 & 0.32 & 1.48 & \\
\hline \multicolumn{9}{|l|}{$\mathrm{G} / \mathrm{C}-\mathrm{C} / \mathrm{C}$} \\
\hline Recesivo & 38 & 90.5 & 64 & 88.9 & 1.00 & & & 0.7886 \\
\hline G/G-G/C & 4 & 9.5 & 8 & 11.1 & 1.19 & 0.33 & 4.21 & \\
\hline \multicolumn{9}{|l|}{$\mathrm{C} / \mathrm{C}$} \\
\hline log-Aditivo & 42 & 36.8 & 72 & 63.2 & 0.85 & 0.48 & 1.48 & 0.5562 \\
\hline $0,1,2$ & & & & & & & & \\
\hline
\end{tabular}


El análisis según el modelo de regresión ajustando por los factores de riesgo HTA, tabaco y alcohol; tampoco encontramos diferencias estadísticamente significativas en la distribución de los genotipos en la mayoría de los grupos de pacientes menores de 55 años con cataratas y mayores de 55 años sin cataratas (Tabla 41).

Tabla 41: Distribución de los genotipos del polimorfismo (rs 1042522) del gen p53 en menores de 55 años con cataratas y mayores de 55 años sin cataratas según el modelo de regresión ajustado por los factores de riesgo HTA, tabaco y alcohol.

P53 (rs 1042522)

\begin{tabular}{|c|c|c|c|c|c|c|c|c|}
\hline & $\begin{array}{l}>55 \text { años sin } \\
\text { cataratas }\end{array}$ & $\%$ & $\begin{array}{c}<55 \text { años con } \\
\text { cataratas }\end{array}$ & $\%$ & OR & inferior & superior & $p$ \\
\hline \multicolumn{9}{|c|}{ Codominante } \\
\hline G/G & 20 & 47.6 & 41 & 56.9 & 1.00 & & & 0.5194 \\
\hline $\mathrm{G} / \mathrm{C}$ & 18 & 42.9 & 23 & 31.9 & 0.55 & 0.19 & 1.57 & \\
\hline $\mathrm{C} / \mathrm{C}$ & 4 & 9.5 & 8 & 11.1 & 0.66 & 0.11 & 4.11 & \\
\hline \multicolumn{9}{|l|}{ Dominante } \\
\hline G/G & 20 & 47.6 & 41 & 56.9 & 1.00 & & & 0.2587 \\
\hline $\mathrm{G} / \mathrm{C}-\mathrm{C} / \mathrm{C}$ & 22 & 52.4 & 31 & 43.1 & 0.57 & 0.21 & 1.52 & \\
\hline \multicolumn{9}{|l|}{ Recesivo } \\
\hline $\mathrm{G} / \mathrm{G}-\mathrm{G} / \mathrm{C}$ & 38 & 90.5 & 64 & 88.9 & 1.00 & & & 0.8422 \\
\hline $\mathrm{C} / \mathrm{C}$ & 4 & 9.5 & 8 & 11.1 & 0.83 & 0.14 & 4.97 & \\
\hline \multicolumn{9}{|l|}{ log-Aditivo } \\
\hline $0,1,2$ & 42 & 36.8 & 72 & 63.2 & 0.69 & 0.32 & 1.48 & 0.3362 \\
\hline
\end{tabular}

Ajustado por los factores de riesgo HTA, tabaco y alcohol. 
Cuando comparamos la distribución de los genotipos del polimorfismo entre los mayores de 55 años que presentan catarata y los que no la presentan no encontramos diferencias significativas. Tampoco encontramos diferencias al agrupar a los pacientes por alelos (Tabla 42).

Tabla 42: Distribución de los genotipos del polimorfismo (rs 1042522) del gen p53 en mayores de 55 años con cataratas y mayores de 55 años sin cataratas.

P53 (rs 1042522)

\begin{tabular}{|c|c|c|c|c|c|c|c|c|}
\hline & $\begin{array}{c}>55 \text { años } \sin \\
\text { cataratas }\end{array}$ & $\%$ & $\begin{array}{c}>55 \text { años con } \\
\text { catarata }\end{array}$ & $\%$ & OR & inferior & superior & $p$ \\
\hline \multicolumn{9}{|c|}{ Codominante } \\
\hline G/G & 20 & 47.6 & 57 & 56.4 & 1.00 & & & 0.2463 \\
\hline $\mathrm{G} / \mathrm{C}$ & 18 & 42.9 & 41 & 40.6 & 0.80 & 0.38 & 1.70 & \\
\hline $\mathrm{C} / \mathrm{C}$ & 4 & 9.5 & 3 & 3.0 & 0.26 & 0.05 & 1.28 & \\
\hline \multicolumn{9}{|l|}{ Dominante } \\
\hline G/G & 20 & 47.6 & 57 & 56.4 & 1.00 & & & 0.3359 \\
\hline $\mathrm{G} / \mathrm{C}-\mathrm{C} / \mathrm{C}$ & 22 & 52.4 & 44 & 43.6 & 0.70 & 0.34 & 1.44 & \\
\hline \multicolumn{9}{|l|}{ Recesivo } \\
\hline G/G-G/C & 38 & 90.5 & 98 & 97.0 & 1.00 & & & 0.1166 \\
\hline $\mathrm{C} / \mathrm{C}$ & 4 & 9.5 & 3 & 3.0 & 0.29 & 0.06 & 1.36 & \\
\hline \multicolumn{9}{|l|}{ log-Aditivo } \\
\hline $0,1,2$ & 42 & 29.4 & 101 & 70.6 & 0.65 & 0.36 & 1.18 & 0.1593 \\
\hline
\end{tabular}


En estos grupos también realizamos el análisis según el modelo de regresión ajustando por los factores de riesgo y no observamos diferencias estadísticamente significativas en la distribución de los genotipos (Tabla 43).

Tabla 43: Distribución de los genotipos del polimorfismo (rs 1042522) del gen p53 en mayores de 55 años con cataratas y mayores de 55 años sin cataratas según el modelo de regresión ajustado por los factores de riesgo HTA, tabaco y alcohol.

P53 (rs 1042522)

\begin{tabular}{|c|c|c|c|c|c|c|c|c|}
\hline & $\begin{array}{l}>55 \text { años } \sin \\
\text { cataratas }\end{array}$ & $\%$ & $\begin{array}{c}>55 \text { años con } \\
\text { cataratas }\end{array}$ & $\%$ & OR & inferior & superior & p \\
\hline \multicolumn{9}{|c|}{ Codominante } \\
\hline G/G & 20 & 47.6 & 57 & 56.4 & 1.00 & & & 0.3071 \\
\hline $\mathrm{G} / \mathrm{C}$ & 18 & 42.9 & 41 & 40.6 & 0.81 & 0.38 & 1.73 & \\
\hline$C / C$ & 4 & 9.5 & 3 & 3.0 & 0.29 & 0.06 & 1.43 & \\
\hline \multicolumn{9}{|l|}{ Dominante } \\
\hline $\mathrm{G} / \mathrm{G}$ & 20 & 47.6 & 57 & 56.4 & 1.00 & & & 0.3656 \\
\hline $\mathrm{G} / \mathrm{C}-\mathrm{C} / \mathrm{C}$ & 22 & 52.4 & 44 & 43.6 & 0.71 & 0.34 & 1.48 & \\
\hline \multicolumn{9}{|l|}{ Recesivo } \\
\hline G/G-G/C & 38 & 90.5 & 98 & 97.0 & 1.00 & & & 0.1516 \\
\hline$C / C$ & 4 & 9.5 & 3 & 3.0 & 0.32 & 0.07 & 1.52 & \\
\hline \multicolumn{9}{|l|}{ log-Aditivo } \\
\hline $0,1,2$ & 42 & 29.4 & 101 & 70.6 & 0.67 & 0.36 & 1.22 & 0.1904 \\
\hline
\end{tabular}

Ajustado por los factores de riesgo HTA, tabaco y alcohol. 


Discusión 



\section{1.- DISCUSIÓN}

La catarata es una de las principales causas de ceguera tratable en el mundo considerándose una patología altamente invalidante ${ }^{(1-3)}$. Esto es especialmente importante en pacientes jóvenes a los que afecta no solo en su vida diaria sino que puede impedirles realizar su actividad laboral.

Hasta el momento no existe ningún estudio que relacione la aparición de cataratas en pacientes jóvenes con polimorfismos genéticos que aumenten la predisposición a padecerla, por eso nos pareció interesante estudiar la asociación entre ciertos polimorfismos y la aparición de cataratas en edades tempranas.

Para ello, obtuvimos de manera secuencial muestras de la sangre periférica de los pacientes menores de 55 años intervenidos de cataratas entre el 1 de enero de 2007 y el 31 de diciembre de 2012 en el Hospital Clínico Universitario de Salamanca, excluyendo aquellos enfermos con cataratas secundarias a factores de riesgo conocidos. Establecimos dos grupos con los que realizar el estudio comparativo, pacientes mayores de 55 años con cataratas y aquellos mayores de 55 años sin cataratas.

Al comparar el grupo de pacientes menores de 55 años con cataratas con los otros dos grupos encontramos que tanto en el grupo de pacientes menores de 55 años como en el de mayores de 55 años con cataratas predominaba el género masculino, mientras que en el grupo de sujetos mayores de 55 años sin cataratas predominaba el género femenino (tabla 6). En nuestro caso, hallamos una mayor frecuencia de cataratas en el género masculino que en el femenino, aunque algunos estudios han encontrado una mayor prevalencia en mujeres respecto a hombres ${ }^{(63-64)}$. Autores como Congdon o Noran ${ }^{(224-225)}$ y colaboradores aseguran que la toma de terapia hormonal sustitutiva disminuía la incidencia de cataratas en mujeres, factor que no tuvimos en cuenta en nuestro estudio, pero podría explicar la menor incidencia en mujeres. 
-La EDAD es la principal causa de formación de cataratas, de ahí que su aparición sea más frecuente en la población de mayor edad $(4,27,34,37,63)$.

Los estudios de Michael R y colaboradores ${ }^{(37)}$ describieron que los principales efectos que la edad produce sobre el cristalino son un aumento de la dispersión de la luz por la formación de agregados proteicos insolubles, una pérdida de elasticidad cristaliniana y alteraciones en las proteínas cristalinas (cambios post-traduccionales, cambios conformacionales, pérdida de la actividad de chaperonas y de la actividad antioxidante). Todos estos cambios justifican que la aparición de cataratas sea una patología altamente asociada al envejecimiento ${ }^{(63)}$.

En este estudio se plantea la posibilidad de que ciertas variantes genéticas en genes reparadores del ADN predispongan a los sujetos a un mayor daño del ADN y al envejecimiento prematuro y, por tanto, a sufrir cataratas de forma prematura. De ahí que hayamos separado a los sujetos de estudio en tres grupos según su edad y según la presencia o no de cataratas; menores de 55 años con cataratas, mayores de 55 años con y sin cataratas; que de jóvenes no presentaron cataratas preseniles.

-Existen estudios que han analizado la repercusión del TABACO y ALCOHOL en el desarrollo de cataratas ${ }^{(80-86)}$.

De todos ellos, el realizado en Maryland (81) por West y colaboradores, el Beaver Dam Eye Study realizado en Estados Unidos por Klein y colaboradores ${ }^{(82)}$ o el Andrha Pradesh ${ }^{\left({ }^{(3)}\right.}$ de la India realizado por Krishnaiah y colaboradores mostraron cierta asociación entre el desarrollo de cataratas y el tabaco, mostrando este último cierta relación dosis dependiente.

Respecto al consumo de alcohol, el Beaver Dam Eye Study mostró su asociación con la formación de cualquier tipo de catarata. ${ }^{\left({ }^{86}\right)}$ 
Al realizar la comparación de la distribución de los factores de riesgo tabaco y alcohol en los diferentes grupos de estudio observamos una fuerte asociación de manera que el grupo de pacientes jóvenes con cataratas presentaba un mayor consumo de tabaco y de alcohol que en los grupos de mayor edad (Tablas 10 y 11). Cuando comparamos la distribución de los factores de riesgo entre los sujetos mayores de 55 años con cataratas y los mayores de 55 años sin catarata, observamos que no existían diferencias estadísticamente significativas en el hábito tabáquico. Sin embargo, existía un mayor consumo de alcohol por parte de los sujetos mayores de 55 años con cataratas, lo que sugiere que el consumo de alcohol puede predisponer a su aparición (Tabla 12).

-La presencia de DIABETES MELLITUS (DM) supone una mayor incidencia y progresión de la catarata en los enfermos que la padecen probablemente debido a la alteración del enzima Aldosa Reductasa que produce el acúmulo de sorbitol en estos enfermos, lo cual induce a una mayor apoptosis y una degeneración hidrópica de las células del cristalino ${ }^{(87-89,91-97) .}$

No obstante, al realizar la comparación de la distribución del factor de riesgo DM entre todos los grupos de estudio de nuestro trabajo no encontramos ninguna asociación estadísticamente significativa (Tablas 10, 11 y 12).

-Varios estudios han tratado de relacionar la presencia de HTA y el desarrollo de cataratas, sin embargo sus mecanismos son desconocidos y no hay un consenso entre ellos.

El Barbados Eye Study ${ }^{(100)}$, realizado por Leske y colaboradores en pacientes de raza negra encontró una relación entre la hipertensión y el desarrollo de opacidad cortical; sin embargo, el Beaver Dam Eye Study ${ }^{(102)}$ realizado en caucásicos americanos, no relacionó la HTA con la catarata. 
Otros estudios realizados en la población caucásica americana que sí encontraron relación entre hipertensión y cataratas fueron el Allen Park Michigan Veterans Administration Medical Center ${ }^{(103)}$, que relacionó la hipertensión arterial con un aumento del riesgo de opacificación capsular posterior; y el Physicians Health Study ${ }^{(45,105)}$ que observó una relación entre la catarata y la presión arterial sistólica aunque no con la presión arterial diastólica ni con la hipertensión.

En nuestro estudio, encontramos una mayor frecuencia, estadísticamente significativa, de la HTA en el grupo de sujetos mayores de 55 años con cataratas que en el grupo de pacientes con cataratas preseniles (Tabla 10); sin embargo, los niveles de HTA eran similares a los del grupo de mayores de 55 años sin cataratas (Tablas 11). En los grupos de pacientes mayores tampoco se encontraron diferencias en los niveles de HTA (Tabla 12). Estos resultados se justifican ya que la HTA es una enfermedad que se presenta con mayor frecuencia en personas de edad avanzada.

-Una de las teorías más recurrentes en la literatura es la relación de la LUZ ULTRAVIOLETA (UV-R) y la RADIACIÓN (infrarroja o rayos X...) con la aparición de cataratas ${ }^{(54-56,110)}$, especialmente el subtipo cortical (107).

Los estudios de Kin y colaboradores ${ }^{(108)}$ describen los diferentes mecanismos que inducen a la apoptosis de las células del cristalino tras su exposición a la luz UV-A.

Jiang y colaboradores estudiaron, en la población china, la relación entre la catarata senil y alteraciones en un grupo de genes reparadores del ADN y hallaron asociación con HSF4 y WRN y el desarrollo de cataratas. ${ }^{(226)}$ El grupo de Su y colaboradores también ha estudiado la relación entre la formación de cataratas (y los diferentes subtipos de cataratas) y dieciocho polimorfismos (SNPs) en los genes reparadores del ADN BLM, WRN, ERCC6 y OGGI en la población China; determinando que podía haber una relación entre los distintos subtipos de cataratas asociadas a la edad y los polimorfismos del gen WRN (227). 
En nuestro trabajo hemos incluidos dos grupos de genes reparadores de ADN, los que reparan el ADN mediante la excisión de nucleótidos (NER) como ERCC1, ERCC2 o XPC; y XRCC1, un gen del grupo de reparación del ADN mediante la excisión de bases (BER). Diderich y colaboradores y el grupo liderado por Andressoo realizaron una revisión en la que estudiaban la asociación entre alteraciones en los mecanismos de reparación del ADN por excisión de nucleótidos (NER) y el envejecimiento prematuro ${ }^{(228,229)}$.

-El excision repair cross-complementing rodent repair deficiency grupo 1 (ERCC1) se encuentra localizado en el brazo largo del cromosoma 19 (19q13.32). Codifica la proteína reparadora del ADN ERCC1, la cual se une a la endonucleasa XPF formando un heterodímero que cataliza la incisión en $5^{\prime}$ de la lesión del ADN (156-158).

Los estudios de Luo y de Gregg y colaboradores, entre otros, han descrito el papel de este gen en la carcinogénesis ${ }^{(167,190)}$. Así mismo se ha descrito la asociación de ERCC1 con el síndrome de Cockayne tipo II, el cual se asocia, entre otros síntomas, a atrofia óptica y la formación de cataratas ${ }^{(230)}$.

En el polimorfismo estudiado por nosotros ( $r$ 11615/c.354 A>G) que produce un cambio de una adenina $(A)$ por una guanina $(G)$ en el nucleótido, no encontramos diferencias significativas en la distribución de los genotipos del polimorfismo entre el grupo de pacientes con cataratas preseniles y el grupo de pacientes con cataratas seniles, ni siquiera al realizar la agrupación por alelos (Tabla 14). Tampoco se encontraron diferencias estadísticamente significativas en la distribución de los genotipos al comparar el grupo de pacientes con cataratas preseniles y el grupo de mayores de 55 años sin cataratas, ni al realizar la comparación agrupando por alelos (Tabla 16). Al comparar los grupos de controles de pacientes con cataratas seniles y pacientes mayores de 55 años sin cataratas, tanto de manera individual como agrupando por alelos, tampoco encontramos diferencias estadísticamente significativas (Tabla 18). 
Debido a que no hay estudios en la literatura que relacionen los polimorfismos estudiados y el desarrollo de cataratas en edades tempranas, los resultados obtenidos necesitan ser confirmados. Por ello, decidimos realizar el análisis según el modelo de regresión ajustando por los diferentes factores de riesgo en los que habíamos encontrado diferencias estadísticamente significativas en todos los grupos; no encontrando diferencias estadísticamente significativas en la distribución de los genotipos (Tablas 15, 17 y 19).

-El gen XPD, también denominado ERCC2, es un gen localizado también en el brazo largo del cromosoma 19 (19q13.32).

Su papel en la reparación del ADN tiene especial importancia durante el proceso de transcripción. La reparación del ADN por excisión de nucleótidos (NER) debe actuar de forma simultánea la misma; un complejo de la polimerasa de ARN se sitúa frente a la lesión y es desplazado para dar acceso a las enzimas de reparación. El gen ERCC2 codifica una helicasa, que forma parte del factor de transcripción TF IIH ${ }^{(142,143,168)}$ esencial para la NER ${ }^{(169)}$ que se encarga del procesamiento y verificación del ADN lesionado.

Los estudios llevados a cabo por Ünal y colaboradores demuestran que el genotipo de ERCC2 XPD-751 Gln/ Gln presenta diferencias estadísticamente significativas entre el grupo con cataratas (12\%) y el grupo control (20\%); diferencias aún mayores entre el grupo con cataratas corticales (4\%) y el grupo control (20\%). ${ }^{(171)}$ Sin embargo, los estudios llevados a cabo por Zhang y colaboradores no encontraron asociación entre el polimorfismo estudiado de ERCC2 (XPD Lys751Gln) y la aparición de cataratas. ${ }^{(231)}$ 
Nosotros hemos estudiado un SNP (rs 13181/ c.2179 T>G) del gen ERCC2 que produce un cambio de una guanina $(G)$ por una timina $(T)$ en el nucleótido y no encontramos diferencias significativas en la distribución de los genotipos del polimorfismo rs 13181 entre el grupo de pacientes con cataratas preseniles y el grupo con cataratas seniles, ni siquiera al realizar la agrupación por alelos (Tabla 20). Tampoco se encontraron diferencias estadísticamente significativas en la distribución de los genotipos al comparar el grupo de pacientes con cataratas preseniles y el grupo de mayores de 55 años sin cataratas, ni al realizar la comparación agrupando por alelos (Tabla 22). Al comparar los grupos de sujetos mayores de 55 años con cataratas y los mayores 55 años sin cataratas, tanto de manera individual como agrupando por alelos, tampoco encontramos diferencias estadísticamente significativas (Tabla 24).

Tras realizar el análisis según el modelo de regresión ajustando por los diferentes factores de riesgo en todos los grupos, tampoco encontramos diferencias estadísticamente significativas en la distribución de los genotipos (Tablas 21, 23 y 25). En nuestro estudio no coincidimos con los resultados obtenidos por el grupo de Ünal ${ }^{(171)}$, pero corroboramos los resultados obtenidos por Zhang ${ }^{(231)}$ ya que, en nuestra población, no encontramos asociación entre este polimorfismo y el desarrollo de cataratas.

-El Gen XPC está localizado en el brazo corto del cromosoma 3 (3p25). Codifica la proteína homónima XPC cuya función es primordial en los primeros pasos de reconocimiento del daño del ADN en el proceso de reparación mediante excisión de nucleótidos (NER). (174-175)

Durante la reparación del ADN, en un primer paso de reconocimiento del daño en el ADN interviene la proteína XPC, al igual que XPA y un complejo de tres proteínas conocidas colectivamente como proteína de replicación A (RPA).

Al reconocerse el ADN dañado, se produce el cambio de conformación en la proteína XPC, de forma que los restos aromáticos de sus aminoácidos se unen a nucleótidos sin emparejar en frente de la lesión, hecho fundamental para la formación de complejos proteicos abiertos y para la reparación de los mismos. ${ }^{(178)}$ 
Estudiamos un SNP (rs $2228000 /$ c. 1385 G>A) del gen en el que se produce un cambio de una adenina $(A)$ por una guanina $(G)$, no encontramos diferencias significativas en la distribución de los genotipos del polimorfismo entre el grupo de pacientes con cataratas preseniles y el grupo con cataratas seniles, ni siquiera al realizar la agrupación por alelos (Tabla 26). Tampoco se encontraron diferencias estadísticamente significativas en la distribución de los genotipos al comparar el grupo de pacientes con cataratas preseniles y el grupo de mayores de 55 años sin cataratas, ni al realizar la comparación agrupando por alelos (Tabla 28). Al comparar los grupos de sujetos mayores de 55 años con cataratas y mayores de 55 años sin cataratas, tanto de manera individual como agrupando por alelos, tampoco encontramos diferencias estadísticamente significativas (Tabla 30).

Decidimos realizar el análisis según el modelo de regresión ajustando por los diferentes factores de riesgo en todos los grupos y tampoco encontramos diferencias estadísticamente significativas en la distribución de los genotipos como muestran las tablas 27, 29 y 31.

Estudiamos también un gen cuyo mecanismo de reparación del ADN es mediante excisión de bases (BER), el XRCC1, mecanismo del que existen dos posibles vías: Long-patch: Cuando se afectan varios nucleótidos; y Short-patch la más frecuente y en la que sólo se implica uno. En esta vía actúa la polimerasa $\beta$ la cual, entre otras funciones, interactúa con el complejo formado por XRCC1 y ADN ligasa III.

-El gen XRCC1 (X-ray repair cross complementation group 1), tiene un tamaño de 33kb y se localiza en el brazo largo del cromosoma 19 (19q13.2-13.3).

Este gen codifica una proteína que resulta fundamental en la reparación del ADN por Escisión de Bases $(B E R)^{(184)}$. Interactúa con múltiples glicosilasas y forma complejos con la mayoría de las proteínas que intervienen en este proceso como APE1 ${ }^{(232)}$, POL $\beta$,

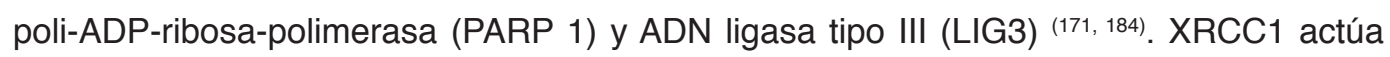
como proteína estabilizadora permitiendo la unión de la polimerasa y la ligasa al sitio de reparación, al tiempo que se une al ADN por su región amino-terminal ${ }^{(143)}$. 
Ladiges y colaboradores realizaron un metaanálisis en el que analizaban ciertos polimorfismos de XRCC1 y su asociación con enfermedades vinculadas a la edad o el cáncer. En él describieron la asociación de polimorfismos como Arg194Trp and Arg399Gln y el desarrollo de cáncer de pulmón, de mama o dermatológico; y concluyeron que mientras el polimorfismo ARG 194Trp es un factor protector para ciertos cánceres como el de pulmón, el SNPArg399Gln aumenta el riesgo de cáncer de pulmón y de mama. Así mismo describieron la relación entre XRCC1 y la arterioesclerosis. ${ }^{(144)}$

Otros estudios consultados como los de Luo y colaboradores estudiaron la asociación entre el desarrollo de cataratas seniles y polimorfismos en el codón 399 del gen XRCC1 estudiando su distribución en 180 pacientes con cataratas seniles y 174 pacientes sanos, observando que los grupos que presentaban al menos un alelo $A$, ya fuera con el genotipo $\mathrm{A} / \mathrm{A} \circ \mathrm{G} / \mathrm{A}$, presentaban un riesgo aumentado en 1,68 de desarrollar cataratas respecto a aquellos pacientes con el genotiopo $G / G$. ${ }^{(190)}$

Nosotros hemos estudiado un SNP ( $r$ s 25487 / c.1196 A>G) en el que se produce un cambio de una guanina $(G)$ por una adenina $(A)$. Este cambio, al transcribirse, supone una substitución de Arginina (Arg) por Glutamina (Gln) en el codón. Este polimorfismo c. $1196^{a}$ (p.GIn399Arg) se localiza en el dominio de unión BRCT 1 y determina un cambio en la conformación tridimensional de la proteína disminuyendo la capacidad de reparación del ADN. ${ }^{(233)}$ Estos cambios conformacionales en diversos sitios del dominio BRCT1 de la proteína XRCC1, incluyen la pérdida de las características estructurales secundarias, que pueden ser fundamentales para las interacciones proteína-proteína. Estos resultados apoyan la hipótesis de que este polimorfismo en XRCC1 podría afectar la capacidad de reparación del ADN mediante la alteración de la estructura del dominio BRCT1 y por lo tanto la capacidad de XRCC1 para coordinar reparación por excisión de nucleótidos $(\mathrm{BER})^{(234)}$. 
En nuestro trabajo, no encontramos diferencias significativas en la distribución de los genotipos del polimorfismo rs 25487 entre el grupo de pacientes con cataratas preseniles y el grupo de mayores de 55 años con cataratas, ni siquiera al realizar la agrupación por alelos (Tabla 32). Tampoco encontramos diferencias estadísticamente significativas en la distribución de los genotipos al comparar el grupo de pacientes con cataratas preseniles y el grupo de mayores de 55 años sin cataratas, ni al realizar la comparación agrupando por alelos (Tabla 34). Al comparar los grupos de individuos con cataratas seniles y los mayores de 55 años sin cataratas, tanto de manera individual como agrupando por alelos, tampoco encontramos diferencias estadísticamente significativas (Tabla 36).

Tras realizar el análisis según el modelo de regresión, ajustando por los diferentes factores de riesgo, en el grupo de pacientes con cataratas preseniles y el grupo de mayores de 55 años con cataratas y tampoco encontramos diferencias estadísticamente significativas en la distribución de los genotipos (Tabla 33).

Sin embargo, al realizar el análisis según el modelo de regresión ajustando por los factores de riesgo entre el grupo de pacientes con cataratas preseniles y el grupo de mayores de 55 años sin cataratas; encontramos diferencias fuertemente significativas en el modelo recesivo (agrupando por el alelo G), observando una mayor frecuencia, estadísticamente significativa, del genotipo A/A (Gln/GIn), en el grupo de pacientes con cataratas preseniles, lo que aumenta el riesgo de padecer cataratas preseniles unas 6,45 veces ( $p=$ 0,02951; OR 1,02-40,67) (Tabla 35).

Al realizar el análisis según el modelo de regresión ajustado por factores de riesgo entre los grupos de mayores de 55 años con cataratas y el de mayores de 55 años sin cataratas, no encontramos diferencias estadísticamente significativas en ninguno de los modelos de herencia; sin embargo, sí se observó una tendencia en el modelo de herencia recesivo $(p=0,05979)$ (Tabla 37). 
Estos resultados pueden justificarse ya que el polimorfismo estudiado modifica la función reparadora de la proteína BRCT1, produciendo una reparación defectuosa del ADN. Esto explicaría que las personas jóvenes portadoras de este genotipo tengan un mayor riesgo a desarrollar cataratas en edades tempranas.

Decidimos ampliar nuestra línea de estudio e incluir el polimorfismo (SNP) del codón 72 del gen p53 ya que varios estudios consultados, como los de Truscott, y los de Ottonello y colaboradores, relacionaban el daño oxidativo con el aumento de apoptosis en las células epiteliales del cristalino, lo que conduce al desarrollo de cataratas. ${ }^{(4,235)}$

-El gen p53 o tp53 se encuentra en el brazo corto del cromosoma 17 (17p13) y codifica un factor de transcripción nuclear.

Se ha asociado la actividad de la proteína p53 al complejo de reparación basal del ADN TFIIH ya que modula la actividad de su ADN helicasa. Wang y colaboradores estudiaron si las helicasas XPB y la XPD eran mediadoras del proceso de apoptosis. ${ }^{(236)}$

En el exón 4 del gen p53, existe un polimorfismo por cambio de un solo nucleótido, SNP, ampliamente estudiado (rs1042522 / c.215 C>G), consistente en el cambio de una citosina $(C)$ por una guanina $(G)$ en el nucleótido. Esto a su vez produce un cambio de Prolina (Pro) por Argina (Arg) en el codón 72 de la proteína.

Este polimorfismo p.Arg72Pro se encuentra situado en la región rica de residuos de prolina del gen p53, localizada entre el dominio de transactivación y el dominio de unión al DNA, que participa en la inducción de la apoptosis ${ }^{(237)}$. El alelo arginina presenta una mayor capacidad de inducir apoptosis debido, tanto a la activación de la transcripción de genes apoptóticos, como a su mayor capacidad de traslocarse a la mitocondria induciendo apoptosis por mecanismos independientes de su actividad transcripcional. Por el contrario, el alelo prolina presenta menor capacidad apoptótica pero induce de manera más eficiente la parada del ciclo celular en la fase G1 en respuesta a daños en el DNA (200, 238-240). 
A nivel ocular, recientes estudios de Pastor y colaboradores, se han centrado en la posible asociación entre polimorfismos del codón 72 de p53 y el desarrollo de proliferación vítreo retiniana (PVR) en población con desprendimiento de retina, demostrando que existe un riesgo aumentado de desarrollar PVR en los pacientes que presentaban el alelo pro-apoptótico de dicho polimorfismo. ${ }^{(221)}$ Sun y colaboradores estudiaron la relación entre la radiación ultravioleta y la actividad apoptótica en las células del cristalino. Sometieron a una población de ratas a radiaciones de $100 \mathrm{~mW} / \mathrm{m} 2$ durante quince minutos y estudiaron mediante inmunohistoquímica la actividad apoptótica en las células epiteliales del cristalino a la hora, a las 6 horas y a las 24 horas de haber sido expuestas a la radiación ultravioleta. Se observó que a las 6 y a las 24 horas existía mayor apoptosis de las células epiteliales del cristalino que en los grupos control y de una hora post radiación (241). Así mismo Tendler y colaboradores detectaron la presencia e incremento de la actividad apoptósica de la proteína p53 en el citoplasma de la células epiteliales corneales tras ser sometidas a radiación ultravioleta. ${ }^{(242)}$

Azizi y colaboradores realizaron un estudio comparativo entre las células endoteliales de pacientes con distrofia endotelial de Fuchs y células endoteliales normales, y observaron su susceptibilidad al daño por estrés oxidativo. Para ello utilizaron dos modelos in vitro expuestos a hidroperóxido de tert butil y observaron la actividad apoptótica usando citometría de flujo. Para diferenciar la proteína p53 utilizaron técnicas de inmunohistoquímica y Western-Blot, observando una mayor actividad apoptótica inducida por p53 en las células endoteliales con distrofia de Fuchs tras el daño oxidativo. (243)

Otros estudios, como el de Bhattacharya y colaboradores, detectaron que el incremento en la apoptosis de las células epiteliales retinianas con el envejecimiento se debe a la disrupción de la unión entre Mdm2 y la proteína p53. (244) 
En el campo del glaucoma p53 ha sido estudiado por numerosos autores. Wiggs y colaboradores estudiaron, en la población estadounidense, la asociación entre el polimorfismo del codón 72 y la parición de defectos campimétricos paracentrales en una población de pacientes con glaucoma primario de ángulo abierto; y detectaron una mayor frecuencia del genotipo Pro/Pro enesta población que en los sujetos con defectos campimétricos periféricos o que en el grupo control. ${ }^{(245)}$ Blanco Marchite y colaboradores llevaron a cabo un estudio en la población española que relacionaba WDR36 y dos polimorfismos del gen p53 con una mayor susceptibilidad a presentar glaucoma primario de ángulo abierto. Observaron que raras variantes de WDR36 y el codón 72 de p53 suponen un factor de riesgo moderado para desarrollar glaucoma primario de ángulo abierto. Así mismo, detectaron interacciones genéticas entre WDR36 y p53 que podrían condicionar a su aparición. (246)

Finalmente, a nivel cristaliniano Ji y colaboradores determinaron que p53 regula los genes

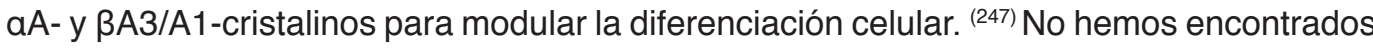
trabajos que relacionen alteraciones en la distribución del polimorfismo del codón 72 de p53 y la aparición de cataratas. Qin y colaboradores mostraron que cambios en el microARN-125b inhiben la apoptosis de las células epiteliales del cristalino a través de p53 lo que conduce a la aparición de cataratas seniles. (248)

En nuestro estudio, encontramos diferencias significativas al analizar el polimorfismo del codón 72 de p53 en el modelo de herencia recesivo, en el que se observó una mayor proporción de pacientes con catarata presenil portadores del genotipo homocigoto Pro/ Pro respecto al grupo de mayores de 55 años con cataratas, con un aumento del riesgo de padecer catarata presenil del 4,083 (Intervalo de confianza (IC) al 95\%: 1,044-15,970) (Tabla 38). No obstante, al ajustar por factores de riesgo, dicha diferencia rozaba la significación estadística ( $p=0,05614$; OR: 4,93; IC al 95\%: 0,89-27,87) (Tabla 39). La disminución de la actividad apoptótica podría derivar en un acúmulo de células con daño celular y la consecuente aparición de cataratas a una edad más temprana, justificando los resultados obtenidos en nuestra serie. 
Al realizar el estudio entre el grupo de pacientes con cataratas preseniles y mayores de 55 años sin cataratas no se observaron diferencias estadísticamente significativas (Tabla 40); y tampoco se obtuvieron diferencias al realizar el modelo de regresión ajustando por los factores de riesgo (Tabla 41).

Tampoco encontramos diferencias al comparar los grupos de mayores de 55 años con cataratas y mayores de 55 años sin cataratas (Tabla 42); ni al realizar el análisis según el modelo de regresión ajustado por los factores de riesgo (Tabla 43).

No resulta sorprendente el no haber hallado asociación entre los polimorfismos estudiados de los genes que se encargan de la reparación del ADN mediante la vía de excisión de nucleótidos (NER) y el desarrollo de cataratas preseniles ya que la función de estos genes consiste en reparar los daños ocasionados por radiaciones de tipo ionizante, como los rayos X. Por el contrario, XRCC1 pertenece a la vía BER implicada en la reparación del daño del ADN por la luz ultravioleta. Nosotros hemos estudiado el polimorfismo rs 25487 (c.1196 G>A/ p 399 Gln>Arg) que modifica la función reparadora de la proteína BRCT1, dando lugar a una reparación defectuosa del ADN. Esto explicaría que las personas jóvenes portadoras de este genotipo tengan un mayor riesgo a desarrollar cataratas en edades tempranas.

Por otra parte, en nuestro trabajo analizamos por primera vez la distribución genotípica del codón 72 de p53 implicado en la regulación de apoptosis y mostramos como los individuos portadores del alelo Pro, asociado con una menor apoptosis, tienen más riesgo de desarrollar cataratas en edades tempranas, probablemente porque las células cristalinianas dañadas, bien por la luz ultravioleta o bien por mecanismos oxidativos, tienen mayor resistencia a la apoptosis y se mantienen dañadas en el cristalino. 


\section{2.- LIMITACIONES DEL ESTUDIO}

- Aunque la diferencia interobservador para el diagnóstico de cataratas podría ser un problema para incluir a los pacientes en nuestro estudio, se trató de paliarlo utilizando como criterio quirúrgico una agudeza visual por debajo a 0,5. Así mismo, se empleó el sistema de clasificación LOCS III para determinar la presencia y grado de las cataratas en los pacientes estudiados.

- El tamaño de muestra no es suficientemente grande para algunos análisis, especialmente en el caso de los sujetos mayores de 55 años que no han desarrollado ningún tipo de cataratas. No obstante, es conocida la dificultad de encontrar sujetos de estas edades $\sin$ opacidades en el cristalino.

- Dadas las características intrínsecas a cualquier estudio que analice polimorfismos genéticos resulta difícil extrapolar a la población general los resultados obtenidos en la muestra seleccionada. 

Conclusiones 



\section{CONCLUSIONES}

\section{CON RESPECTO A LOS OBJETIVOS GENERALES}

Factores de riesgo como el consumo de tabaco y alcohol, así como la presencia de HTA están relacionados con una susceptibilidad a desarrollar cataratas preseniles.

Las variantes alélicas de los genes ERCC1, ERCC2 XPC no modifican el riesgo de padecer cataratas. Las variantes alélicas de p53 y XRCC1 están en relación con un aumento del riesgo de padecer cataratas preseniles.

\section{CON RESPECTO A LOS OBJETIVOS SECUNDARIOS:}

-El consumo de tabaco y alcohol, así como la presencia de HTA aumentan la susceptibilidad a desarrollar cataratas preseniles.

-Las variantes génicas del polimorfismo rs 11615 de ERCC1 no modifican la susceptibilidad para desarrollar cataratas preseniles en nuestra población.

-Las variantes génicas del polimorfismo rs 13181 del gen ERCC2 tampoco modifican la susceptibilidad para desarrollar cataratas preseniles en nuestra población.

-Las variantes génicas del polimorfismo rs 2228000 del gen XPC no modifican la susceptibilidad para desarrollar cataratas preseniles en nuestra población.

-Las variantes génicas del polimorfismo rs 25487 del gen XRCC1 no modifican la susceptibilidad para desarrollar cataratas preseniles en nuestra población. Sin embargo, al realizar el análisis ajustando por los factores de riesgo, el genotipo Gln/Gln del polimorfismo rs 25487 del gen XRCC1, se objetiva un aumento del riesgo de sufrir cataratas preseniles.

-En la población incluida en nuestro estudio, el riesgo de padecer cataratas preseniles se asocia con el genotipo Pro/Pro del polimorfismo del exón 72 de p53 y se acerca a la significación estadística al ajustar el análisis por los factores de riesgo. 

Bibliografía 



\section{BIBLIOGRAFÍA}

1.- Kupfer C. The conquest of cataract: a global challenge. Trans Ophthal Soc UK 1984; 104:1.

2.- Schwab L. Cataract blindness in developing nations. Int Ophthalmol Clin 1990; 30:16.

3.- Organization WH. Use of intraocular lenses in cataract surgery in developing countries. Bull World Health Org 1991; 69:657.

4.- Truscott RJW. Age-related nuclear cataract- Oxidation is the key. Experimental Eye Research 2005; 80: 709-725.

5.- A Armesto. La catarata a través de los siglos. Méd Oftalmól 2002; 15(1):1515-4785.

6.- Lozano-Alcázar J. La cirugía de catarata hasta 1748. Cir Ciruj 2001; 69:141-143.

7.- Jampel RS. The four eras in the evolution of cataract surgery. In: Kwitco ML and Kelman CD. Ed: The History of Modern Cataract. Kugler publication/ The Hague/ The Netherlands, 1998: pp17-33.

8.- Krwawicz. Intracapsular Extraction of intumescent cataract by application of low temperature. Br J Ophthalmol. 1961; 45(4): 279-283.

9.- Linebarger EJ, Hardten DR, Shak GK, Lindstrom RL. Phacoemulsification and modern cataract surgery. Surv Ophthalmol 1999; 44: 123-47.

10.- Choyce DD. In: Intraocular lenses and implants. Lewis and Co. Ltd, London HQ; 1964: 211-222.

11.- Kelman CD. Phacoemulsification and aspiration, a new technique of cataract removal. A preliminary report. Am J Ophthalmol 1967; 64:23-35.

12.- Kelman CD. The history and development of Phacoemulsification. Int Ophthalmol Clin 1994; 34:1-12.

13.- Powe NR, Schein OD, Geiser SC, Tielsch JM, Luthra R, Javitt J, Steinberg EP. Synthesis of the literature on visual acuity and complications following cataract extraction with intraocular lens implantation. Cataract Patient Outcome Research Team. Arch Ophthalmol 1994; 112: 239-252.

14.- Wong TY, Klein BEK, Klein R. Tomany SC, Lee KE. Refractive Errors and Incident Cataracts: The Beaver Dam Eye Study IOVS, June 2001; 42(7): 1449-1454. 
15.- Liesegang TJ, Skuta GL, Cantor LB. In: Fundamentos y principios de Oftalmología. American Academy of Ophthalmology. Barcelona: Elsevier España; 2008; p 73-76.

16.- Carreras Matas B. Consideraciones sobre la senilidad y biomorfosis del cristalino. Secretariado de publicaciones de la Universidad de Granada; 1980; 15.

17.- Tripathi RC, Thripati BJ. Lens morphology, aging and cataract. J Gerontol 1983; 38: 258-270.

18.- Lorente R; Anatomía del cristalino; In: Mendicute J et al; Facoemulsificación; Madrid: CF Comunicación; 1999: P 3-9

19.- Harding CV, Reddan JR, Unakar NJ, Bagchi M. The control of cell division in the ocular lens. Int Rev Cytol 1971; 31: 215-300.

20.- Reddy MA, Francis PJ, Berry V, Bhattacharya SS, Moore AT. Molecular genetic basis of inherited cataract and associated phenotypes. Surv Ophthalmol 2004; 49:300 -315.

21.- Graw J. Congenital hereditary cataracts. Int J Dev Biol 2004; 48:1031-1044.

22.- Francis PJ, Moore AT. Genetics of childhood cataract. Curr Opin Ophthalmol 2004; 15: $10-15$.

23.- Mutti DO, Zadnik K, Egashira S, Kish L. The effect of cycloplegia on measurement of the ocular components. Invest Ophthalmol Vis Sci, 1994; 35 (2): 515-527.

24.- Capítulo XI Patología Del Cristalino. Cataratas Inmaculada Garbín Fuentes y Gerardo Pérez Chica. Sociedad Española De Pediatría Extrahospitalaria y Atención Primaria (SEPEAP) En: http://www.sepeap.org/archivos/libros/OFTALMOLOGIA/Ar_1_8_44_ APR_8.pdf

25.- Datiles MB, Lasa MS, Podgor MJ, Hernandez-Galilea E, Magno BV. Measurement error in assessing the size of cortical cataracts from retroillumination photographs. Curr Eye Res. 1995 Jan;14(1):19-26.

26.- Harding, J. The normal lens. In: Harding J ed. Cataract Biochemistry, Epidemiology and Pharmacology. London: Chapman and Hall, London; 1991:1-70.

27.- Harding JJ. Physiology, biochemistry, pathogenesis and epidemiology of cataract. Current Opinion in Ophthalmology 1991; 2: 3-15. 
28.- Morales M. Protocolo de manejo de las cataratas en la edad pediátrica. Annals d’Oftalmologia 2007; 15 (4): 206-211.

29.- Lambert SR, Drack AV. Infantile cataracts. Surv Ophthalmol 1996; 40:427- 458.

30.- Lambert SR, Lynn MJ, Reeves R, Plager DA, Buckley EG, Wilson ME. Is there a latent period for the surgical treatment of children with dense bilateral congenital cataracts? J AAPOS 2006; 10 (1): 30-6.

31.- Vîrgolici B, Stoian I, Muscurel C, Mărăcine M, Moraru C, Dinu V. Plasma redox status and premature onset of senile cataract Rom J Intern Med 2007; 45 (1): 59-65.

32.- Praveen MR, Shah GD, Vasavada AR, Mehta PG, Gilbert C, Bhagat G. A study to explore the risk factors for the early onset of cataract in India. Eye (Lond) 2010; 24 (4): 686-694.

33.- Chiang CC, Lin CL, Peng CL, Sung FC, Tsai YY. Increased risk of cancer in patients with early-onset cataracts: a nationwide population-based study. Cancer Sci 2014; 105 (4): 431-436.

34.- Truscott RJW. Human cataract: the mechanisms responsible; light and butterfly eyes. The International Journal of Biochemistry \& Cell Biology 2003; 35 (11): 1500-1504.

35.- Vrensen, G. F. Early cortical lens opacities: a short overview. Acta Ophthalmol. 2009; 87: 602-610.

36.- Costello, M. J., Johnsen, S., Metlapally, S., Gilliland, K., Ramamurthy, B., Krishna, P., Balasubramanian, D. Ultrastructural analysis of damage to nuclear fiber cell membranes in advanced age-related cataracts from India. Exp. Eye Res 2008; 87 (2): 147-158.

37.- Michael R, Bron AJ. The ageing lens and cataract: a model of normal and pathological ageing. Phil. Trans. R. Soc. B 2011; 366: 1278-1292.

38.- Thylefors, B., Chylack Jr., L.T., Konyama, K., Sasaki, K., Sperduto, R., Taylor, H.R., West, S., Group, W.H.O.C.G. A simplified cataract grading system. Ophthalmic Epidemiol 2002; 9, 83-95.

39.- Marcantonio J, Duncan G. Aminoacid transport and protein synthesis in human normal and cataractous lenses. Curr Eye Res 1987; 6: 1299-1308. 
40.- Chylack LT, Wolfe JK, Singer DM, Leske C, Bullimore MA, Bailey IL, Friend J, McCarthy D, Shu-Yuh W. The Lens Opacities Classification System III. Arch Ophthalmol 1993; 111: 831-836.

41.- Chylack LT, Leske MC, McCarthy D, Khu PM, Kashiwagi T, Sperduto R. Lens Opacities Classification System II (LOCS II). Arch Ophthalmol 1989; 107 (7): 991-997.

42.- Leske MC, Wu SY, Hyman L, Sperduto R, Underwood B, Chylack LT, Milton RC, Srivastava S, Ansari N. Biochemical factors in the lens opacities. Case-control Study. The Lens Opacities Case-Control Study Group. Arch Ophthalmol 1995; 113 (9): 11131119.

43.- Maraini G, Pasquini P, Sperduto RD, Bonacini M, Carrieri MP, Corona R, Graziosi P, Tomba MC, Williams SL. The effect of cataract severity and morphology on the reliability of the Lens Opacities Classification System II (LOCS II). Invest Ophthalmol Vis Sci 1991; 32: 2400-2403.

44.- Gieser SC; Schein OD. Cataract epidemiology and world blindness. Current Opinion in Ophthalmology 1994; 5 (1):5-8.

45.- Sánchez-Jara Sánchez A. Nuevas aportaciones a la correlación clínico molecular de la catarata senil. [Tesis doctoral] Salamanca: Departamento de medicina, Unidad de medicina molecular. Facultad de medicina, Universidad de Salamanca; 2010.

46.- Age-Related Eye Disease Study Research Group. The age-related eye disease study (AREDS) system for classifying cataracts from photographs: AREDS report no.4. Am J Ophthalmol 2001; 131 (2): 167-175.

47.- Sparrow JM, Bron AJ, Brown NA, Ayliffe W, Hill AR. The Oxford Clinical Cataract Classification and Grading System. Int Ophthalmol 1986; 9(4): 207-225.

48.- Klein BE, Klein R Linton KL, Magli YL, Neider MW. Assessment of cataracts from photographs in the Beaver Dam Eye Study. Ophthalmology 1990; 97(11): 1428-1433.

49.- Datiles MB 3rd, Magno BV, Freidlin V. Study of nuclear cataract progression using the National Eye Institute Scheimpflug system. Br J Ophthalmol 1995; 79 (6): 527-534.

50.- Chew M, Pei-Chia Chiang P, Zheng Y, Lavanya R, Wu R, Saw S M, Wong T Y, Lamoureux E L. The Impact of Cataract, Cataract Types, and Cataract Grades on Vision-Specific Functioning Using Rasch Analysis. American Journal of Ophthalmology 2012; 154 (1): 29-38. 
51.- Pongo Águila L, Carrión R, Luna W, Silva JC, Limburg H. Ceguera por catarata en personas mayores de 50 años en una zona semirrural del norte del Perú. Rev Panam Salud Pública. 2005; 17(5/6):387-93.

52.- Thylefors B. The WHO Programme for the Prevention of Blindness and Cataract in Developing Countries. Doc Ophthalmol 1992; 81:339-344.

53.- Foster A, Johnson G. Blindness in the Developing World. Br J Ophthalmol 1993; 77 (7): 398-399.

54.- Taylor HR, West SK, Rosenthal FS, Muñoz B, Newland HS, Abbey H, Emmet EA. Effect of Ultraviolet Radiation on Cataract Formation. N Engl J Med 1988; 319 (22): 1429-1433.

55.- Bochow TW, West SK, Azar A, Muñoz B, Sommer A, Taylor HR. Ultraviolet Light Exposure and Risks of Posterior Subcapsular Cataracts. Arch Ophthalmol 1989; 107 (3): 369-372.

56.- Cruickshanks KJ, Klein BE, Klein R. Ultraviolet Light Exposure and Lens Opacities: The Beaver Dam Eye Study. Am J Public Health 1992; 82 (12): 1658-1662.

57.- Keith R. Solomon KR. Effects of ozone depletion and UV-B radiation on humans and the environment, Atmosphere-Ocean 2008; 46 (1): 185-202.

58.- Sperduto RD, Hiller R. The prevalence of nuclear, cortical, and posterior subcapsular lens opacities in a general population sample. Ophthalmology 1984; 91: 815-818.

59.- Maraini G, Pasquini P, Sperduto RD, Rosimi F, Bonacini M, Tomba MC, Corona R. Distribution of lens opacities in the Italian-American case-control study of age-related cataract. Ophthalmology 1990; 97 (6): 752-756.

60.- Klein BEK, Klein R, Linton KLP. Prevalence of age-related lens opacities in a population: the Beaver Dam Eye Study. Ophthalmology 1992; 99: 546 -552.

61.- Giuffre G, Giammanco R, Di Pace F, Ponte F. Casteldaccia eye study: prevalence of cataract in the adult and elderly population of a Mediterranean town. Int Ophthalmol 1995; 18:363-371.

62.- Mitchell P, Cumming RG, Attebo K, Panchapakesan J. Prevalence of cataract in Australia: the Blue Mountains Eye Study. Ophthalmology 1997; 104: 581-588. 
63.- Acosta R, Hoffmeister L, Román R, Comas M, Castilla M, Castells X. Revisión Sistemática De Estudios Poblacionales De Prevalencia De Catarata. Arch Soc Esp Oftalmol 2006; 81: 509-516.

64.- Reidy A, Minassian DC, Desai P, Vafidis G, Joseph J, Farrow S, Connolly A. Increased mortality in women with cataract: a population based follow up of the North London Eye Study. Br J Ophthalmol 2002; 86: 424-428.

65.- Truscott, R. J. Presbyopia. Emerging from a blur towards an understanding of the molecular basis for this most common eye condition. Exp. Eye Res. 2009; 88: 241-247.

66.- Weeber H A, Eckert G, Pechhold W, Van der Heijde RG. 2007 Stiffness gradient in the crystalline lens. Graefes Arch. Clin. Exp. Ophthalmol. 2007; 245: 1357-1366.

67.- Glasser A. Restoration of accommodation. Curr. Opin. Ophthalmol. 2006; 17: 12-18.

68.- Sharma KK, Santhoshkumar P. Lens aging: effects of crystallins. Biochim. Biophys. Acta 2009; 1790: 1095-1108.

69.- Santhoshkumar P, Udupa P, Murugesan R, Sharma KK. Significance of interactions of low molecular weight crystallin fragments in lens aging and cataract formation. J. Biol. Chem. 2008; 283: 8477-8485

70.- Shang F, Taylor A Function of the ubiquitin proteolytic pathway in the eye. Exp. Eye Res. 2004; 78 (1): 1-14.

71.- Harding $\mathrm{J} J$. Free and protein bound glutathione in normal and cataractous human lenses. Biochem. J. 1970; 117: 957-960.

72.- Sanderson J, Marcantonio J M, Duncan G. A human lens model of cortical cataract: Ca2p-induced protein loss, vimentin cleavage and opacification. Invest. Ophthalmol. Vis. Sci. 2000; 41 (8): 2255-2261.

73.- Duncan G, Hightower KR, Gandolfi SA, Tomlinson J, Maraini G. Human lens membrane cation permeability increases with age. Invest. Ophthalmol. Vis. Sci. 1989; 30: 1855-1859.

74.- Bassnett, S., Shi, Y, Vrensen, G. F. J. M. Biological glass: structural determinants of eye lens transparency. Phil. Trans. R. Soc. B 2011; 366: 1250-1264. 
75.- Michael, R., Van Marle, J., Vrensen, G. F. J. M., Van den Berg, T. J. T. P. Changes in the refractive index of lens fibre membranes during maturation- impact on lens transparency. Exp. Eye Res 2003; 77: 93-99.

76.- Bassnett, S. Fiber cell denucleation in the primate lens. Invest. Ophthalmol. Vis. Sci. 1997; 38: 1678-1687.

77.- Bassnett, S. Lens organelle degradation. Exp. Eye Res. 2002; 74 (1): 1-6.

78.- Thorne JE, Daniel E, Jabs DA, Kedhar SR, Peters GB, Dunn JP. Smoking as a risk factor for cystoids macular edema complicating intermediate uveitis. Am J Ophthalmol 2008; 145:841-846.

79.- Lin P, Loh AR, Margolis TP, Acharya NR. Cigarette smoking as a risk factor for uveitis. Ophthalmology 2010; 117:585-590.

80.- Philips Cl, Clayton RM, Cuthbert J, Qian W, Donnelly CA, Prescott RJ. Human cataract risk factors: significance of abstention from, and high consumption of ethanol (U-curve) and non-significance of smoking. Ophthalmic Res 1996; 28 (4): 237-247.

81.- West SK, Muñoz B, Schein OD, Vitale S, Maguire M, Taylor HR, Bressler NM. Cigarette smoking and risk for progression of nuclear opacities. Arch Ophthalmol 1995; 113 (11): 1377-1380.

82.- Klein BE, Klein R, Linton KL, Franke T. Cigarette smoking and lens opacities: the Beaver Dam Eye Study. Am J Prev Med 1993; 9:27-30.

83.- Krishnaiah S, Vilas K, Shamanna BR, Rao GN, Thomas R, Balasubramanian D. Smoking and its association with cataract: results of the Andhra Pradesh eye disease study from India. Invest Ophthalmol Vis Sci 2005; 46:58-65

84-. Solberg Y, Rosner M, Belkin M. The association between cigarette smoking and ocular diseases. Surv Ophthalmol 1998; 42:535-547.

85.- Muñoz B, Tajchman U, Bochow T, West S. Alcohol use and risk of posterior subcapsular opacities. Arch Ophthalmol 1993; 111: 110-112.

86.- Ritter LL, Klein BEK, Klein R, Mares-Periman JA. Alcohol use and lens opacities in The Beaver Dam Study. Arch Opthalmol 1993; 111: 113-117.

87.- Harding JJ, Egerton M, van Heyningen R, Harding RS. Diabetes, glaucoma, sex, and cataract: analysis of combined data from two case control studies. British Journal of Ophthalmology, 1993; 77 (1): 2-6. 
88.- Kahn HA, H. Leibowitz M, Ganley JP, Kini MM, Colton T, Nickerson RS, Dawber TR. The Framingham eye study. II. Association of ophthalmic pathology with single variables previously measured in the Framingham heart study. American Journal of Epidemiology 1977; 106 (1): 33-41.

89.- Stanga PE, Boyd SR, Hamilton AMP. Ocular manifestations of diabetes mellitus. Current Opinion in Ophthalmology 1999; 10 (6): 483-489.

90.- Tabin G, Chen M, Espandar L. Cataract surgery for the developing world. Current Opinion in Ophthalmology 2008; 19 (1): 55-59.

91.- Kinoshita JH. Mechanisms initiating cataract formation. Proctor lecture. Investigative Ophthalmology 1974; 13 (10): 713-724.

92.- Kinoshita JH, Fukushi S, Kador P, Merola LO. Aldose reductase in diabetic complications of the eye. Metabolism 1979; 28 (4): 462-469.

93.- Srivastava SK, Ramana KV, Bhatnagar A. Role of aldose reductase and oxidative damage in diabetes and the consequent potential for therapeutic options. Endocrine Reviews 2005; 26 (3): 380-392.

94.- Takamura Y, Sugimoto Y, Kubo E, Takahashi Y, Akagi Y. Immunohistochemical study of apoptosis of lens epithelial cells in human and diabetic rat cataracts. Japanese Journal of Ophthalmology 2001; 45 (6): 559-563.

95.- Li W-C, Kuszak JR, Dunn K, Wang RR, Ma W, Wang GM, Spector A et al. Lens epithelial cell apoptosis appears to be a common cellular basis for non congenital cataract development in humans and animals. Journal of Cell Biology 1995; 130 (1): 169-181.

96.- Wilson ME Jr., Levin AV, Trivedi RH, et al. Cataract associated with type-1 diabetes mellitus in the pediatric population. Journal of AAPOS 2007; 11 (2): 162-165.

97.- Datiles MB III, Kador PF. Type I diabetic cataract. Archives of Ophthalmology 1999; $117(2): 284-285$.

98.- Clayton RM, Cuthbert J, Phillips CI, Bartholomew RS, Stokoe NL, Ffytche T, McK. Reid J, Duffy J, Seth J, Alexander M. Analysis of individual cataract patients and their lenses: a progress report. Exp Eye Res 1980; 31(5): 553-566. 
99.- Cumming RG, Mitchell P. Medications and cataracts. The Blue Mountains Eye Study. Ophthalmology 1998; 105: 1751-58.

100.- Leske MC, Wu SY, Hennis A, Connell AMS, Hyman L, Schachat A and The Barbados Eye Study Group 124. Diabetes, hypertension, and central obesity as cataract risk factors in a black population. The Barbados Eye Study. Ophthalmology 1999; 106(1): $35-41$.

101.- Klein BEK, Klein R, Lee KE, Danforth LG. Drug use and five-year incidence of age-related cataracts: The Beaver Dam Eye Study. Ophthalmology 2001; 108(9): 1670-4.

102.- Klein R, Klein BE, Moss SE, Wong TY, Hubbard L, Cruickshanks KJ, Palla M.The relation of retinal vessel caliber to the incidence and progression of diabetic retinopathy: XIX: the Wisconsin Epidemiologic Study of Diabetic Retinopathy. Arch Ophthalmol 2004; 122(1): 76-83.

103.- Burgess CA, Sowers M. Systemic hypertension and senile cataracts: an epidemiologic study. Optom Vis Sci 1992; 69(4): 320-4.

104.- Tan AG, Mitchell P, Burlutsky G, Rochtchina E, Kanthan G, Islam FMA, Wang JJ. Retinal vessel caliber and the long-term incidence of age-related cataract: the Blue Mountains Eye Study. Ophthalmology 2008; 115(10): 1693-1698.

105.- Schaumberg DA, Glynn RJ, Christen WG, Ajani UA, Stürmer T, Hennekens CH. A prospective study of blood pressure and risk of cataract in men. Ann Epidemiol 2001; 11(2): 104-10.

106.- De Gruijl FR, Longstreth J, Norval M, Cullen AP, Slaper H, Kripke ML, Takizawa Y, Van Der Leun JC. Health Effects From Stratospheric Ozone Depletion And Interactions With Climate Change. Photochem. Photobiol. Sci. 2003; 2: 16-28.

107.- Kwok L S, Daszynski DC, Kuznetsov VA, Pham T, Ho A, Coroneo MT. Peripheral Light Focusing As A Potential Mechanism For Phakic Dysphotopsia And Lens Phototoxicity. Ophthalmic Physiol. Optics 2004; 24: 119-129.

108.- Kin ST, Koh JW. Mechanisms of Apoptosis on Human Lens Epithelium after Ultraviolet Light Exposure. Korean J Ophthalmol 2011; 25(3):196-201.

109.- Parisi AV, Downs N. Cloud cover and horizontal plane eye damaging Solar UV Exposures. Int. J. Biometeorol. 2004; 49: 130-136. 
110.- Parisi AV, Downs N. Variation of the Enhanced Biologically Damaging Solar UV due to Clouds. Photochem. Photobiol. 2004; 3: 643-647.

111.- West SK, Longstreth JD, Muñoz BE, Pitcher HM, Duncan DD. Model of risk of cortical cataract in the US population with exposure to increased ultraviolet radiation due to stratospheric ozone depletion. Am. J. Epidemiol. 2005; 162: 1080-1088.

112.- Klein BEK, Lee KE,,Danforth LG, Schaich TM, Cruickshanks KJ, Klein R. Selected Sun-Sensitizing Medications and Incident Cataract. Arch Ophthalmol. 2010; 128(8): 959-963.

113.- Chalupecky H. Ueber die Wirkung der Röntgenstrahlen. In: Centralblatt für praktische Augenheilkunde. Hirschberg J, ed: Leipzig, Germany, Veit \& Comp. 1897; 386-401

114.- Vano E, Kleiman NJ, Duran A, Rehani MM, Echeverri D, Cabrera M. Radiation cataract risk in interventional cardiology personnel. Radiat Res 2010; 174:490-495.

115.- Wilde G, Sjöstrand J. A clinical study of radiation cataract formation in adult life following g irradiation of the lens in early childhood. Br J Ophthalmol 1997; 81:261-266.

116.- Chodick G, Bekiroglu N, Hauptmann M, Alexander BH, Freedman DM, Doody MM, Cheung LC, Simon SL, Weinstock RM, Bouville A, Sigurdson AJ. Risk of cataract after exposure to low doses of ionizing radiation: a 20 -year prospective cohort study among US radiologic technologists. Am J Epidemiol 2008; 168:620-631.

117.- Cumming RG, Mitchel P, Leeder SR. Use of inhaled corticosteroids and the risk of cataracts. N Eng J Med 1997; 337: 8-14.

118.- Luntz MH. Clinical types of cataract. In: Duane's Ophthalmology on CD ROM. Philadelphia: Lippincott-Raven Publishers; 1996. Vol 1, Chap. 73.

119.- Sanchez Rico CR, Fernández Aparicio AJ, Pérez Moreno A, Rodríguez Sánchez FA, Estéban Ortega M. Cataratas cortisónicas en portadores de lentes de contacto. Rev Esp de contactología 1996; 6(2): 111-114.

120.- Jones WL. Traumatic injury to the lens. Optom Clin 1991; 1(2): 125-142.

121.- Yasukawa T, Kita M, Honda Y. Traumatic cataract with a ruptured posterior capsule from a non penetrating ocular injury. J Cataract Refract Surg 1998; 24(6): 868-869. 
122.- Fagerholm PP. The response of the lens to trauma. Trans Ophthalmol Soc U K 1982; 102 (3): 369-374.

123.- Canavan YM, Archer DB. Anterior segment consequences of blunt ocular injury. Br J Ophthalmol 1982; 66(9): 549-555.

124.- Feldman F, Heathcote JG. Persistence of intralenticular squamous epithelium after trauma. Can J Ophthalmol 1992; 27(1): 32-33.

125.- Drincic R, Smiljanic N, Vukosavljevic M, Durovic B, Tanjga S. Analysis of treatment of perforating ocular injuries during warfare in Bosnia-Herzegovina. Vojnosanit Pregl 1994; 51(5): 381-383.

126.- Hu T, Zhang F, Wang W. Surgical treatment of traumatic cataract. Chung Hua Yen Ko Tsa Chih 1995; 31(1): 13-15.

127.- Cordero Coma M. Estudio clínico e inmunológico de la acción de adalimumab en el tratamiento de las uveítis inmunomediadas refractarias. [Tesis doctoral] Salamanca: Departamento de cirugía. Facultad de medicina, Universidad de Salamanca; 2014.

128.- Haugen OH, Hovding G, Riise R. Ocular changes in Down syndrome. Tidsskr Nor Laegeforen. 2004; 124(2):186-8.

129.- Evans DGR. Neurofibromatosis type 2 (NF2): A clinical and molecular review. Orphanet J Rare Dis. 2009; 4: 16.

130.- Chopra R, Chander A, Jacob JJ. Ocular associations of metabolic syndrome. Indian J Endocrinol Metab 2012; 16 (1): 6-11.

131.- Crabtree HL, Hildreth AJ, O'Connell JE, et al. Measuring visual symptoms in British cataract patients: the cataract symptom scale. Br J Ophthalmol 1999; 83:519-523.

132.- Kulmala J, Viljanen A, Sipila S, et al. Poor vision accompanied with other sensory impairments as a predictor falls in older women. Age Ageing 2009; 38:162-167.

133.- Freeman EE, Gresset J, Djafari F, et al. Cataract-related vision loss and depression in a cohort of patients awaiting cataract surgery. Can J Ophthalmol 2009; 44:171-176. 134.- Strachan T, Read AP. Human Molecular Genetics, Oxford: BIOS scientific Publishers; 1996: 73. 
135.- Castro Marcos E. Estudio de polimorfismos de genes reparadores de AND en cáncer de mama. [Tesis doctoral] Salamanca: Departamento de medicina, Facultad de medicina, Universidad de Salamanca; 2010.

136.- Johnson AB, Barton MC. Hypoxia-induced and stress-specific changes in chromatin structure and function. Mutat Res 2007; 618:149-62.

137.- Spector A, Wang GM, Wang RR, Li WC, Kleiman NJ. A brief photochemically induced oxidative insult causes irreversible lens damage and cataract. II. Mechanism of action. Exp Eye Res 1995; 60:483-93.

138.- Sasaki H, Lin LR, Yokoyama T, Sevilla MD, Reddy VN, Giblin FJ. TEMPOL protects against lens DNA strand breaks and cataract in the X-rayed rabbit. Invest Ophthalmol Vis Sci 1998; 39:544-52.

139.- Pendergrass W, Penn P, Possin D, Wolf N. Accumulation of DNA, nuclear and mitochondrial debris, and ROS at sites of age-related cortical cataract in mice. Invest Ophthalmol Vis Sci 2005; 46:4661-70.

140.- Wood RD, Mitchell M, Sgouros J, Lindahl T. Human DNA repair genes. Science $2001 ; 291: 1284-9$.

141.- De Boer J, Hoeijmakers JHJ. Nucleotide excision repair and human syndromes. Carcinogenesis 2000; 21 (3): 453-460.

142.- Friedberg E. How Nucleotide excision repair protects against Cancer. Nature reviews in Cancer 2001; 1:22-23.

143.- Hoeijmakers JH. Genome maintenance mechanisms for preventing cancer. Nature2001; 411:366-374.

144.- Ladiges W, Wiley J, MacAuley A. Polymorphisms in the DNA repair gene XRCC1 and age-related disease. Mech Ageing Dev 2003; 124:27-32.

145.- Stern MC, Siegmund KD, Conti DV, Corral R, Haile RW. XRCC1, XRCC3, and XPD polymorphisms as modifiers of the effect of smoking and alcohol on colorectal adenoma risk.Cancer Biomarkers Prev 2006; 15:2384-90.

146.- Liu G, Zhou W, Yeap BY, Su L, Wain JC, Poneros JM, Nishioka NS, Lynch TJ, Christiani DC. XRCC1 and XPD polymorphisms and esophageal adenocarcinoma risk. Carcinogenesis 2007; 28:1254-8. 
147.- Povey JE, Darakhshan F, Robertson K, Bisset Y, Mekky M, Rees J, Doherty V, Kavanagh G, Anderson N, Campbell H, Mackie RM, Melton DW. DNA repair gene polymorphisms and genetic predisposition to cutaneous melanoma. Carcinogenesis 2007; 28 (5):1087-93.

148.- Castro R, Torres R, Ballona R. El potencial maligno del xeroderma pigmentoso. Rev Dermatol 2005; 16: 93-5.

149.- Olaussen KA, Dunant A, Fouret P, Brambilla E, Andre F, Haddad V. DNA repair by ERCC1 in non-small-cell lung cancer and cisplatin-based adjuvant chemotherapy. N Engl J Med 2006; 355: 983-991.

150.- Bellmunt J, Paz-Ares L, Cuello M, Cecere FL, Albiol S, Guillen V. Gene expression of ERCC1 as a novel prognosis marker in advanced bladder cancer patients receiving cisplatin-based chemotherapy. Ann Oncol 2007; 18: 522-528.

151.- Hicks SD, Lewis L, Ritchie J, Burke P, Abdul-Malak Y, Adackapara N, Canfield K, Shwarts E, Gentile K, Meszaros ZS, Middleton FA. Evaluation of cell proliferation, apoptosis, and DNA-repair genes as potential biomarkers for ethanol-induced CNS alterations. BMC Neurosci. 2012; 13: 128.

152.- Lehman AR. DNA reapair-deficient diseases, xeroderma pigmentosum, Cockayne syndrome and trichothiodystrophy. Biochimie 2003; 85: 1101-1111.

153.- Hang B. Base Excision Repair, in Wei Q. LL, and Chen D., (ed): DNA repair, genetic instability and cancer. London, World Science, 2007, pp 23-64.

154.- De Laat WL, Sijbers AM, Odijk H, Jaspers NGJ, Hoeijmakers JH. Mapping of interaction domains between human repair proteins ERCC1 and XPF. Nucleic Acids Research 1998; 26 (18): 4146-4152.

155.- Zhu XD, Niedernhofer L, Kuster B, Mann M, Hoeijmakers JH, Lange T. ERCC1/ XPF removes the 3 overhang from uncapped telomeres and represses formation of telomeric DNA-containing double minute chromosomes. Molec Cell 2003; 12: 1489-1498. 156.- Sijbers AM, de Laat WL, Ariza RR, Biggerstaff M, Wei YF, Moggs JG, Carter KC, Shell BK, Evans E, de Jong MC, Rademakers S, de Rooij J, Jaspers NG, Hoeijmakers $\mathrm{JH}$, Wood RD. Xeroderma pigmentosum group $\mathrm{F}$ caused by a defect in a structure-specific DNA repair endonuclease. Cell. 1996; 86: 811-822. 
157.- Brookman KW, Lamerdin JE, Thelen MP, Hwang M, Reardon JT, Sancar A, Zhou ZQ, Walter CA, Parris CN, Thompson LH. ERCC4 (XPF) encodes a human nucleotide excision repair protein with eukaryotic recombination homologs. Mol. Cell. Biol. 1996; 16 (11): 6553-6562.

158.- Bessho T, Sancar A, Thompson LH, Thelen MP. Reconstitution of human excision nuclease with recombinant XPF-ERCC1 complex. J. Biol. Chem. 1997; 272:3833-3837.

159.- Biggerstaff M, Szymkowski DE, Wood RD. Co-correction of the ERCC1, ERCC4 and xeroderma pigmentosum group F DNA repair defects in vitro. Embo J. 1993; 12:3685-3692.

160.- van Vuuren AJ, Appeldoorn E, Odijk H, Yasui A, Jaspers NG, Bootsma D, Hoeijmakers $\mathrm{JH}$. Evidence for a repair enzyme complex involving ERCC1 and complementing activities of ERCC4, ERCC11 and xeroderma pigmentosum group F. EMBO J. 1993; 12:3693-3701.

161.- Aravind L, Walker DR, Koonin EV. Conserved domains in DNA repair proteins and evolution of repair systems. Nucleic Acids Res. 1999; 27: 1223-1242.

162.- Enzlin JH, Schärer OD. The active site of the DNA repair endonuclease XPF-ERCC1 forms a highly conserved nuclease motif. Embo J. 2002; 21: 2045-2053.

163.- Li L, Peterson CA, Lu X, Legerski RJ. Mutations in XPA that prevent association with ERCC1 are defective in nucleotide excision repair. Mol. Cell. Biol. 1995; 15:19931998

164.- Li L, Elledge SJ, Peterson CA, Bales ES, Legerski RJ. Specific association between the human DNA repair proteins XPA and ERCC1. Proc. Natl. Acad. Sci. USA. 1994; $87(24): 9908-12$

165.- Tsodikov OV, Ivanov D, Orelli B, Staresincic L, Shoshani I, Oberman R, Schärer OD, Wagner G, Ellenberger T. Structural basis for the recruitment of ERCC1-XPF to nucleotide excision repair complexes by XPA. EMBO J. 2007; 26:4768-4776.

166.- McNeil EM, Melton DW. DNA repair endonuclease ERCC1-XPF as a novel therapeutic target to overcome chemoresistance in cancer therapy. Nucleic Acids Research 2012; 40 (20): 9990-10004.

167.- Gregg SQ, Robinson AR, Niedernhofer LJ. Physiological consequences of defects in ERCC1-XPF DNA repair endonuclease. DNA Repair 2011; 10(7): 781-791. 
168.- Clarkson SG, Wood RD. Polymorphisms in the human XPD (ERCC2) gene, DNA repair capacity and cancer susceptibility: an appraisal. DNA repair 2005; 4: 1068-1074. 169.- Bienstock RJ, Skorvaga M, Mandavilli BS, Van Houten B. Structural and functional characterization of the human DNA repair helicase XPD by comparative molecular modeling and site-directed mutagenesis of the bacterial repair protein UvrB. Journal of Biological Chemistry 2003; 278: 5309-5316.

170.- Schaeffer L, Moncollin V, Roy R, et al: The ERCC2/DNA repair protein is associated with the class II BTF2/TFIIH transcription factor. EMBO J 1994; 13:2388-92.

171.- Ünal M, Güven M, Batar B, Özaydin A. Polymorphisms of DNA repair genes XPD and XRCC1 and risk of cataract development. Exp Eye Research 2007; 85:328-334.

172.- Padma G, Mamata M, Reddy KRK, Padma T. Polymorphisms in two DNA repair genes (XPD and XRCC1) association with age related cataracts. Mol Vission 2011; 17: 127-133.

173.- Görgün E, Güven M, Ünal M, Batar B, Güven GS, Yenerel M, Tathmar S, Seven M, Yüksen A.Polymorphisms of the DNA repair genes XPD and XRCC1 and the risk of age-related macular degeneration. IOVS 2010; 51 (9): 4732-4737.

174.- Sugasawa, K., Ng, J. M., Masutani, C., Iwai, S., van der Spek, P. J., Eker, A. P.,Hanaoka, F., Bootsma, D. \& Hoeijmakers, J. H. Mol. Cell 1998; 2: 223-232.

175.- Volker, M., Mone, M. J., Karmakar, P., van Hoffen, A., Schul, W., Vermeulen, W., Hoeijmakers, J. H., van Driel, R., van Zeeland, A. A. \& Mullenders, L. H. Mol. Cell 2001; 8: 213-224.

176.- Bergink S, Toussaint W, Luijsterburg MS, Dinant C, Alekseev S, Hoeijmakers JHJ, Dantuma NP, Houtsmuller AB, Vermeulen W. Recognition of DNA damage by XPC coincides with disruption of the XPC-RAD23 complex. JCell Biol 2012; 196(6): 681688.

177.- De Laat WL, Jaspers NG, Hoeijmakers JH. Molecular mechanism of nucleotide excision repair. Genes Dev. 1999; 13(7): 768-85.

178.- Melis JPM, Luijten M, Mullenders LHF, Van Steeg H. The role of XPC: implication in cancer and oxidative DNA damage. Mutat Res 2011; 728 (3): 107-117.

179.- Li C, Hu Z, Liu Z et al.Polymorphisms in the DNA repair genes XPC, XPD and XPG and risk of cutaneous melanoma: a case-control analysis. Cancer Epidemiol Biomarkers Prev 2006; 15: 2526-2532. 
180.- Van Steeg H, Kraemer KH. Xeroderma pigmentosum and the role of UV-induced DNA damage in skin cancer. Mol Med Today 1999; 5 (2): 86-94.

181.- Almeida KH and Sobol RW. A unified view of base excision repair: lesion-dependent protein complexes regulated by post-translational modification. DNA Repair 2007; 6 : 695-711.

182.- David SS, O'Shea VL, and Kundu S. Base-excision repair of oxidative DNA damage. Nature 2007; 447: 941-950.

183.- Friedberg EC, Walker GC, Siede W, Wood RD, Schultz RA, and Ellenberger T. DNA Repair and Mutagenesis. 2nd Ed. Washington, DC: ASM Press; 2006: 164.

184.- Caldecott KW. XRCC1 and DNA strand break repair. DNA repair (Amst) 2003; 2: 955-969.

185.- Chen D, Yu Z, Zhu Z, et al. E2F1 regulates the base excision repair gene XRCC1 and promotes DNA repair. J Biol Chem 2008; 283:15381-9.

186.- Tebbs RS, Flannery ML, Meneses JJ, et al. Requirement for the Xrcc1 DNA base excision repair gene during early mouse development. Dev Biol 1999; 208: 513-529.

187.- Shen MR, Zdzienicka MZ, Mohrenweiser H, et al. Mutations in hamster single-strand break repair gene XRCC1 causing defective DNA repair. Nucleic Acids Res 1998; 26 : 1032-1037.

188.- Duell EJ, Cheng TJ, Varkonvi A, Zuo ZF, Ashok TD, Mark EJ, Wain JC, Cristiani DC, Kelse KT. Polymorphims in the DNA repair genes XRCC1 and ERCC2 and biomarkers of DNA damage in human blood mononuclear cells. Carcinogenesis 2000; 21: 965-971.

189.- Matullo G, Palli D, Peluso M, et al. XRCC1, XRCC3, XPD gene polymorphisms, smoking and (32) P-DNA adducts in a sample of healthy subjects. Carcinogenesis $2001 ; 22: 1437-45$.

190.- Luo YF, Wang BB, Zhou Z, Ding XC, Hu SS, Zhou GK, Ma X, Qi YH. Polymorphisms of the DNA repair genes XPD and XRCC1 and the risk of age-related cataract development in Han Chinese. Curr Eye Res 2011; 36 (7): 632-636.

191.- Li WC, Spector A. Lens epithelial cell apoptosis is an early event in the development of UVB-induced cataract. Free Radic Biol Med 1996; 20:301-11. 
192.- Godar DE. Preprogrammed and programmed cell death mechanisms of apoptosis: UV-induced immediate and delayed apoptosis. Photochem Photobiol 1996; 63:82530.

193.- Hightower KR, Reddan JR, McCready JP, Dziedzic DC. Lens epithelium: a primary target of UVB irradiation. Exp Eye Res 1994; 59:557-64.

194.- Tamada Y, Fukiage C, Nakamura Y, et al. Evidence for apoptosis in the selenite rat model of cataract. Biochem Biophys Res Commun 2000; 275:300-6.

195.- Harding JJ, Crabbe MJ. The lens: development, proteins, metabolism and cataract. In: Davson H, editor. The eye. Vol. 1B. London: Academic Press; 1984: p. 207-492.

196.- Hall PA, McKee PH, Menage HD, et al. High levels of p53 protein in UV-irradiated normal human skin. Oncogene 1993; 8(1): 203-7.

197.- van Oijen MG, Slootweg PJ. Gain-of-function mutations in the tumor suppressor gene p53. Clin Cancer Res. 2000; 6(6): 2138-2145.

198.- May P, May E. Twenty years of p53 research: structural and functional aspects of the p53 protein. Oncogene. 1999; 18:7621-7636.

199.- Okorokov AL, Orlova EV. Structural biology of the p53 tumour suppressor. Curr Opin Struct Biol. 2009; 19:197-202.

200.- Rodríguez Hernández I. Nuevas aportaciones a la caracterización molecular de los gliomas. [Tesis doctoral] Salamanca: Departamento de medicina, Unidad de medicina molecular. Facultad de medicina, Universidad de Salamanca; 2013.

201.- el-Deiry WS, Kern SE, Pietenpol JA, Kinzler KW, Vogelstein B. Definition of a consensus binding site for p53. Nat Genet. 1992; 1:45-49.

202.- Marine JC, Francoz S, Maetens M, Wahl G, Toledo F, Lozano G. Keeping p53 in check: essential and synergistic functions of Mdm2 and Mdm4. Cell Death Differ. 2006; 13:927-934.

203.- Toledo F, Wahl GM. Regulating the p53 pathway: in vitro hypotheses, in vivo veritas. Nat Rev Cancer. 2006; 6:909-923.

204.- Bode AM, Dong Z. Post-translational modification of p53 in tumorigenesis. Nat Rev Cancer. 2004; 4:793-805.

205.- Riley T, Sontag E, Chen P, Levine A. Transcriptional control of human p53-regulated genes. Nat Rev Mol Cell Biol. 2008; 9:402-412. 
206.- Cox LS, Lane DP. Tumour suppressors, kinases and clamps: how p53 regulates the cell cycle in response to DNA damage. Bioessays. 1995; 17(6): 501-508.

207.- Levine AJ. p53, the cellular gatekeeper for growth and division. Cell. 1997; 88(3): 323-331.

208.- Lloyd AC. p53: only ARF the story. Nat Cell Biol. 2000; 2:E48-50.

209.- Vousden KH, Prives C. Blinded by the Light: The Growing Complexity of p53. Cell. $2009 ; 137: 413-431$.

210.- Yu J, Zhang L. The transcriptional targets of p53 in apoptosis control. Biochem Biophys Res Commun. 2005; 331:851-858.

211.- Green DR, Kroemer G. Cytoplasmic functions of the tumour suppressor p53. Nature. 2009; 458:1127-1130.

212.- Fuster JJ, Sanz-Gonzalez SM, Moll UM, Andres V. Classic and novel roles of p53: prospects for anticancer therapy. Trends Mol Med. 2007; 13:192-199.

213.- Vogelstein B, Lane D, Levine AJ. Surfing the p53 network. Nature. 2000; 408:307310.

214.- Smith ML, Seo YR. p53 regulation of DNA excision repair pathways. Mutagenesis. 2002; 17:149-156.

215.- Elledge RM, Lee WH. Life and death by p53. Bioessays. 1995; 17(11): 923-930.

216.- Hainaut P, Hollstein M. p53 and human cancer: the first ten thousand mutations. Adv Cancer Res. 2000; 77: 81-137.

217.- Soussi T, Caron de Fromentel C, May P. Structural aspects of the p53 protein in relation to gene evolution. Oncogene. 1990; 5(7): 945-52.

218.- Dittmer D, Pati S, Zambetti G, Chu S, Teresky AK, Moore M, et al. Gain of function mutations in p53. Nat Genet. 1993; 4(1): 42-46.

219.- Soto de Prado Otero D. Estudio de polimorfismos de genes reparadores en población fumadora con y sin cáncer de pulmón. [Tesis doctoral] Salamanca: Departamento de medicina: unidad de medicina molecular, Facultad de medicina, Universidad de Salamanca; 2008.

220.- Ayala M, Strid H, Jacobsson U, Soderberg PG. p53 expression and apoptosis in the lens after ultraviolet radiation exposure. Invest Ophthalmol Vis Sci 2007; 48(9): 4187-91. 
221.- Pastor Idoate S, Rodríguez Hernández I, Rojas J, Fernández I, García Gutiérrez MT, Ruiz Moreno JM, Rocha Sousa A, Ramkissoon Y, Harsum S, Maclaren RE, Charteris D, Van Meurs J, González Sarmiento R, Pastor JC, Genetics on PVR Study Group. The p53 Codon 72 Polimorphism (rs 1042522) in associated with proliferative vitreoretinopathy: the Retina 4 Project. Ophthalmology 2013; 120 (3): 623-628.

222.- Cruz González F. Análisis clínico y genético de la degeneración macular asociada a la edad. [Tesis doctoral ] Salamanca: Departamento de medicina, Facultad de medicina, Universidad de Salamanca; 2010.

223.- Gonzalez JR, Armengol L, Sole X, Guino E, Mercader JM, Estivill X, Moreno V. Snpassoc: an r package to perform whole genome association studies. Bioinformatics 2007; 23(5): 644-645.

224.- Congdon N, West SK, Buhrmann RR, Kouzis A, Muñoz B, Mkocha H. Prevalence of the different types of age-related cataract in an African population. Invest Ophthalmol Vis Sci 2001; 42(11): 2478-2482.

225.- Noran NH, Salleh N, Zahari M. Relationship between reproductive exposures and age-related cataract in women. Asia Pac J Public Health 2007; 19(2): 23-8.

226.- Jiang J, Zhou J, Yao Y, Zhu R, Liang C, Jiang S, Yang M, Lu Y, Xing Q, Guan H. Copy number variations of DNA Repair genes and the Age-related cataract: Jiangsu eye Study. Investigative Ophthalmology \& Visual Science 2013; 54 (2): 932-938.

227.- Su S, Yao Y, Zhu R, Liang C, Jiang S, Hu N, Zhou J, Yang M, Xing Q, Guan H. The Associations between Single Nucleotide Polymorphisms of DNA Repair Genes, DNA Damage, and Age-Related Cataract: Jiangsu Eye Study. Investigative Ophthalmology \& Visual Science 2013; 54 (2): 1201-1207.

228.- Diderich K, Alanazi M, Hoejimakers JHJ. Premature aging and cancer in nucleotide excision repair-disorders. DNA Repair 2011; 10 (7): 772- 780.

229.- Andressoo JO, Hoeijmakers JHJ. Transcription-coupled repair and premature ageing. Mutation Research 2005; 577: 179-194. 
230.- Kashiyama K, Nakazawa Y, Pilz DT, Guo C, Shimada M, Sasaki K, Fawcett H, Wing JF, Lewin SO, Carr L, Li TS, Yoshiura K, Utani A, Hirano A, Yamashita S, Greenblatt D, Nardo T, Stefanini M, McGibbon D, Sarkany R, Fassihi H, Takahashi Y, Nagayama Y, Mitsutake N, Lehmann AR, Ogi T. Malfunction of Nuclease ERCC1-XPF Results in Diverse Clinical Manifestations and Causes Cockayne Syndrome, Xeroderma Pigmentosum, and Fanconi Anemia. The American Journal of Human Genetics 2013; 92 (2): 807-819.

231.- Zhang Y, Zhang L, Song Z, Sun DL, Liu HR, Bin Fu S, Liu DR, Liu P. Genetic Polymorphisms in DNA Repair Genes OGG1, APE1, XRCC1, and XPD and the Risk of Age-Related Cataract. Ophthalmology 2012; 119: 900-906.

232.- Vidal, A.E., Boiteux, S., Hickson, I.D., Radicella, J.P. XRCC1 coordinates the initial and late stages of DNA abasic site repair through protein/protein interactions. EMBO J.2001; 20: 6530-6539.

233.- Ginsberg G, Angle K, Guyton K, Sonawane B. Polymorphism in the DNA repair enzyme XRCC1: utility of the current database and implications for human health risk assessment. Mutat Res. 2011; 727:1-15

234.- Monaco R, Rosal R, Dolan MA, Pincus MR, Brandt-Rauf PW. Conformational effects of a common codon 399 polymorphism on the BRCT1 domain of the XRCC1 protein. Protein J.2007; 26(8):541-6.

235.- Ottonello S, Foroni C, Carta A, Petrucco S, Maraini G. Oxidative stress and age-related cataract. Ophthalmologica 2000; 214:78-85.

236.- Wang XW, Vermeulen W, Coursen JD, Gibson M, Lupold SE, Forrester K, Xu G, Elmore L, Yeh H, Hoeijmakers JHJ, Harris CC. The XPB and XPD DNA helicases are components of the p53-mediated apoptosis pathway. Genes \& Development 1996; 10: 1219-1232.

237.- Sakamuro D, Sabbatini P, White E, Prendergast GC. The polyproline region of p53 is required to activate apoptosis but not growth arrest. Oncogene. 1997; 15:887-98.

238.- Dumont P, Leu JI, Della Pietra AC, 3rd, George DL, Murphy M. The codon 72 polymorphic variants of p53 have markedly different apoptotic potential. Nat Genet. 2003; 33:357-65. 
239.- Pim D, Banks L. p53 polymorphic variants at codon 72 exert different effects on cell cycle progression. Int J Cancer. 2004; 108:196-9.

240.- Whibley C, Pharoah PD, Hollstein M. p53 polymorphisms: cancer implications. Nat Rev Cancer. 2009; 9 (2): 95-107.

241.- Sun X, Zou W, Zhao C. Expression of P53 during lens epithelial cell apoptosis induced by ultraviolet. J Tongii Med Univ 2001; 21 (3): 263-264.

242.- Tendler Y, Pokroy R, Panshin A, Weisinger G. P53 protein subcellular localization and apoptosis in rodent corneal epithelium cell culture following ultraviolet irradiation. Int J Mol Med 2013; 31(3): 540-546.

243.- Azizi B, Ziaei A, Fuchsluger T, Schmedt T, Chen Y, Jurkunas UV. P53-regulated increase in oxidative-stress-induced apoptosis in Fuchs endotelial corneal dystrophy: a native tissue model. Invest Ophthalmol Vis Sci 2011; 52 (13) 9291-9297.

244.- Bhattacharya S, Chaum E, Johnson DA, Johnson LR. Age-related susceptibility to apoptosis in human retinal pigment epitelial cells is triggered by disruption of p53Mdm2 association. Invest Ophthalmol Vis Sci 2012; 53 (13) 8350-8366.

245.- Wiggs JL, Hewitt AW, Fan BJ, Wang DY, Figueiredo Sena DR, O’Brien C, Realini A, Craig JE, Dimasi DP, Mackey DA, Haines JL, Pasquale LR. The p53 codon 72 PRO/ PRO genotype may be associated with initial central visual field defects in caucasians with primary open angle glaucoma. PLoS One 2012; 7(9): e45613.

246.- Blanco Marchite C, Sánchez Sánchez F, López Garrido MP, Iñigez de Onzoño M, López Martínez F, López Sanchez E, Alvarez L, Rodríguez Calvo PP, Méndez Hernández C, Fernández Vega L, García Sanchez J, Coca Prados M, García Feijoo J, Escribano J. WDR36 and P53 gene variants and susceptibility to primary open-angle glaucoma: analysis of gene-gene interactions. Invest Ophthalmol Vis Sci 2011;52(11) 8467-8478.

247.- Ji WK, Tang XC, Yi M, Chen PQ, Liu FY, Hu XH, Hu WF, Fu SJ, Liu JF, Wu KL, Wu MX, Liu XL, Luo LX, Huang S, Liu ZZ, Yu MB, Liu YZ, Li DW. P53 directly regulates aA- and $\beta A 3 / A 1-c r y s t a l l i n$ genes to modulate lens differentiation. Curr Mol Med 2013; 13 (6): 968-978.

248.- Qin Y, Zhao J, Min X, Wang M, Luo W, Wu D, Yan Q, Li J, Wu X, Zhang J. MicroRNA-125b inhibits lens epithelial cell apoptosis by targeting p53 in age-related cataract. Biochim Biophys Acta 2014; 1842 (12PA): 2439-2447. 

ANEXO 1 



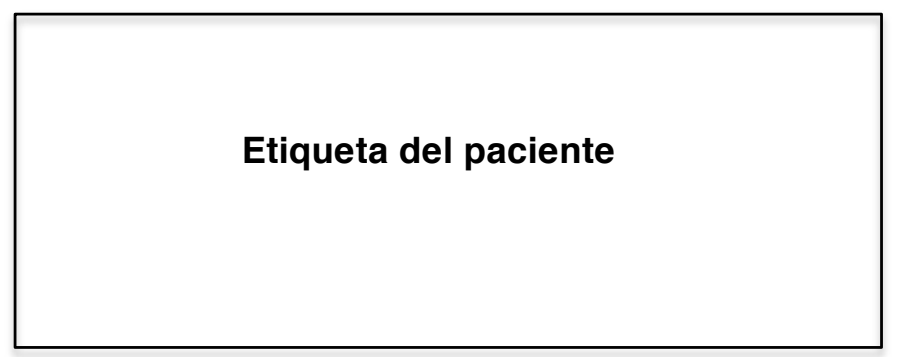

Se me va a extraer una muestra de sangre para realizar un estudio genético. Se me ha explicado por parte del Dr.

$Y$ he entendido que:

1- El objetivo de dicho estudio es analizar los genes que pueden estar implicados en la patología: Catarata. Del tipo y número de genes que pueden intervenir no se conoce nada en la actualidad, por lo que este estudio debe ser considerado de investigación sin ninguna repercusión práctica a corto plazo.

2- La unidad de Medicina Molecular del Departamento de Medicina de la Universidad de Salamanca realizará los estudios genéticos y preservará el anonimato de la muestra, guardando confidencialidad sobre la identidad del paciente.

3- Los resultados obtenidos podrán ser utilizados para una posible publicación científica, guardando estricta confidencialidad sobre la identidad del paciente.

4- Mi ADN sin identificación se podrá utilizar como control en otros estudios genéticos: SI/NO (Táchese lo que no proceda).

He sido informado adecuadamente de los puntos anteriores y de los temas que de ellos derivan por el facultativo $\mathrm{Dr}$.

En .a. de. $20 \ldots$

\section{Firma:}

\section{DNI $n^{\circ}$ :}



